\title{
Redshift Anomaly on the Solar Disk as Multiple Interactions between Photons and Electrons
}

\author{
Alessandro Trinchera (1) \\ Independent Researcher, Stuttgart, Germany \\ Email: trinchera.ale@gmail.com
}

How to cite this paper: Trinchera, A. (2021) Redshift Anomaly on the Solar Disk as Multiple Interactions between Photons and Electrons. Journal of High Energy Physics, Gravitation and Cosmology, 7, $1-51$.

https://doi.org/10.4236/jhepgc.2021.71001

Received: September 24, 2020

Accepted: November 22, 2020

Published: November 25, 2020

Copyright $\odot 2021$ by author(s) and Scientific Research Publishing Inc. This work is licensed under the Creative Commons Attribution International License (CC BY 4.0).

http://creativecommons.org/licenses/by/4.0/

\begin{abstract}
This paper analyses the center-to-limb problem of the Sun encountered in the solar lines by using for the first time the New Tired Light theory based on photons of light losing energy due to interaction with electrons. For this scope, a detailed geometrical orbital model on the scale was created in order to trace back all physical characteristics of the Earth orbiting the Sun for three days in the year 1946, when the redshift measurements were taken. This paper suggests that, since the space between the Sun and the Earth consists of a high exponential distribution of electrons, it works out as a medium for the photons of light. Indeed, in the line of sight of a terrestrial observer, the distance between the Sun and the Earth is greater at the limb than in the center, valid for each orbital position. Accordingly, the interactions between photons and electrons cause a slight difference in redshift along the entire solar disk, matching the observational data. An important factor is the definition of objective criteria for the radial velocity component of the solar granules, whose variable values refer, in turn, to existing observational data, crucial for the success of the study. The redshift anomaly on the solar disk has been repeatedly detected in many scientific researches but only a few attempts so far, mostly based on parametrized models, have been done to give a reliable explanation to the measurements.
\end{abstract}

\section{Keywords}

Redshift Anomaly, Center-to-Limb Problem, Solar Corona, New Tired Light

\section{Introduction}

The conceptual idea of photons of light losing energy on its journey throughout space dates back to the beginning of the last century when the drag effect was first introduced by F. Zwicky to explain the redshift of light [1]. Historically, it 
was left for a long time in the realm of conjecture until the recent and detailed development of the New Tired Light (NTL) by L.E. Ashmore which marks a new way to interpret the redshift of photons of light [2] [3] [4]. If we take a few steps back, even the father of Hubble's law, E.P. Hubble himself, has repeatedly and publicly expressed his doubts about the cosmological nature of the redshift [5] [6] [7], even though he himself had first misinterpreted the redshift as a Doppler effect. We can nowadays openly draw similar conclusions about the cosmological redshifts since the model based on the expansion of space is characterized by many assumptions. The new developments of the Tired Light theory provide an alternative explanation to the redshift, which consists of interactions between photons and electrons in the intergalactic space. Electrons are like obstacles to the path of light; they absorb and re-emit the various frequencies causing the energy of the light itself to diminish interaction after interaction. In the specific case of the study, there is a distribution of electrons between the Sun and the Earth that interacts with the photons emitted by the solar photosphere. The calculations would not be possible without three electron distributions provided by an important scientific research [8]. Furthermore, the measurements in terms of redshift made on the solar disk by another research [9], provide surprisingly unexpected results. We will focus in detail on these scientific elements to provide an explanation to the center-to-limb problem. The solution to the redshift anomaly on the solar disk has an impact on Modern Cosmology as, by solving this anomaly, we might be able to explain controversial redshifts of cosmological objects scattered everywhere in the Cosmos (Figure 1).

The NTL provides us evidence that the stellar redshift is proportional to the distance travelled by the photons of light as they undergo interactions with electrons

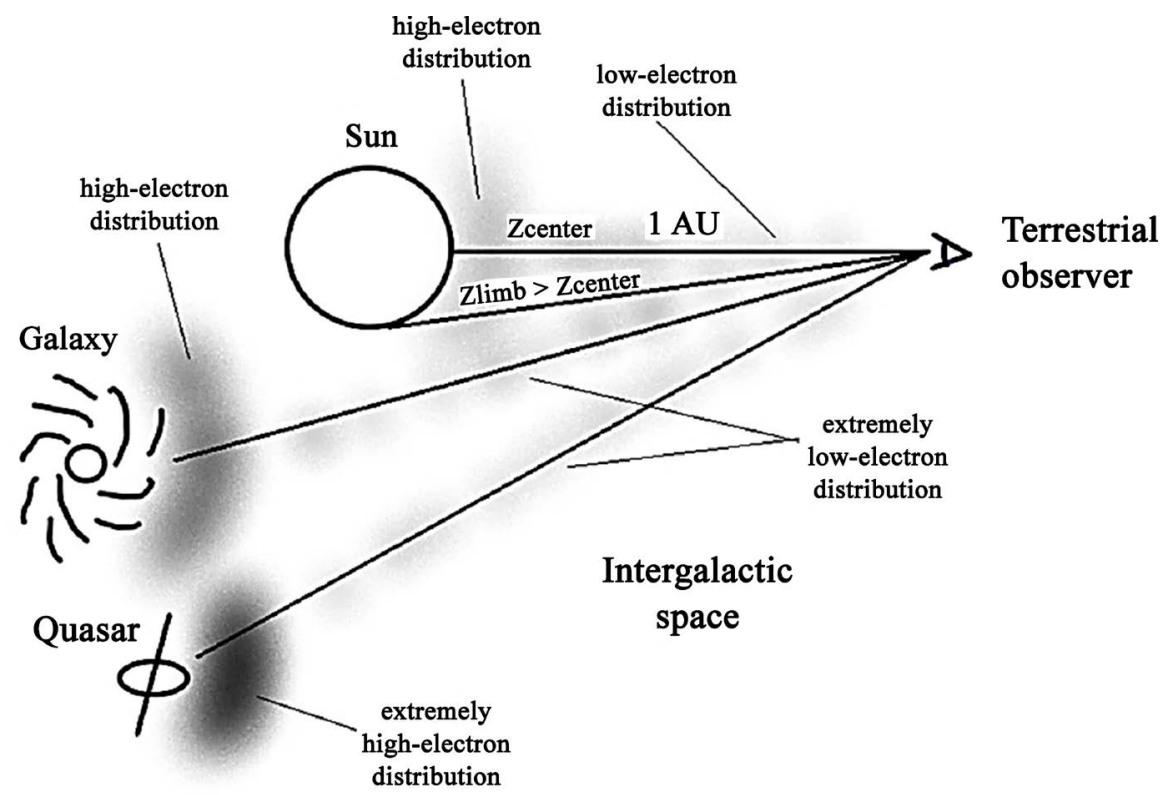

Figure 1. Electron densities varying in the intergalagtic space, in the space surrounding astronomical objects and in the space between the Sun and the Earth according to A. Trinchera's hypothesis. 
in the intergalactic space. The theory does not yet take the interactions into account that occur in the environment, dense of electrons, surrounding the astronomical objects. In order to calibrate exactly the distances, the non-cosmological redshift should be intended as the sum of two contributes: on the one hand, the redshift resulting from the intergalactic space (provided by the NTL), and on the other hand, the redshift occurring in the surrounding environment of the astronomical object emitting the light (provided by this study). As already mentioned, this paper focuses on the space between the Sun and the Earth. The Sun is the best possible candidate for this study being the nearest star and because several previous kinds of research detected a redshift anomaly on its solar disk. In Tired Light terms, a close astronomical object surrounded by a high-electron density might have the same redshift as a far-away object surrounded by a low-electron density, giving difficulties for us to calibrate the distances. Indeed, in the literature, we can find many controversial high-redshift Quasars close to low-redshift galaxies [10]. They are supposed to have an extremely high density even in the Standard Model. The electron distribution is exactly the main parameter to focus on, since it causes a redshift that can be ultimately used, together with redshift contribution of the intergalactic space, to measure the distances. With this argument, currently, an astronomical object that has been found at a great cosmological distance and that is surrounded by a high-electron density might actually be closer than expected. The redshift anomaly detected on the solar disk constitutes an integral part of this reasoning. It consists of unusual redshift components explainable as interactions between photons and electrons.

\section{Solar Redshift Anomaly}

Observational studies of the solar radiation show a substantial difference between the redshift of the solar center and the solar limb, contrary to the expectations [9]. The redshift, once considered all Doppler and gravitational contributes, confirms low-redshift values near to the solar center and high-redshift values at the limb, as shown in Figure 2.

The measurements of the redshift on the solar disk made between September

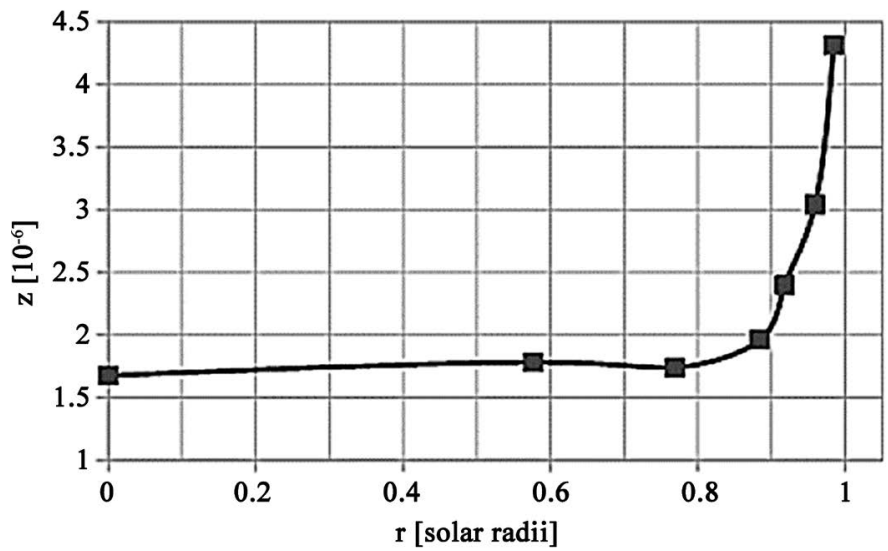

Figure 2. Redshift trend on the solar disk according to M.G. Adam's paper. 
15 and October 11, 1946 have been reported in terms of recession velocities expressed in 1/1000 Armstrong. In order to simplify the latter, we can re-calculate the velocities in terms of redshift. Table 1 contains mean values determined over the measurement days as well as on both sides of the solar disk. We will indicate with the index $w$, which consists of a maximum of 14 values, the different wavelengths starting from Mn $601.35 \mathrm{~nm}(w=1)$ followed by Mn $601.66 \mathrm{~nm}(w=2)$ up to Fe $627.02 \mathrm{~nm}(w=14)$. The values used in the calculations are those that refer to three different curves [8] which describe the electron distribution used for the redshift computation.

The electron density in the solar corona extends up to the Earth varying from a very high value close to the photosphere to lower values close to the Earth's orbit. Several distributions have been analysed in the paper to get an idea of the behaviour of photons in each of them. In order to simplify the calculations, we can choose the mathematical distributions which have only one contribute of decreasing power that well approximates the real trend of the electrons in the solar corona. This allows us to avoid equations with big orders which might complicate the calculations and its computing time. The generic formula for the electron distribution in the solar corona expressed in $\mathrm{el} / \mathrm{m}^{3}$ is the following

$$
n_{e}= \begin{cases}0 & \text { for } r<1\left(R_{S}\right) \\ \frac{t}{r^{\varepsilon}} & \text { for } 1\left(R_{s}\right) \leq r \leq \frac{d-R_{E}}{R_{s}}\left(R_{s}\right)\end{cases}
$$

Table 1. Transcription of M.G. Adam's redshift measurements.

\begin{tabular}{|c|c|c|c|c|c|c|c|c|}
\hline \multirow{2}{*}{ Element } & \multirow{2}{*}{$\begin{array}{c}\text { Wavel. } \\
(\mathrm{nm})\end{array}$} & \multicolumn{7}{|c|}{$\mathbf{z}$} \\
\hline & & 0.984 & 0.959 & 0.918 & 0.884 & 0.769 & 0.577 & 0 \\
\hline $\mathrm{Mn}$ & 601.35 & $3.74 \mathrm{E}-06$ & $1.67 \mathrm{E}-06$ & $1.43 \mathrm{E}-06$ & $1.40 \mathrm{E}-06$ & $1.10 \mathrm{E}-06$ & $1.27 \mathrm{E}-06$ & $9.34 \mathrm{E}-07$ \\
\hline $\mathrm{Mn}$ & 601.66 & $4.10 \mathrm{E}-06$ & $3.27 \mathrm{E}-06$ & $2.10 \mathrm{E}-06$ & $1.67 \mathrm{E}-06$ & $1.27 \mathrm{E}-06$ & $1.93 \mathrm{E}-06$ & $1.70 \mathrm{E}-06$ \\
\hline $\mathrm{Mn}$ & 602.18 & $4.74 \mathrm{E}-06$ & $3.34 \mathrm{E}-06$ & $2.33 \mathrm{E}-06$ & $2.50 \mathrm{E}-06$ & $2.00 \mathrm{E}-06$ & $2.33 \mathrm{E}-06$ & $2.17 \mathrm{E}-06$ \\
\hline $\mathrm{Fe}$ & 602.41 & $3.00 \mathrm{E}-06$ & $2.57 \mathrm{E}-06$ & $1.50 \mathrm{E}-06$ & $9.34 \mathrm{E}-07$ & $1.33 \mathrm{E}-06$ & $5.00 \mathrm{E}-07$ & $8.34 \mathrm{E}-07$ \\
\hline $\mathrm{Fe}$ & 602.71 & $5.60 \mathrm{E}-06$ & $4.90 \mathrm{E}-06$ & $3.94 \mathrm{E}-06$ & $2.33 \mathrm{E}-06$ & $2.94 \mathrm{E}-06$ & $2.90 \mathrm{E}-06$ & $3.20 \mathrm{E}-06$ \\
\hline $\mathrm{Fe}$ & 604.21 & $6.17 \mathrm{E}-06$ & $4.40 \mathrm{E}-06$ & $3.67 \mathrm{E}-06$ & $3.77 \mathrm{E}-06$ & $3.17 \mathrm{E}-06$ & $3.10 \mathrm{E}-06$ & $2.54 \mathrm{E}-06$ \\
\hline $\mathrm{Fe}$ & 605.6 & $3.84 \mathrm{E}-06$ & $2.44 \mathrm{E}-06$ & $2.00 \mathrm{E}-06$ & $1.17 \mathrm{E}-06$ & $1.00 \mathrm{E}-06$ & $1.17 \mathrm{E}-06$ & $8.34 \mathrm{E}-07$ \\
\hline $\mathrm{Fe}$ & 606.55 & $4.84 \mathrm{E}-06$ & $4.00 \mathrm{E}-06$ & $3.40 \mathrm{E}-06$ & $3.24 \mathrm{E}-06$ & $2.60 \mathrm{E}-06$ & $2.60 \mathrm{E}-06$ & $2.40 \mathrm{E}-06$ \\
\hline $\mathrm{Ni}$ & 610.81 & $2.77 \mathrm{E}-06$ & $1.00 \mathrm{E}-06$ & $9.01 \mathrm{E}-07$ & $4.34 \mathrm{E}-07$ & $-2.33 \mathrm{E}-07$ & $-1.00 \mathrm{E}-07$ & $4.34 \mathrm{E}-07$ \\
\hline $\mathrm{Ca}$ & 612.22 & $4.67 \mathrm{E}-06$ & $3.74 \mathrm{E}-06$ & $3.57 \mathrm{E}-06$ & $3.17 \mathrm{E}-06$ & $2.44 \mathrm{E}-06$ & $2.50 \mathrm{E}-06$ & $2.10 \mathrm{E}-06$ \\
\hline $\mathrm{Fe}$ & 620.03 & $4.60 \mathrm{E}-06$ & $3.50 \mathrm{E}-06$ & $2.27 \mathrm{E}-06$ & $2.40 \mathrm{E}-06$ & $2.44 \mathrm{E}-06$ & $1.90 \mathrm{E}-06$ & $1.83 \mathrm{E}-06$ \\
\hline $\mathrm{Fe}$ & 621.93 & $3.60 \mathrm{E}-06$ & $2.60 \mathrm{E}-06$ & $2.33 \mathrm{E}-06$ & $9.34 \mathrm{E}-07$ & $1.57 \mathrm{E}-06$ & $1.27 \mathrm{E}-06$ & $1.07 \mathrm{E}-06$ \\
\hline $\mathrm{Fe}$ & 626.51 & $6.40 \mathrm{E}-06$ & $4.07 \mathrm{E}-06$ & $4.07 \mathrm{E}-06$ & $3.34 \mathrm{E}-06$ & $3.00 \mathrm{E}-06$ & $3.44 \mathrm{E}-06$ & $3.27 \mathrm{E}-06$ \\
\hline \multirow[t]{2}{*}{$\mathrm{Fe}$} & 627.02 & $2.33 \mathrm{E}-06$ & $1.07 \mathrm{E}-06$ & $1.00 \mathrm{E}-07$ & $1.67 \mathrm{E}-07$ & $-2.33 \mathrm{E}-07$ & $1.00 \mathrm{E}-07$ & $1.33 \mathrm{E}-07$ \\
\hline & mean & $4.31 \mathrm{E}-06$ & $3.04 \mathrm{E}-06$ & $2.40 \mathrm{E}-06$ & $1.96 \mathrm{E}-06$ & $1.74 \mathrm{E}-06$ & $1.78 \mathrm{E}-06$ & $1.67 \mathrm{E}-06$ \\
\hline
\end{tabular}


where $t=p \cdot 10^{12}$ is a numerical coefficient, $p$ is a dimensionless numerical parameter of the solar corona, $10^{12}$ is the conversion factor to express the electron density in $\mathrm{el} / \mathrm{m}^{3}, r$ is the solar radius expressed in solar radii, $\varepsilon$ is the numerical dimensionless fall-off parameter of the curve as result of the same experimental observations. The curves considered for this paper are summarized in Figure 3.

Since the difference between the three curves is extremely small, we will show in the plot only the density value up to $r$ equal to 2.5 , despite it proceeds up to $r_{\max }$. The solution of the redshift problem lays to a different approach in astrophysics by taking into account the loss of energy of the emitted photons which travel through different paths depending on the observation angle of the observer on Earth. Observers placed in different locations in space might measure different values of the redshift whereas the number density of the electrons in the solar corona is a fixed parameter as it is invariant.

\section{Applied Calculation Method}

The method for the determination of the redshift in the solar disk, used for the comparison with the M.G. Adam's redshift of Table 1, is mainly based on:

- a Keplerian and Newtonian approach for the orbital motion and the velocity components (Section 4);

- a personal procedure developed on the distribution of electrons in the solar corona suitable to divide the volume in sub-spherical sectors (or sub-intervals on a plane) in order to reduce the exponential distribution of electrons to a constant average distribution for each sector (Section 5). In this model, we distinguish between sub-intervals, a constant division of the distance between the

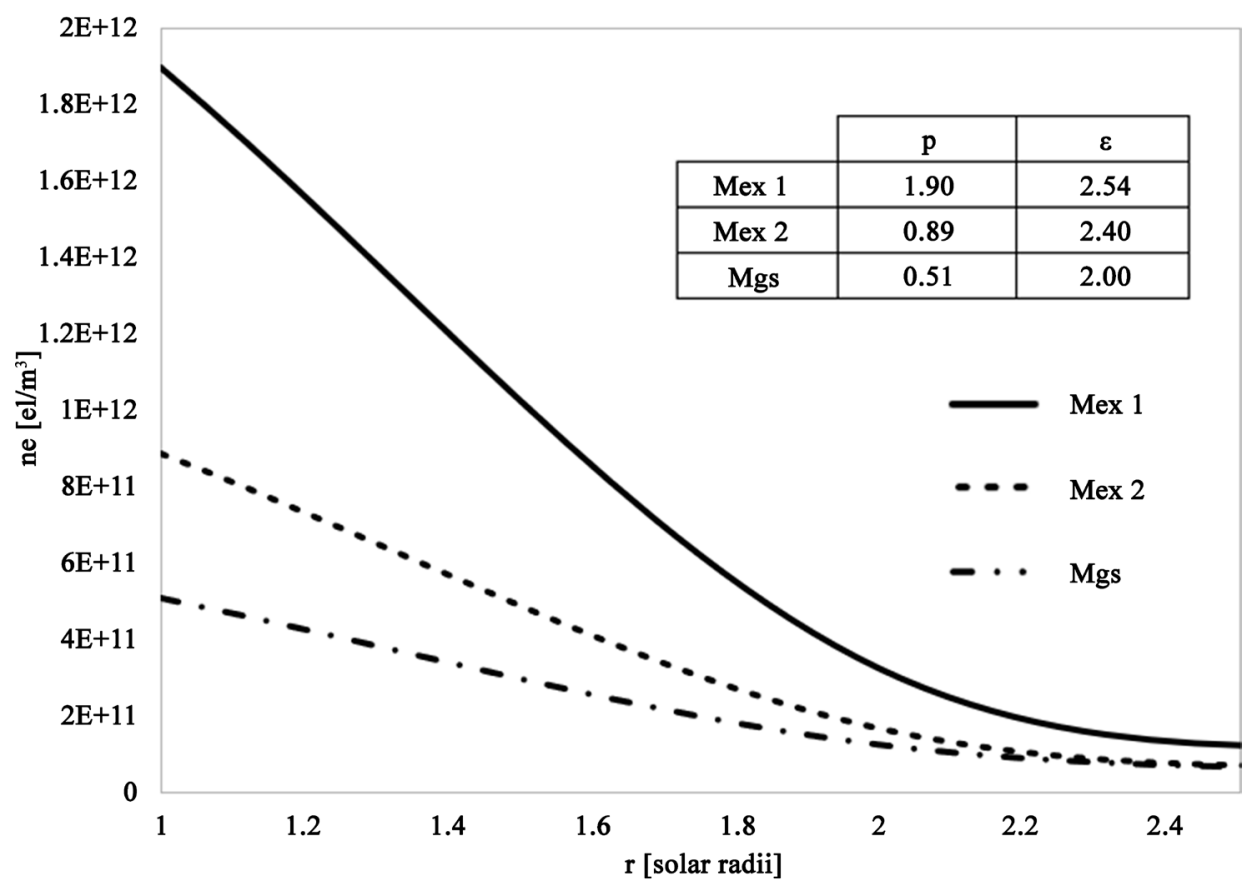

Figure 3. Three different possible distributions of electrons in the solar corona under examination in this study. Mex 1 (Mex Oct. 2006), Mex 2 (Mex Dec. 2008) and Mgs (Mgs Aug. 2002). 
Sun and the Earth in equidistant sectors, and interactional intervals or just intervals. Their length is variable and univocally determined by the physical quantities involved (considered wavelength, average-electron density, free mean path) and describes the interactions between the photons and the electrons in place;

- a CAD (Computer-aided design) model, created on purpose which realizes the observational orbital model on scale. The latter allows us to measure all involved angles and distances. Despite of that, mostly all images shown are not representations on scale because their geometry exceeds the dimension of this document;

- a Doppler's approach for the redshift of the velocity components and on L.E. Ashmore's approach for the multiple interactions between photons and electrons (Section 6);

- a personal procedure built to apply the NTL theory to the space between the Sun and the Earth. It is based on a calculation sheet with matrix and vector notation developed to merge all physical parameters (Section 6.7);

- an analysis of the results (Section 7) and a consequent discussion (Section 8).

\section{Orbital Motion of the Earth around the Sun}

The measurements relating to the solar redshift took place over three days in the year 1946: September 15, September 28 and October 11. The year 1946 was not a leap year and the measurements related to the redshift in different zones on the solar disk and at different times during each day, as shown in Figure 4, are the following ones: radial position 0.984 (limb), 0.959, 0.918, 0.884, 0.769, 0.577 and 0 (center). The main approach for calculating distances is Keplerian as we are able to calculate with a very low margin of error the position of the Earth at each moment in its orbit around the Sun [11]. The reference year is 1946 and the position of the Earth varies according to the day taken into consideration.

Kepler's equation allows us to calculate the mean anomaly which is the base value to find iteratively the eccentric anomaly $E$. We will indicate the days of measurement through the index $x$ which can assume only three possible values

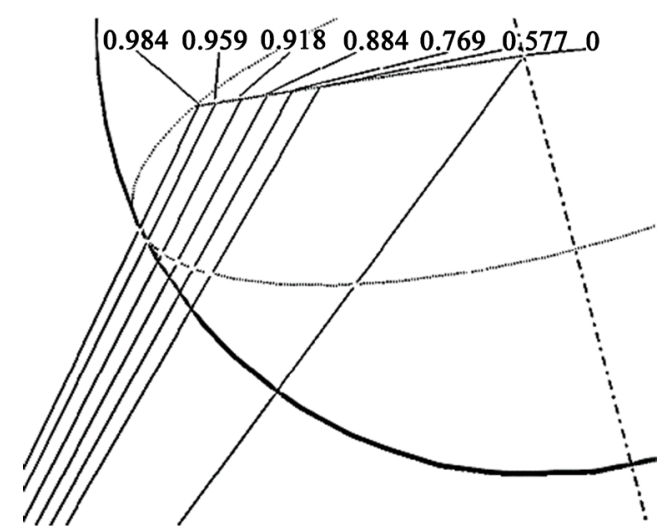

Figure 4. Radial position of the measurements on the solar disk according to an external perspective. 
(September 15, September 28 and October 11).

$$
M_{x}=\frac{2 \pi}{P}\left(T_{x}-t\right)
$$

All values of the formula refer to the year 1946: $T$ is the reference time of the measurements expressed in days from January $1, t=2$ is the perihelion passage on January 2, $P$ is the period between two perihelion passages, $R_{p}$ is the perihelion distance, $e$ is the eccentricity and the semi-major axis is given by the formula

$$
a=\frac{R_{p}}{1-e}
$$

Iteratively, we can calculate the eccentric anomaly $E$ as

$$
E_{x}-e \sin \left(E_{x}\right)=M_{x}
$$

Once the equality has been verified by iterations, we can determine the exact linear and angular position of the Earth in the orbit respectively as

$$
d_{x}=a\left(1-e \cos E_{x}\right)
$$

and

$$
\phi_{x}=2 \tan ^{-1}\left(\sqrt{\frac{1+e}{1-e}} \cdot \tan \frac{E_{x}}{2}\right)
$$

In Figure 5, we measure three different orbital distances and express them in solar radii. The first photon is emitted at $r=1$ corresponding to one solar radius $\left(1 R_{s}\right)$ on the surface of the Sun, technically speaking the photosphere. The mean

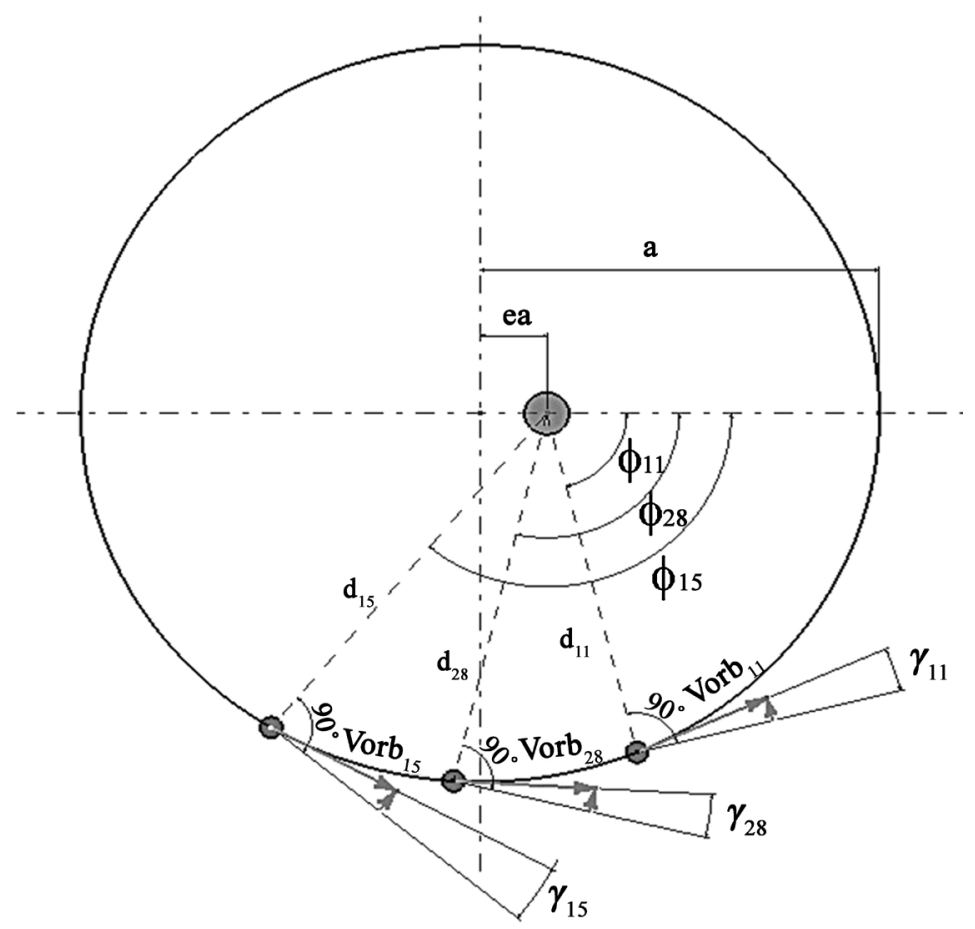

Figure 5. The orbit of the Earth around the Sun on each day of measurement. 
distance between the Sun and the Earth expressed in solar radii is equal to

$$
r_{\max }=\frac{d-R_{\text {Earth }}}{R_{\text {Sun }}}
$$

The value of the mean distance between the Sun and the Earth in solar radii corresponds to the end scale of the electron distribution of Equation (2.1). All calculated parameters are enclosed in Table 2 . The orbital velocity expressed in $\mathrm{Km} / \mathrm{sec}$ is

$$
v_{\text {orb }_{x}}=\sqrt{G\left(M_{s}+M_{E}\right)\left(\frac{2}{d_{x}}-\frac{1}{a}\right)}
$$

\section{Electron Distribution in the Solar Corona}

The fundamental part of the calculation concerns the understanding of the geometric configuration of the problem and the interactional dynamics between photons emitted by the solar photosphere and the electrons encountered on the way to Earth. Given that the electron distribution is well defined by previous studies [8], we can now go into the detail of the calculation. The target is to determine the solar redshift at the exact observation points taking into account all the involved astrophysical parameters. The first step is to calculate the electron density for each radius of the solar corona down to the distance corresponding to the position of the Earth (Figure 6). To get a first overview, we can initially divide the mean distance between the Sun and the Earth into intervals corresponding to $0.1 R_{s}$ and, once calculated the redshift, we can then divide the intervals into smaller and smaller values increasing each time the number of calculations needed to determine the redshift. It is clear that the more the intervals get reduced,

Table 2. Calculation of the orbital parameters.

\begin{tabular}{ccccc}
\hline & & September 15, 1946 & September 28, 1946 & October 11, 1946 \\
\hline$T$ & {$[$ days $]$} & 258 & 271 & 284 \\
$t$ & {$[$ days $]$} & & 2 & \\
$P$ & {$[$ days $]$} & & 365.8 & 4.8437897 \\
$M$ & {$[\mathrm{rad}]$} & 4.3971991 & 4.6204944 & \\
$e$ & {$[-]$} & & 0.0167313 & 4.8452029 \\
$E$ & {$[\mathrm{rad}]$} & 4.398479 & 4.621843 & 277.5288063 \\
$E$ & {$[\mathrm{deg}]$} & 251.9410808 & 264.7349465 & -83.42264996 \\
$\Phi$ & {$[\mathrm{deg}]$} & -108.9680151 & -96.2189542 & \\
$R_{p}$ & {$\left[10^{6} \mathrm{Km}\right]$} & & 147.104418 & \\
$a$ & {$\left[10^{6} \mathrm{Km}\right]$} & & 149.607547 & 149.279575 \\
$d$ & {$\left[10^{6} \mathrm{Km}\right]$} & 150.383504 & 149.837242 & -83.4226499 \\
$\Phi$ & {$[\mathrm{deg}]$} & -108.9680151 & -96.2189542 & 214.624 \\
$r_{\max }$ & {$[\mathrm{solar} \mathrm{radii]}$} & 216.211 & 215.426 & \\
\hline
\end{tabular}


the higher the redshift value will be. In theory, we could divide the intervals infinitely towards even smaller values reaching the atomic scale always obtaining increasing redshift values. This is certainly not the proper way to proceed in mathematical terms as there is an interaction probability. The latter is a function of the free mean path which is, in turn, related to the interactional cross section. Therefore, it is necessary to determine an average-electron density for a serie of reasonable sub-intervals which do not overload the calculations and which give, at the same time, a stable result in terms of redshift. For this reason, we will later see how to each sub-interval has been attributed a fixed value equal to $10^{-5} R_{s}$ Figure 8.

In Figure 7, the average value of electrons expressed in $\mathrm{el} / \mathrm{m}^{3}$ in a generic interval $r_{i+1}-r_{i}$ in which we have decreasing exponential trend is calculated as follows

$$
\begin{gathered}
\bar{n}_{e}=\frac{\int_{r_{i}}^{r_{i+1}} \frac{t}{r^{\varepsilon}} \mathrm{d} r}{\left(r_{i+1}-r_{i}\right)} \\
\bar{n}_{e}=\frac{t}{\left(r_{i+1}-r_{i}\right)} \int_{r_{i}}^{r_{i+1}} r^{-\varepsilon} \mathrm{d} r
\end{gathered}
$$

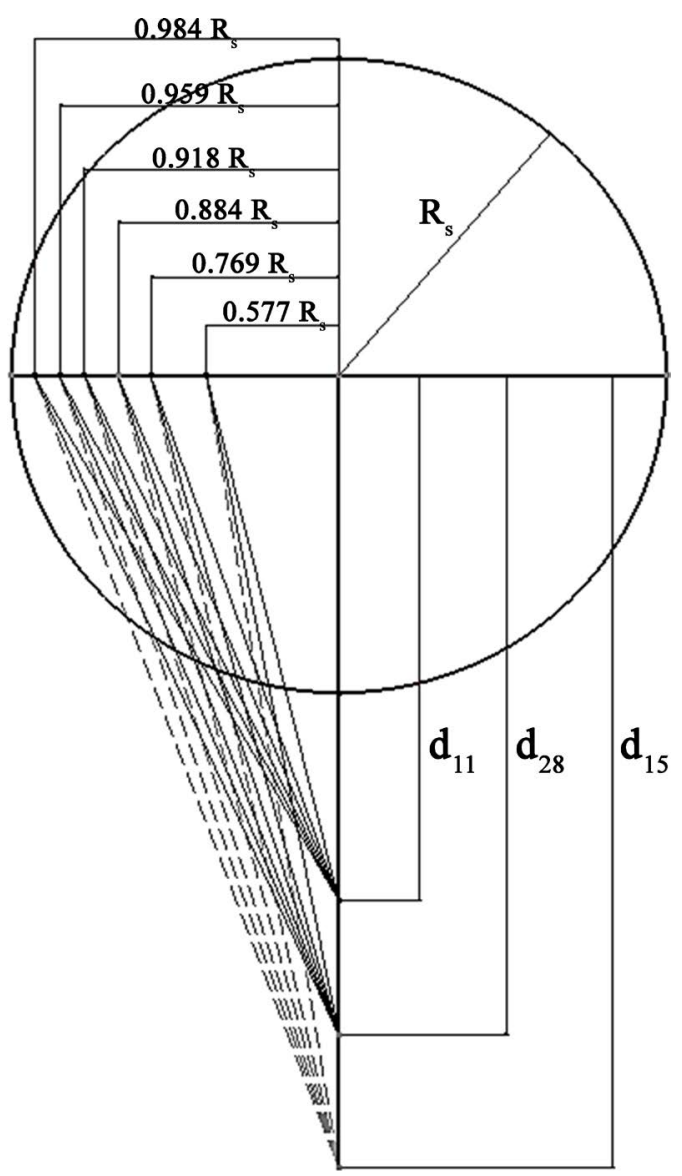

Figure 6. Observational scheme of the Sun/Earth system at each orbital position acc. to A. Trinchera's model. 


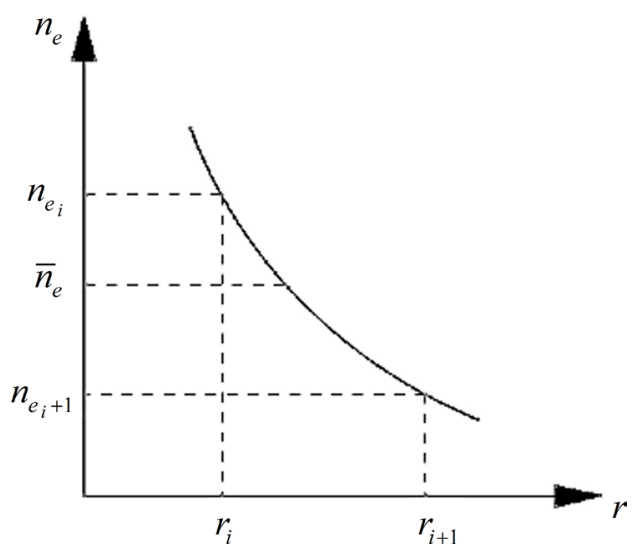

Figure 7. Average value of an interval characterized by a decreasing exponential trend acc. to A. Trinchera's model

$$
\begin{gathered}
\bar{n}_{e}=\frac{t}{\left(r_{i+1}-r_{i}\right)}\left[\frac{r^{1-\varepsilon}}{1-\varepsilon}\right]_{r_{i}}^{r_{i+1}} \\
\bar{n}_{e}=\frac{t}{(1-\varepsilon)\left(r_{i+1}-r_{i}\right)}\left(\frac{1}{r_{i+1}^{\varepsilon-1}}-\frac{1}{r_{i}^{\varepsilon-1}}\right) \\
\bar{n}_{e}=\frac{t}{(\varepsilon-1)\left(r_{i+1}-r_{i}\right)}\left(\frac{1}{r_{i}^{\varepsilon-1}}-\frac{1}{r_{i+1}^{\varepsilon-1}}\right)
\end{gathered}
$$

Our primary target is to understand how long an interactional interval can be in order to detect, on average, at least one photon/electron interaction. An essential condition necessary for the success of the calculation is that the choice of the intervals (expressed in solar radii) must be greater than or equal to the free mean path $\Lambda$ for each interval, taking into account an average-electron density. It is expressed as the integral of the density of electrons in that particular interval divided by the length of the interval itself. We can define the following indices: $i$ is the index related to the smallest radius, namely the beginning of the generic interactional interval (which coincides with the sub-interval previously defined) expressed in solar radii, $i+1$ is the index related to the largest radius, i.e. the extreme of the interactional interval expressed in solar radii. By imposing this condition, we are able to determine the correct length of the interactional intervals in meter in order to have, on average, at least one photon/electron interaction and to detect the loss of energy, which is a synonym of redshift.

$$
\begin{gathered}
I \geq \Lambda \\
\left(r_{i+1}-r_{i}\right) R_{s} \geq \frac{1}{2 r_{e} \lambda \frac{1}{(\varepsilon-1)\left(r_{i+1}-r_{i}\right)}\left(\frac{1}{r_{i}^{\varepsilon-1}}-\frac{1}{r_{e}^{\varepsilon-1}}\right)} \\
\left(r_{i+1}-r_{i}\right) R_{s} \geq \frac{(\varepsilon-1)\left(r_{i+1}-r_{i}\right)\left(r_{i}^{\varepsilon-1} r_{i+1}^{\varepsilon-1}\right)}{k\left(r_{i+1}^{\varepsilon-1}-r_{i}^{\varepsilon-1}\right)}
\end{gathered}
$$




$$
\begin{gathered}
R_{s} \geq \frac{(\varepsilon-1)\left(r_{i}^{\varepsilon-1} r_{i+1}^{\varepsilon-1}\right)}{k\left(r_{i+1}^{\varepsilon-1}-r_{i}^{\varepsilon-1}\right)} \\
k R_{s} r_{i+1}^{\varepsilon-1}-k R_{s} r_{i}^{\varepsilon-1} \geq(\varepsilon-1)\left(r_{i}^{\varepsilon-1} r_{i+1}^{\varepsilon-1}\right) \\
r_{i+1}^{\varepsilon-1}\left[k R_{s}-(\varepsilon-1) r_{i}^{\varepsilon-1}\right] \geq k R_{s} r_{i}^{\varepsilon-1} \\
r_{i+1}=r_{i} \cdot \sqrt[\frac{1}{\varepsilon-1}]{\frac{k R_{s}}{k R_{s}-(\varepsilon-1) r_{i}^{\varepsilon-1}}}
\end{gathered}
$$

After Equation (5.8) we have defined the factor $k$ as the product of twice the classic electron radius with the wavelength under examination and multiplied by the experimental numerical coefficient of the electron distribution.

$$
k=2 r_{e} \lambda t
$$

With Equation (5.13) the equality has been imposed in order to determine a specific value for $r_{i+1}$. For instance, based on the expression determined if we consider $r_{i}=1$ corresponding to $1 R_{s}$ and after the calculation we obtain $r_{i+1}=2.074 R_{s}$, it means that, based on the distribution of electrons and on the minimum-allowed value of the interval imposed $r_{p}$ we are sure that at least one interaction between a photon and an electron will take place up to $2.074 R_{s^{\prime}}$ Another important condition has to be verified for the $r_{i+1_{\text {lim }}}$ interval

$$
r_{i+l_{\text {limx }}} \leq r_{\max _{x}}
$$

It allows us to define a mathematical operation in order to stop the calculation in the spreadsheet. The extreme of the interactional interval cannot exceed the physical distance between the Sun and the Earth at each day of measurement indicated by the index $x$, otherwise, we could proceed indefinitely. In addition, the final result clearly shows that, based on the trend of the electron density in the solar corona and on the basis of the previous requirement, another secondary condition of fundamental importance has to be satisfied

$$
0<r_{i}<\sqrt[\frac{1}{\varepsilon-1}]{\frac{k R_{s}}{\varepsilon-1}}
$$

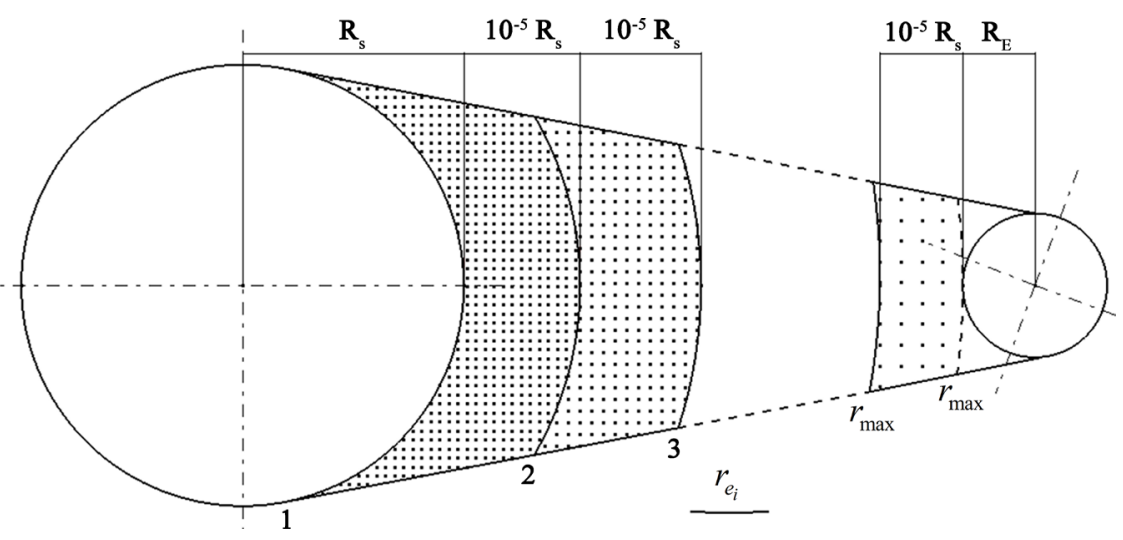

Figure 8. A. Trinchera's scheme of the distribution of e-between Sun and Earth. Each sector is a sub-interval. 
from which, imposing the equality we obtain

$$
r_{i_{\text {lim }}}=\sqrt[\frac{1}{\varepsilon-1}]{\frac{k R_{s}}{\varepsilon-1}}
$$

It is the radial length over which we cannot calculate an interactional redshift contribution.

In Figure 9, we can clearly point out the difference between the sub-intervals which divide the distance between the Sun and the Earth as well as the interactional intervals denoting the physical length (they are actually spherical sectors with a three-dimensional approach) through which at least one interaction photon/electron takes place. There is certainly a limit to the number of these intervals since the distance between the Sun and the Earth is a finite value (e.g. $r_{\max }=$ 215.426 on September 28,1946$)$. It only varies depending on the day of measurement and on the value of the considered wavelength, when the average density has already been established.

In Table 3, we can observe an example of calculation from the spreadsheet for one of the specific days of measurement and for one specific wavelength. We can notice how $r_{i+1_{\text {lim }}}=215.7$ is compatible with the distance between the Sun and the Earth on the day of measurement over which the intervals cannot assume values. The limit value is imposed by $r_{\max }$ in Table 2 as well as in Equation (5.15). The limit radius of the sub-interval $r_{i_{\text {lim }}}=2.05415$ is the margin for which we can detect at least one interaction photon/electron. The limit is imposed by Equation (5.17). The smaller the sub-intervals, the more precise is the redshift but at the same time, the greater are the steps of the computer to calculate the redshift. In our case, in order to avoid overloading the program with computations and since the redshift value does not differ too much in mathematical terms, the fixed value of the sub-interval for the study of the solar redshift has been imposed to be $10^{-5} R_{s}$. As shown in the last row of Table 3, since the $r_{i}$ intervals are discrete values, they are sometimes slightly over or below the imposed limit, nevertheless, we can always adjust the last calculation row by

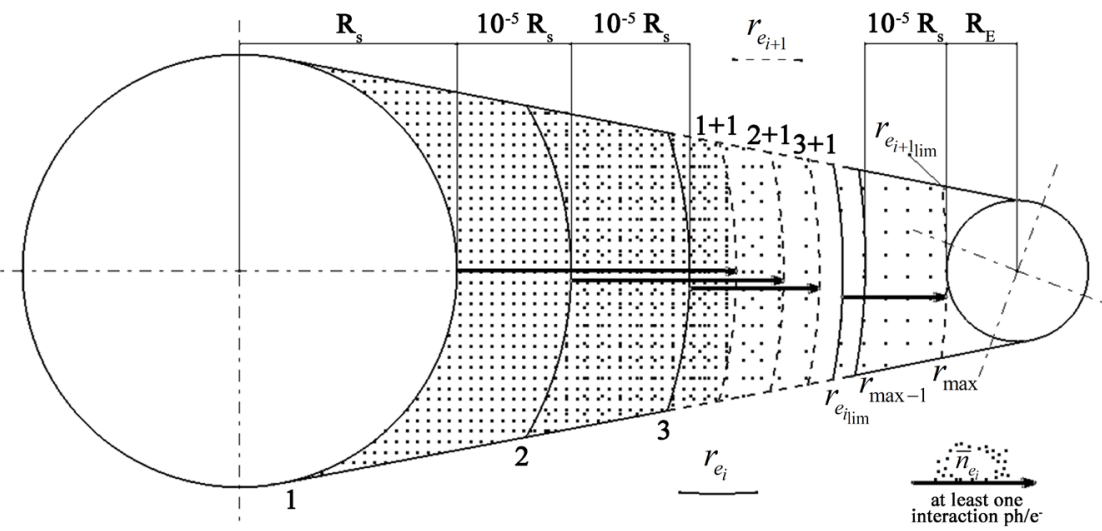

Figure 9. A. Trinchera's schematization of the sub-intervals (continuous curve) and corresponding interactional intervals (dashed curve) in the space between the Sun and the Earth. The last-mentioned intervals are characterized by different average distribution of electrons (dots). 
calculating the $r_{i_{\text {lim }}}$, imposing the $r_{i+1_{\text {lim }}}$ in Equation (5.13) as follows

$$
r_{i_{\text {lim }}}=r_{i+1_{\text {lim }}} \cdot \sqrt[\frac{1}{\varepsilon-1}]{\frac{k R_{s}}{k R_{s}+(\varepsilon-1) r_{i+1_{\text {lim }}} \varepsilon-1}}
$$

\section{Redshift Calculation}

The total redshift is the sum of various components and, in general, we take advantage by introducing vectors and matrices instead of single formulas. In such a way, each vector is related to a specific physically quantity involved in the calculations, indicated by a specific index.

The vector $x$ represents the days of measurements, the vector $y$ represents the zones of observation on the solar disk expressed in terms of solar radii, the vector $w$ represents the reference wavelengths used for the redshift calculation in Adam's research, the vector $s_{L}$ consists of all redshift components calculated on the left-hand side of the solar disk and the vector $s_{R}$ consists of all redshift components calculated on the right-hand side of the solar disk. Concerning the suffixes

Table 3. Informative example of calculations from the spreadsheet.

\begin{tabular}{|c|c|c|c|}
\hline$r e_{i}$ & $r e_{i+1}$ & average ne $\left(\mathrm{el} / \mathrm{m}^{3}\right)$ & $\Lambda(\mathrm{m})$ \\
\hline 1 & 1.29670659 & $1.3713 \mathrm{E}+12$ & $206,362,399$ \\
\hline 1.00001 & 1.29672593 & $1.3712 \mathrm{E}+12$ & $206,368,900$ \\
\hline 1.00002 & 1.29674528 & $1.3712 \mathrm{E}+12$ & $206,375,401$ \\
\hline 1.00003 & 1.29676463 & $1.3711 \mathrm{E}+12$ & $206,381,903$ \\
\hline 1.00004 & 1.29678398 & $1.3711 \mathrm{E}+12$ & $206,388,404$ \\
\hline 1.00005 & 1.29680333 & $1.371 \mathrm{E}+12$ & $206,394,906$ \\
\hline 1.00006 & 1.29682268 & $1.371 \mathrm{E}+12$ & $206,401,408$ \\
\hline 1.00007 & 1.29684202 & $1.3709 \mathrm{E}+12$ & $206,407,910$ \\
\hline$\cdots \cdots$ & $\cdots \cdots$ & $\ldots \ldots$ & $\cdots \cdots$ \\
\hline 2.05413 & 213.044352 & $1,928,332,474$ & $1.4675 \mathrm{E}+11$ \\
\hline 2.05414 & 214.373784 & $1,916,258,372$ & $1.4767 \mathrm{E}+11$ \\
\hline 2.05415 & 215.724476 & $1,904,145,058$ & $1.4861 \mathrm{E}+11$ \\
\hline
\end{tabular}

Table 4. Vector components containing physical quantities for the computation.

\begin{tabular}{|c|c|c|c|c|c|c|c|c|c|c|c|c|c|c|c|}
\hline \multirow{2}{*}{ vector } & & \multicolumn{14}{|c|}{ indices } \\
\hline & & 1 & 2 & 3 & 4 & 5 & 6 & 7 & 8 & 9 & 10 & 11 & 12 & 13 & 14 \\
\hline [days] & $\mathrm{x}$ & Sep 15 & Sep 28 & Oct 11 & $\sim$ & $\sim$ & $\sim$ & $\sim$ & $\sim$ & $\sim$ & $\sim$ & $\sim$ & $\sim$ & $\sim$ & $\sim$ \\
\hline [solar radii] & $y$ & 0.984 & 0.959 & 0.918 & 0.884 & 0.769 & 0.557 & 0 & $\sim$ & $\sim$ & $\sim$ & $\sim$ & $\sim$ & $\sim$ & $\sim$ \\
\hline$\left[10^{-7} \mathrm{~m}\right]$ & $\mathrm{w}$ & 6.013 & 6.016 & 6.021 & 6.241 & 6.271 & 6.042 & 6.056 & 6.065 & 6.108 & 6.122 & 6.200 & 6.219 & 6.265 & 6.270 \\
\hline$[-]$ & SL & $z_{g r_{+}}^{S}$ & $z_{g r_{-}}^{E}$ & $z_{p r_{-}}^{S}$ & $z_{p r_{+L}}^{E}$ & $z_{o m_{-}}^{E}$ & $z_{g m h_{-}}^{S}$ & $z_{g m r_{-}}^{S}$ & $Z_{n t l_{+}}$ & $\sim$ & $\sim$ & $\sim$ & $\sim$ & $\sim$ & $\sim$ \\
\hline$[-]$ & SR & $z_{g r_{+}}^{S}$ & $z_{g r_{-}}^{E}$ & $z_{p r_{+}}^{S}$ & $Z_{p r_{+R}}^{E}$ & $z_{o m_{-}}^{E}$ & $z_{g m h_{+}}^{S}$ & $z_{g m r_{-}}^{S}$ & $Z_{n t l_{+}}$ & $\sim$ & $\sim$ & $\sim$ & $\sim$ & $\sim$ & $\sim$ \\
\hline
\end{tabular}


used: $S$ stands for Sun, $E$ for Earth, $g r$ for gravitational shift, $p r$ for proper rotation, om for orbital motion, $g m$ for granular motion, $h$ for horizontal component, $r$ for radial component, $n t l$ for interactional contribute photons/electrons according to L.E. Ashmore's NTL, $L$ for left and $R$ for right. The sign at the end of the suffix helps to indicate, in the perspective of an observer on Earth, a receding value if the sign is positive $(+)$ or an approaching value if the sign is negative (-).

In the following paragraphs we explain in detail how the calculations are performed and we will refer to a generic electron distribution of the three available distributions. The values and their physical meanings of all constants which appear in the formulas, are listed in Appendix A, whereas the results appear in Section 7. All detailed calculations related specifically to the three cases of electron distributions are listed in Appendix B.

\subsection{Gravitational Shift of the Sun and the Earth}

We can show how a photon of light loses energy by escaping the gravitational field of the Sun whereas it gains energy by approaching the gravitational field of the Earth. Therefore, its frequency becomes respectively longer and then shorter. The final gravitational contribution will be a shift towards longer wavelengths (redshift) since the gravitational influence of the Sun is greater than the gravitation influence of the Earth, taking into account the distance between them. From the conservation of the total energy, we can obtain the value of the wavelength leaving a gravitational field

$$
\begin{gathered}
E_{\text {tot }}=K E+P E \\
E_{\text {tot }}=h v-\frac{G m_{p h} M_{S}}{d_{x}} \\
E_{\text {tot }}=h v-\frac{G M_{S}}{d_{x}} \frac{h v}{c^{2}} \\
E_{t o t}=h v\left(1-\frac{G M_{S}}{d_{x} c^{2}}\right) \\
E_{t o t}=h v^{\prime}
\end{gathered}
$$

In Figure 10, in terms of gravitational redshift, the expression becomes

$$
\begin{array}{r}
z_{g r}=\frac{\lambda^{\prime}-\lambda}{\lambda} \\
z_{g r}=\frac{\left(1-\frac{G M_{S}}{d_{x} c^{2}}\right)}{\lambda}-\lambda \\
z_{g r}=\frac{1}{\left(1-\frac{G M_{S}}{d_{x} c^{2}}\right)}-1
\end{array}
$$




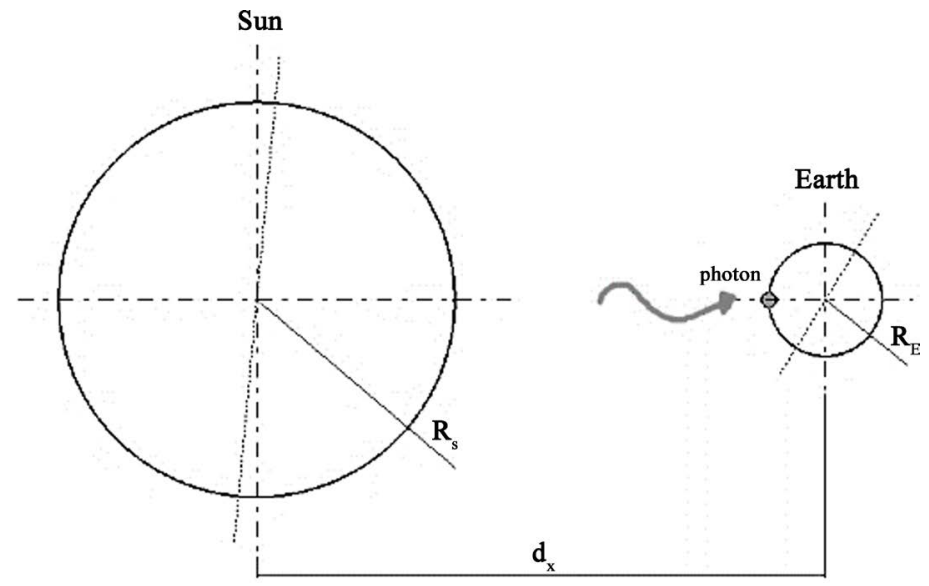

Figure 10. Effect of the gravitational shift on the Sun/Earth system acc. to a Newtonian approach.

In the case of a photon leaving the Sun, the redshift has a positive sign due to the fact that the photon loses energy to overcome the gravitational field of the Sun, whereas in the case of a photon approaching the Earth, we calculate a gravitational blueshift because, as previously mentioned, the photon gains energy by approaching the gravitational field of the Earth. Therefore, in mathematical terms, we can express them as follows

$$
z_{g r_{+}}^{S}=\frac{1}{\left(1-\frac{G M_{S}}{d_{x} c^{2}}\right)}-1>0
$$

and

$$
z_{g r_{-}}^{E}=\frac{1}{\left(1-\frac{G R_{E}}{R_{E} c^{2}}\right)}-1<0
$$

For small distances like the Sun/Earth system, the gravitational redshift calculated by using both Newton's and Einstein's approach, according to General Relativity, is the same. In this current study, we keep the Newtonian formulation. In vector notation, since the gravitational contribute depends only on the distance of the received photon on Earth in relation to the Sun, we can express it as follows

$$
z_{g r_{+}}^{S}=\left(\begin{array}{c}
\frac{1}{\left(1-\frac{G M_{S}}{d_{x} c^{2}}\right)}-1 \\
\frac{1}{\left(1-\frac{G M_{S}}{d_{x} c^{2}}\right)}-1 \\
\vdots \\
\frac{1}{\left(1-\frac{G M_{S}}{d_{x} c^{2}}\right)}-1
\end{array}\right)
$$


Both the left-hand side and the right-hand side of the solar corona do not play any role in gravitational terms. However, the contribution of the Earth is always the same on each day of measurement since the radial position of the observatory does not change.

$$
Z_{g r_{-}}^{E}=\left(\begin{array}{c}
\frac{1}{\left(1-\frac{G M_{E}}{R_{E} c^{2}}\right)}-1 \\
\frac{1}{\left(1-\frac{G M_{E}}{R_{E} c^{2}}\right)}-1 \\
\vdots \\
\frac{1}{\left(1-\frac{G M_{E}}{R_{E} c^{2}}\right)}-1
\end{array}\right)
$$

\subsection{Doppler Shift of the Sun Due to Proper Rotation}

The Sun is not a solid object but consists of a series of concentric sectors rotating at different speeds with respect to each other. In order to determine the redshift of the solar disk, our field of interest is restricted to the equatorial zone of the Sun which has a well-known speed. $T_{e q}=25.6$ days is the equatorial period or the time that a generic point on the equatorial sector requires to complete a turn around the Sun itself. On the basis of this parameter, we can establish the equatorial speed of the Sun expressed in $\mathrm{m} / \mathrm{sec}$ which corresponds to a tangential speed along the whole equatorial perimeter.

$$
\begin{gathered}
\left|v_{S}\right|=\left|v_{A}\right|=\left|v_{R}\right|=\omega R_{S} \\
\left|v_{S}\right|=\frac{2 \pi}{T_{S_{\text {eq }}}} R_{S} \\
\left|v_{S}\right|=\frac{2 \pi \times 695510 \times 10^{3} \mathrm{~m}}{25.6 \mathrm{~d} \times 24 \times 3600 \mathrm{sec} / \mathrm{d}}=1975.738
\end{gathered}
$$

In the front view of Figure 11, the radial vector is represented by a point as it leaves the plane whereas on the right it is represented with a cross because it enters the plane. It is an exact representation of an observer's point of view from the surface of the Earth. In the top view, the configuration of the velocity vector is much clearer.

This speed is very important as it allows the determination of the Doppler shift in approach and recession of the solar edge. The angle between the direction of observation from the Earth and the velocity vector at the specific point of the solar disk, as shown in Figure 12, provides us with the velocity component at the time of the measurements. The value of the tangential velocity along the line of sight of a terrestrial observer is

$$
v_{s_{y}}=\left|v_{S}\right| \cos \alpha_{t_{y}}
$$



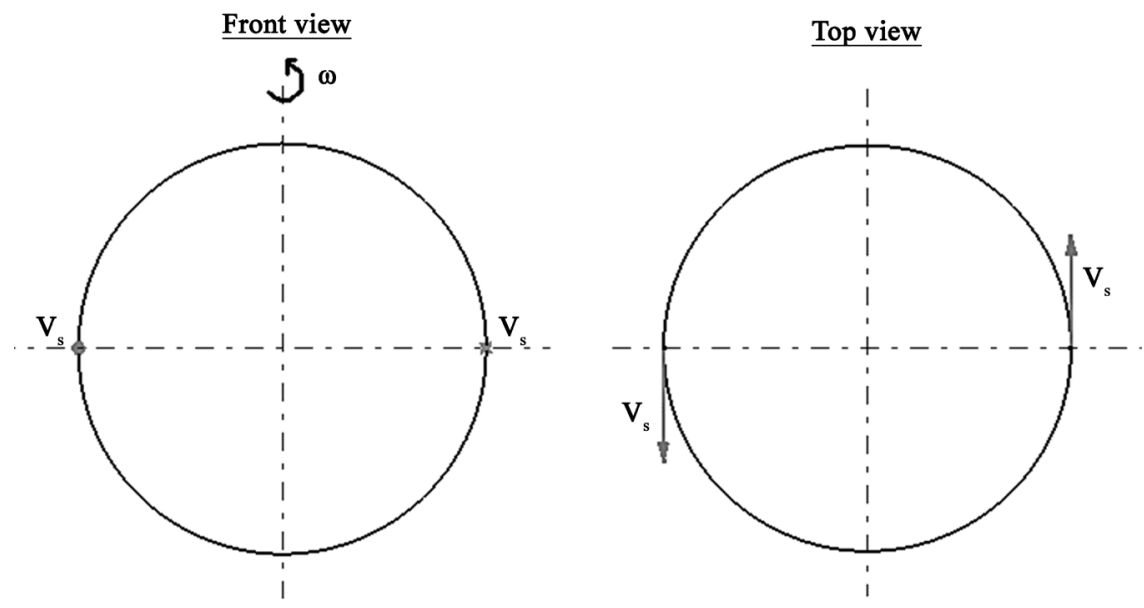

Figure 11. Representation of the equatorial velocity of the Sun.
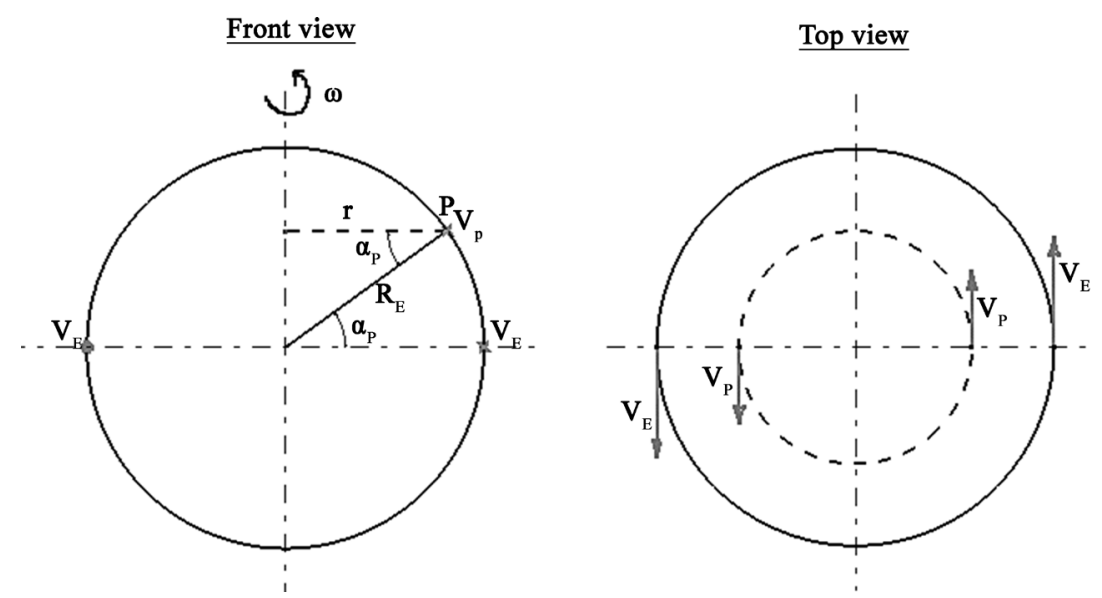

Figure 12. Representation of the rotational velocity of the Earth on the equator and on a generic point $\mathrm{P}$ on its surface acc. to A. Trinchera's calculations.

It strictly depends on the equatorial point of the solar corona under examination. The velocity components are specular but with sign inverted. Therefore, the redshift value is approaching on the left-hand side and receding on the right-hand side. We express the redshifts as follows

$$
z_{p r_{-}}^{S}=\sqrt{\frac{1-\beta_{p r}^{S}}{1+\beta_{p r}^{S}}}-1
$$

and

$$
z_{p r_{+}}^{S}=\sqrt{\frac{1+\beta_{p r}^{S}}{1-\beta_{p r}^{S}}}-1
$$

With the positive sign, we indicate a receding case and with the negative sign an approaching case, where

$$
\beta_{p r}^{S}=\frac{v_{s_{y}}}{C}
$$

It is only dependent on the point under examination $y$ on the solar corona. 
Furthermore, it is appropriate to differentiate the previous formulas by the vector notation for the left-hand side and the right-hand side, equal in module but not in sign, as follows

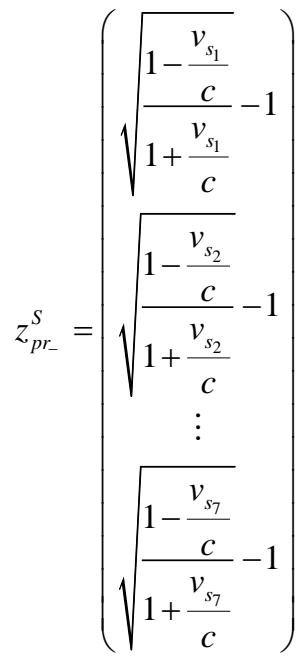

and

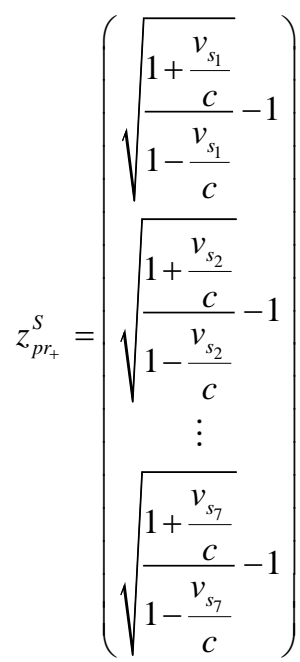

\subsection{Doppler Shift of the Earth Due to Proper Rotation}

The measurements were made by the Oxford Observatory having the coordinates $\left(51.608^{\circ} \mathrm{N}, 1.2639^{\circ} \mathrm{W}\right)$ [9]. In Table 5, we can find the transcription of all the measurements of the hour angle and altitude of the Sun related to the various positions of the solar disk on the approaching and the receding side.

With the next calculation, we are able to determine the rotational speed component of the Earth at each measurement expressed in $\mathrm{m} / \mathrm{sec}$. In the presence of numerous measurements in various points of the solar disk and in three different days, the values have to be averaged.

$$
\bar{v}_{e_{y x}}=v_{E_{e q}} \sin H_{y x} \cos \delta_{y x} \cos \Phi_{y x}
$$

$H$ is the hour angle, $\delta$ is the declination of the Sun and $\Phi$ is the latitude of the observer on Earth. 
Table 5. Transcription in terms of Doppler shift velocities of the Earth measured by M.G. Adam.

\begin{tabular}{|c|c|c|c|c|c|c|c|c|c|c|c|}
\hline & & & 0.984 & 0.959 & 0.918 & 0.884 & 0.769 & 0.577 & \multicolumn{2}{|c|}{0} & \\
\hline \multirow{6}{*}{$\begin{array}{c}\mathrm{H} \\
(\mathrm{deg})\end{array}$} & Sep 15 & $\mathrm{~L}$ & 48.036 & 45.500 & 55.116 & 53.000 & 47.866 & 45.750 & 39.366 & 9.866 & \\
\hline & & $\mathrm{R}$ & 39.366 & 35.366 & 62.116 & 17.000 & 37.866 & 41.500 & & & \\
\hline & Sep 28 & $\mathrm{~L}$ & 30.000 & 27.500 & 20.250 & 24.750 & 27.250 & 43.116 & 25.500 & 12.250 & \\
\hline & & $\mathrm{R}$ & 22.755 & 20.000 & 15.500 & 13.866 & 32.000 & 35.116 & 29.000 & 44.750 & \\
\hline & Oct 11 & $\mathrm{~L}$ & 41.366 & 38.616 & 19.000 & 16.750 & 25.616 & 30.366 & 45.250 & 21.250 & \\
\hline & & $\mathrm{R}$ & 50.116 & 47.366 & 19.000 & 13.750 & 21.116 & 33.866 & 23.000 & 36.000 & \\
\hline \multirow{6}{*}{$\begin{array}{l}\text { delta } \\
(\text { deg) }\end{array}$} & Sep 15 & $\mathrm{~L}$ & 27.050 & 28.500 & 23.333 & 24.483 & 27.216 & 28.283 & 29.666 & 40.733 & \\
\hline & & $\mathrm{R}$ & 31.433 & 33.200 & 19.350 & 39.383 & 32.050 & 30.383 & & & \\
\hline & Sep 28 & $\mathrm{~L}$ & 30.683 & 31.550 & 33.650 & 32.366 & 31.566 & 25.150 & 32.183 & 35.366 & \\
\hline & & $\mathrm{R}$ & 33.016 & 33.766 & 34.783 & 35.100 & 29.883 & 28.650 & 30.983 & 24.383 & \\
\hline & Oct 11 & $\mathrm{~L}$ & 21.566 & 22.733 & 29.150 & 29.616 & 27.350 & 25.800 & 19.816 & 28.616 & \\
\hline & & $\mathrm{R}$ & 17.483 & 18.816 & 29.100 & 30.183 & 28.600 & 24.550 & 28.100 & 23.716 & \\
\hline \multirow{6}{*}{$\begin{array}{l}\text { phi } \\
(\mathrm{deg})\end{array}$} & Sep 15 & $\mathrm{~L}$ & 51.761 & 51.761 & 51.761 & 51.761 & 51.761 & 51.761 & 51.761 & 51.761 & \\
\hline & & $\mathrm{R}$ & 51.761 & 51.761 & 51.761 & 51.761 & 51.761 & 51.761 & 51.761 & 51.761 & \\
\hline & Sep 28 & $\mathrm{~L}$ & 51.761 & 51.761 & 51.761 & 51.761 & 51.761 & 51.761 & 51.761 & 51.761 & \\
\hline & & $\mathrm{R}$ & 51.761 & 51.761 & 51.761 & 51.761 & 51.761 & 51.761 & 51.761 & 51.761 & \\
\hline & Oct 11 & $\mathrm{~L}$ & 51.761 & 51.761 & 51.761 & 51.761 & 51.761 & 51.761 & 51.761 & 51.761 & \\
\hline & & $\mathrm{R}$ & 51.761 & 51.761 & 51.761 & 51.761 & 51.761 & 51.761 & 51.761 & 51.761 & \\
\hline \multirow{6}{*}{$\begin{array}{c}\mathbf{v} \\
(\mathrm{m} / \mathrm{sec})\end{array}$} & Sep 15 & $\mathrm{~L}$ & 190.185 & 180.016 & 216.319 & 208.738 & 189.396 & 181.157 & 158.281 & 37.288 & \\
\hline & & $\mathrm{R}$ & 155.426 & 139.091 & 239.508 & 64.900 & 149.415 & 164.164 & 0.000 & 0.000 & \\
\hline & Sep 28 & $\mathrm{~L}$ & 123.493 & 113.008 & 82.746 & 101.556 & 112.041 & 177.680 & 104.642 & 49.691 & \\
\hline & & $\mathrm{R}$ & 93.145 & 81.656 & 63.035 & 56.310 & 131.954 & 144.975 & 119.367 & 184.153 & \\
\hline & Oct 11 & $\mathrm{~L}$ & 176.508 & 165.311 & 81.658 & 71.954 & 110.284 & 130.709 & 191.882 & 91.374 & \\
\hline & & $\mathrm{R}$ & 210.194 & 199.994 & 81.698 & 59.007 & 90.838 & 145.570 & 98.987 & 154.551 & \\
\hline \multirow{2}{*}{$\begin{array}{c}\text { v average } \\
(\mathrm{m} / \mathrm{sec})\end{array}$} & $\begin{array}{c}\text { over } \\
\text { all }\end{array}$ & $\mathrm{L}$ & 163.395 & 152.778 & 126.908 & 127.416 & 137.240 & 163.182 & 151.601 & 59.451 & 105.526 \\
\hline & days & $\mathrm{R}$ & 152.922 & 140.247 & 128.080 & 60.072 & 124.069 & 151.570 & 109.177 & 169.352 & 139.265 \\
\hline
\end{tabular}

The equatorial rotation speed of the Earth in $\mathrm{m} / \mathrm{sec}$ is expressed by the following formula

$$
\begin{gathered}
v_{E_{e q}}=\omega R_{E} \\
v_{E_{e q}}=\frac{2 \pi}{T_{E}} R_{E} \\
v_{E_{e q}}=\frac{2 \pi \times 6371 \times 10^{3} \mathrm{~m}}{23.93 \mathrm{~h} \times 3600 \mathrm{sec} / \mathrm{h}} \cong 464
\end{gathered}
$$

The sign at each measurement is positive so that the whole velocities are receding. 


$$
z_{p r_{+}}^{E}=\sqrt{\frac{1+\beta_{p r}^{E}}{1-\beta_{p r}^{E}}}-1
$$

where

$$
\beta_{p r}^{E}=\frac{\bar{v}_{e_{y x}}}{C}
$$

As previously seen, the redshift component is function of the position $y$ on the solar corona and of the day of measurement $x$. In vector formulation, all components are different if we focus on the left-hand side or on the right-hand side of the solar corona. We can express the vectors as

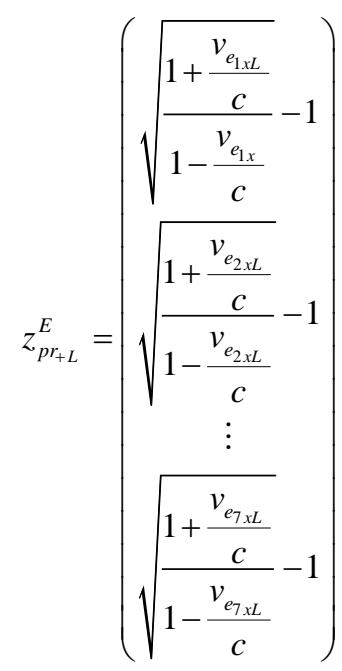

and

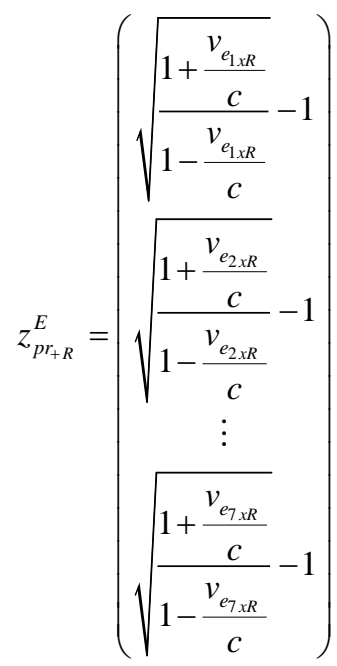

There is a total of 6 vectors: two (L/R) for each day of measurement.

\subsection{Doppler Shift of the Earth Due to Orbital Motion}

We previously calculated the average between the Sun and the Earth distance and the angle from the horizontal orbital semi-axis at the time of the observa- 
tions. Based on these data, we can know exactly the orbital velocity of the Earth and the angle with respect to the line that connects the Earth and the Sun. After introducing now the index $y$ as well, the previous Equation (4.7) becomes

$$
v_{\text {orb }}=\sqrt{G\left(M_{s}+M_{E}\right)\left(\frac{2}{d_{x}}-\frac{1}{a}\right)}
$$

where once again $x$ is an index representing the measurement day taken into consideration.

Depending on the direction and on the angle with which a terrestrial observer makes the measurements, one will detect a different component of the orbital velocity of the Earth according to the scheme in Figure 13. All speed components along the direction of the observation are of approach

$$
z_{o m-}^{E}=\sqrt{\frac{1-\beta_{o m}^{E}}{1+\beta_{o m}^{E}}}-1
$$

and

$$
\beta_{o m}^{E}=\frac{V_{o r b} b_{x}}{C}
$$

The angles strictly depend on the exact point of the solar disk from which the measurements were made. Due to this, the velocity components involved in the orbital motion give different blueshift (negative sign) contributions. In vector notation

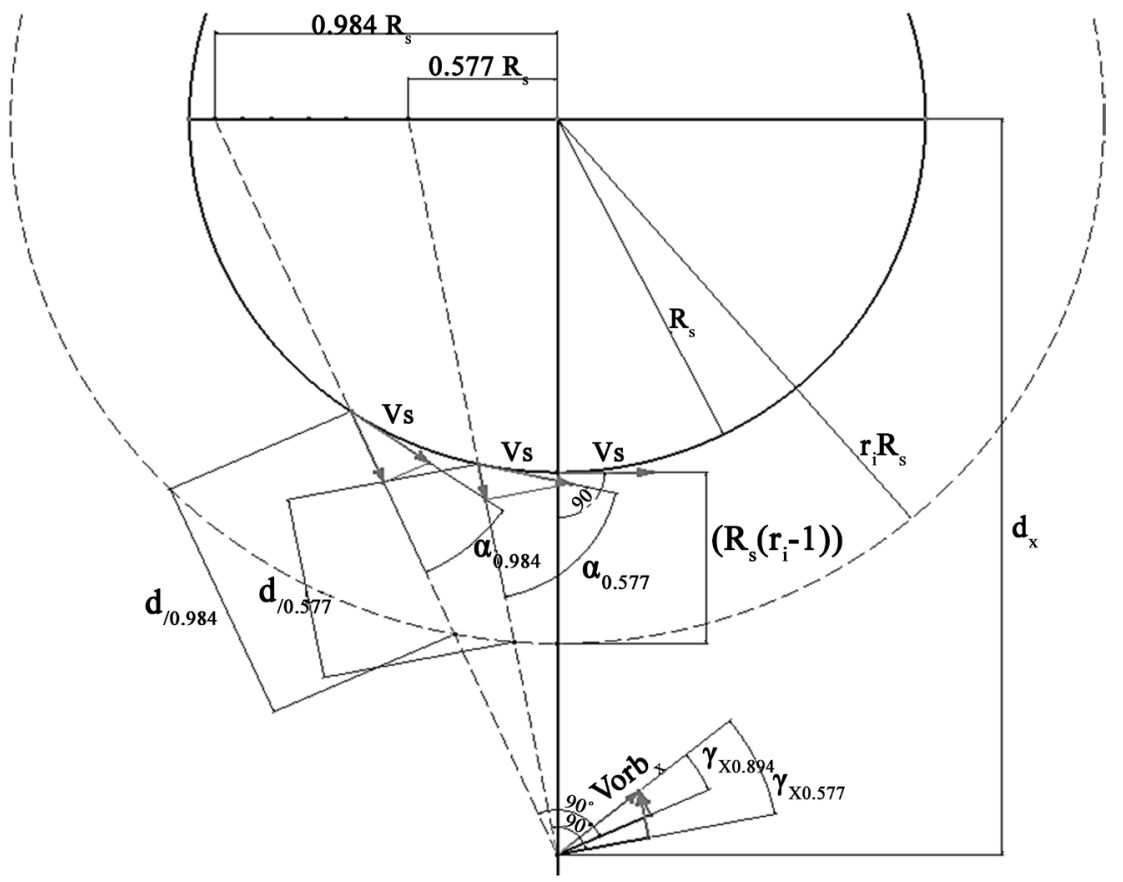

Figure 13. A. Trinchera's scheme of the Doppler shift of the Earth due to orbital motion and contributes of the rotational velocity components of the Sun. 


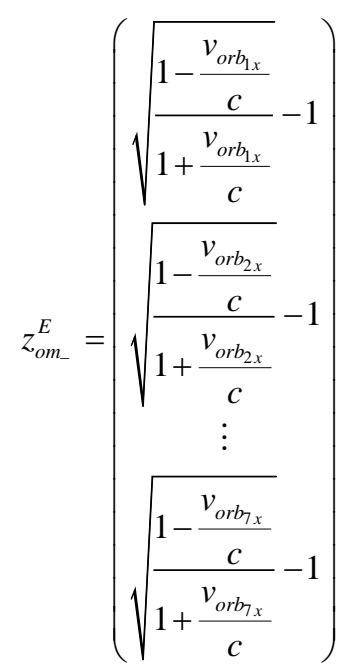

We find a total of three vectors, one for each day of measurement.

\subsection{Doppler Shift of the Sun Due to Granular Motion}

The contribution given by the solar granules consists of a horizontal and a radial component coming out from the Sun [12]. Since we can use the angles determined in the previous calculations for the horizontal speed of the granules (on average equal to $350 \mathrm{~m} / \mathrm{sec}$ ), we can calculate the speed component along the direction of observation.

$$
v_{g m h_{y x}}=v_{g m h} \cdot \cos \alpha_{y}
$$

The Doppler shift can be expressed by the following formula

$$
z_{g m h}^{S}=\sqrt{\frac{1-\beta_{g m h}^{S}}{1+\beta_{g m h}^{S}}}-1
$$

and

$$
z_{g m h_{+}}^{S}=\sqrt{\frac{1+\beta_{g m h}^{S}}{1-\beta_{g m h}^{S}}}-1
$$

where

$$
\beta_{g m h}^{S}=\frac{V_{g m h_{y x}}}{C}
$$

In Figure 14, with regards to the radial velocity of granular motion, it is considered in the first place, on average, equal to the maximum observed value $(1000 \mathrm{~m} / \mathrm{sec})$ [13]. All the speed components along the direction of observation are of approach as they face the Earth, reduced by the cosine of the angle being $90^{\circ}-\alpha$

$$
z_{g m r_{-}}^{S}=\sqrt{\frac{1-\beta_{g m r}^{S}}{1+\beta_{g m r}^{S}}}-1
$$

where 


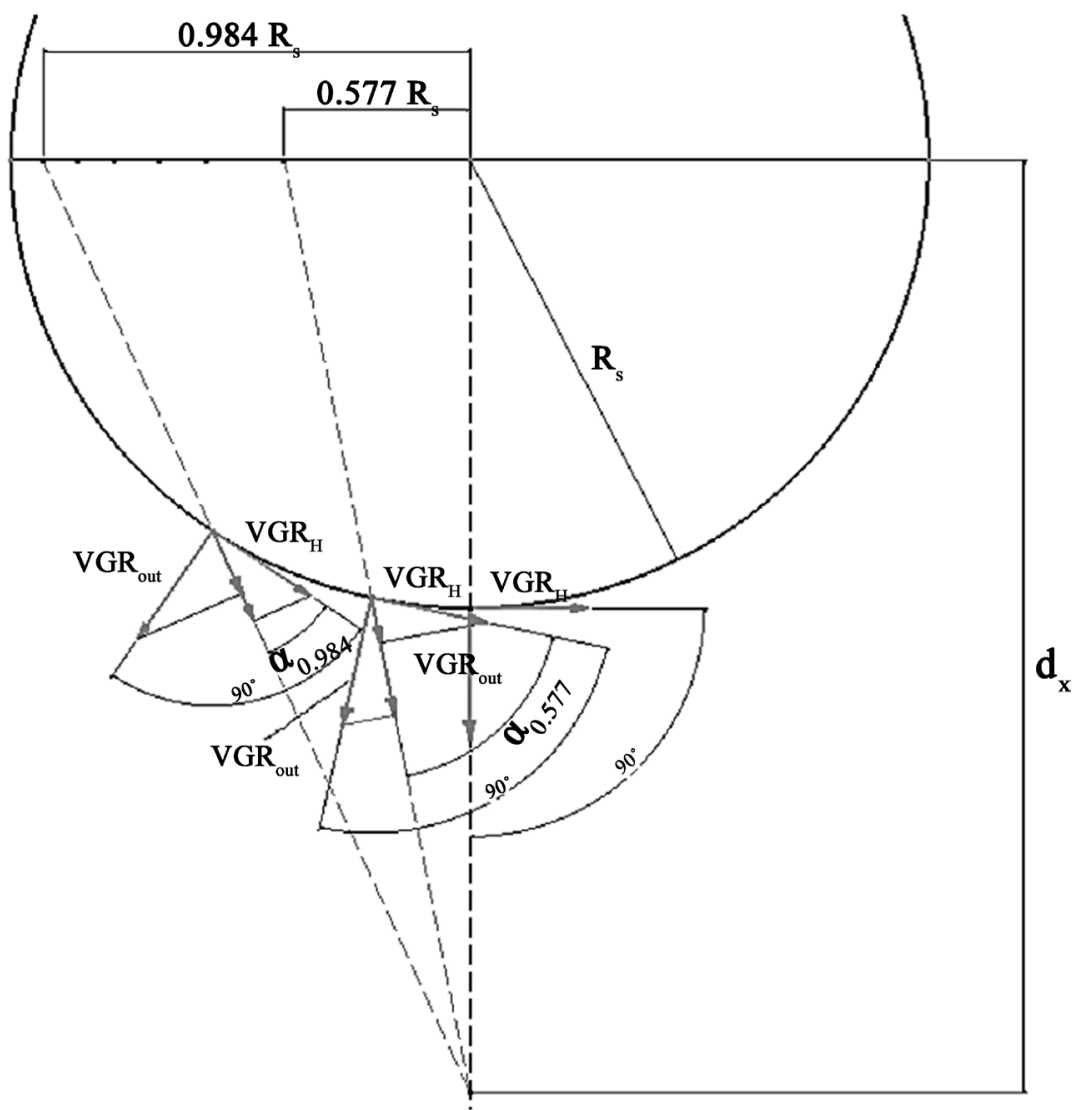

Figure 14. A. Trinchera's scheme of the Doppler shift of the Sun due to tangential and radial velocity components of granular motion.

$$
\beta_{g m r}^{S}=\frac{v_{g m r_{y x}}}{C}
$$

and

$$
v_{g m r_{y x}}=v_{g m r} \cdot \cos \left(90-\alpha_{y}\right)
$$

In vector formulation, the redshifts become respectively

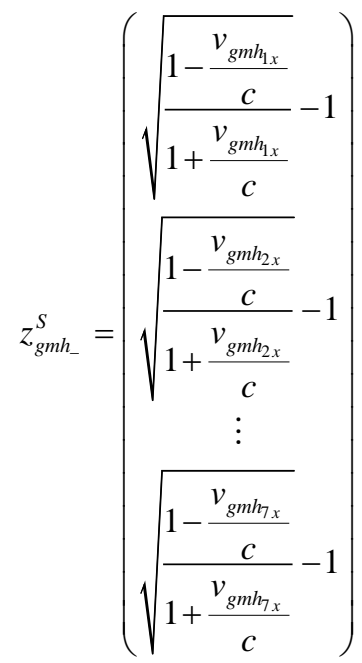




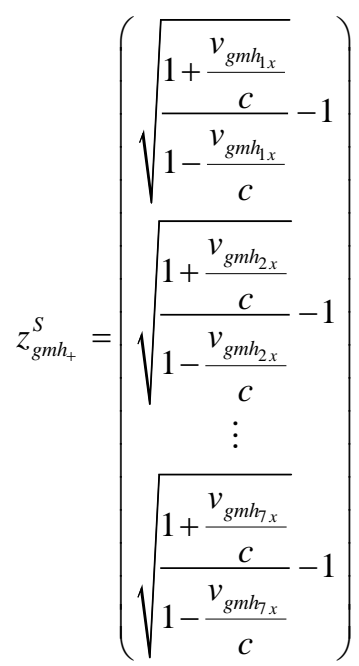

and

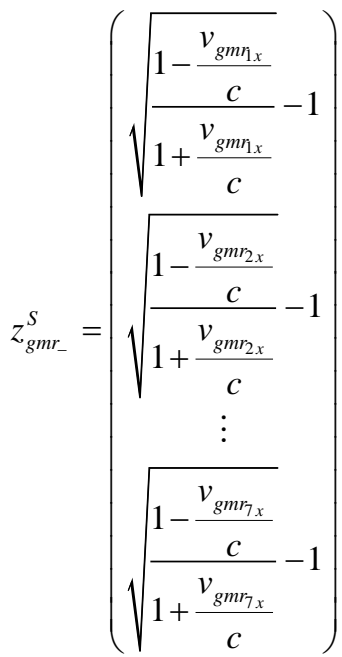

\subsection{Doppler Shift of the Sun Due to Its Axis Inclination}

The axis of the Sun is tilted $7.25^{\circ}$ compared to the ecliptic. It means, we can see better the north pole of the Sun in September since the tilt of the axis is directed towards the orbital position of the Earth, corresponding to September in our calendar. Coincidentally, it is exactly the month chosen from M.G. Adam for the redshift measurements. In geometrical terms, the distance between the Sun and the Earth is so huge that we can neglect the component of the rotational velocity of the Sun along the line of sight as the corresponding angle to the horizontal plane is equal to $0.05^{\circ}$, not able to influence the Doppler shift calculations.

\subsection{Calculation Procedure of the Interactional Redshift}

The process that rules the redshift in the NTL [2], and accordingly in the present study, is shown in Figure 15. It provides us with a value of the Hubble constant that no longer assumes the meaning of an expansion ratio of the Universe, but rather it represents a loss of energy as a function of two fundamental parameters 


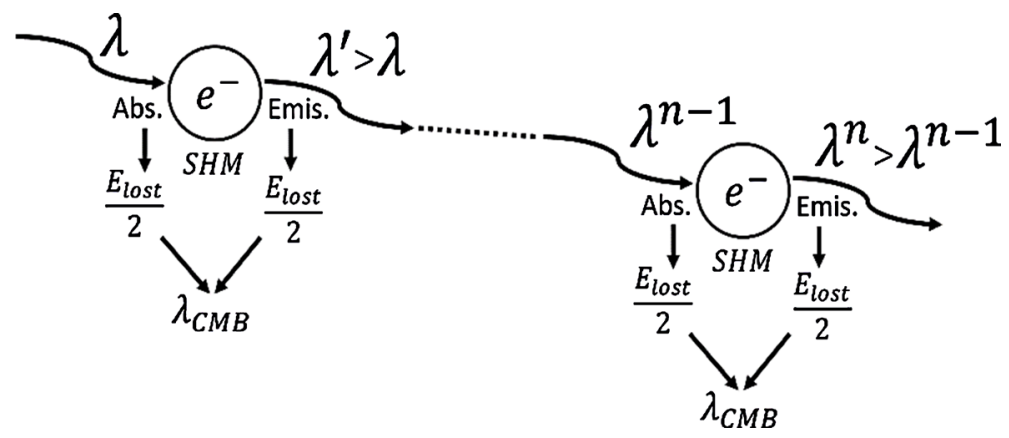

Figure 15. L.E. Ashmore's redshift mechanism proposed in the NTL.

of the electron: its classic radius and its mass, besides the Planck constant and the speed of light. Therefore, what appears to be an expansion of space, might be, according to this kind of approach, only a matter of photons and electrons that interact with each other and that provide us with a redshift having an exponential trend with increasing distance.

The NTL applies to the intergalactic space where we can detect a certain amount of electron in each cubic meter of space. If we fix, for instance, the amount of collisions between photons and electrons, there are two cases that will determine the same redshift value: in the first case the electrons are arranged along a very large path in the cosmic space, in the second case the same electrons are confined in a limited region, such as in the solar corona which extends from the Sun to the Earth. The purpose of this paper is precisely to analyse the second case in order to demonstrate mathematically, by adapting the NTL formulas to our specific case, that in the space between the Sun and the Earth the same redshift process discussed in the NTL is capable of explaining the anomaly on the solar disk.

\subsubsection{Choice of the Electron Distribution}

The first step is the choice of the electron density distribution between the Sun and the Earth from an existing publication shown in a previous paragraph. Choosing the electron distribution is equivalent to choose the coefficients $t$ and $\varepsilon$ in Equation (2.1). Based on the wavelength value taken into consideration, we can also calculate the coefficient $k$ from Equation (5.14).

\subsubsection{Division of the Solar Corona into Sub-Intervals}

The distance between the Sun and the Earth has been divided into sub-intervals equal to $10^{-5} \mathrm{R}_{\mathrm{s}}$. The division into smaller intervals of the mentioned value has a hundredth effect on the final results. Therefore, this value has been confirmed in order to reduce the number of computational steps to the computer. The condition to satisfy is dictated by Equation (5.16) as the limit of the interval.

\subsubsection{Extreme of the Interval to Have at Least One Interaction}

Based on Equation (5.13), we can calculate the value of the end interval in which we are able to detect on average at least one photon/electron interaction. Unlike the equidistant intervals with which we have divided the solar corona, these 
newly calculated values are different from each other. The reason is that the distribution of electrons decreases moving away from the Sun so that the average interval, characterized by at least one photon/electron interaction, will grow. Moreover, the length of the interval varies at each reference wavelength.

The limit to the sequence of intervals $i+1$ is dictated by the effective distance between the Sun and the Earth $r_{\max }$ on the day of measurement as shown in the last row of Table 2.

\subsubsection{Average Electron Distribution in Each Interval}

Since the interactional interval limits, for which we have at least one photon/electron interaction, are known and as the parameters characterizing the distribution of electrons in the solar corona are well defined, we can calculate, using Equation (5.5), the average value of the distribution of electrons for each considered interval.

\subsubsection{Free Mean Path}

The value of the $\Lambda$, shown in Equation (5.7), is necessary to have at least one interaction between photons and electrons in the considered interval. It is a function of the average value of the distribution of electrons, the classic radius of the electron and the wavelength taken into consideration.

\subsubsection{Diagonal Length in Each Interval}

We can introduce the coefficient $\mathrm{k} \lambda$ named Trench coefficient which is very important in the calculations to determine the length of the interactional intervals along the line of sight of the observer. For simplicity, we show in Figure 16 only the line of sight corresponding to 0.984 solar radii. Theoretically, we should calculate the diagonal length value from geometrical equivalence of triangles as

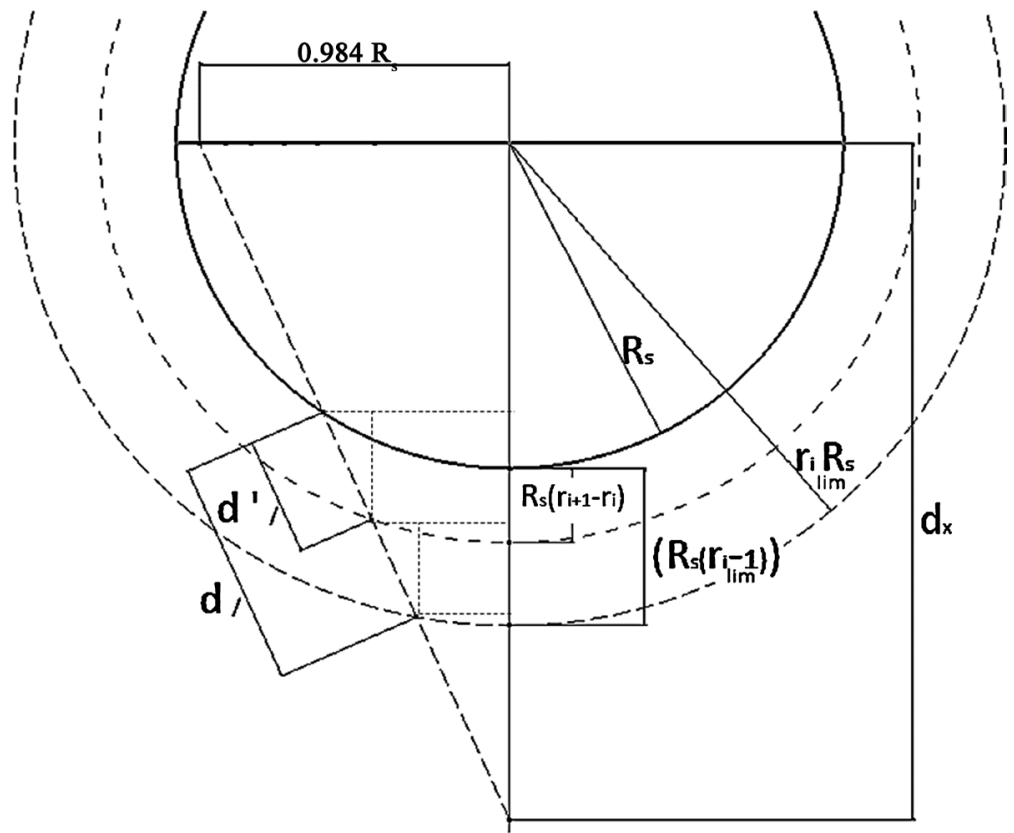

Figure 16. Illustration of the geometrical meaning of A. Trinchera's Trench coefficient $k_{\lambda}$. 
they have in common the angle between the line of sight and the vertical axis of the Sun. Nevertheless, for thousands of intervals, it would require too much time to determine their geometrical characteristics. It is the reason why, taking advantage from the CAD model on scale, we can find a factor of proportionality, with a small margin of error reaching the fourth digit after the comma, between the extension of the interval measured radially and its diagonal extension along the line of sight.

$$
k_{\lambda}=\frac{d_{\text {diag }}}{R_{S}\left(r_{\text {lim }_{\text {lim }}}-1\right)}=\frac{d_{\text {diag }}^{\prime}}{R_{S}\left(r_{i+1}-r_{i}\right)}
$$

In principle, if the $k_{\lambda}$ coefficient represents the increase in length of the limit interval, then it also represents the increase in length for any other considered interval. We can therefore calculate

$$
d_{\text {diag }}^{\prime}=I=k_{\lambda}\left(r_{i+1}-r_{i}\right) R_{S}
$$

This geometrical calculation makes sense as long as we operate in a small portion of the solar radius, in which the angles and the lengths have small deviations to each other. It is the case of the interval extension within the $r_{i_{\text {lim }}}$ for which we need to determine the diagonal length. In this sense, the used method allows us to simplify and optimize the calculations without making errors.

In this way, we can impose a computation procedure in the spreadsheet. The latter provides us instantaneously with the diagonal length of the intervals, namely the paths travelled by photons of light in order to undergo at least one interaction with electrons. The Trench coefficient is clearly equal to 1 along the direction of observation at 0 solar radii where the diagonal length of the interval is equal to the interval itself. Moreover, it varies at each position on the solar disk and on each considered wavelength of reference. It can be expressed through the matrix formulation by the object $k_{\lambda x}$

\section{$(w)$}

$$
\begin{gathered}
x=1,2,3 \\
(y) \begin{array}{c}
1 \\
2 \\
\vdots \\
7
\end{array}\left[\begin{array}{cccc}
k_{\lambda_{11}} & k_{\lambda_{12}} & \cdots & k_{\lambda_{114}} \\
k_{\lambda_{21}} & k_{\lambda_{22}} & \cdots & k_{\lambda_{214}} \\
\vdots & \vdots & \ddots & \vdots \\
k_{\lambda_{71}} & k_{\lambda_{72}} & \cdots & k_{\lambda_{714}}
\end{array}\right]
\end{gathered}
$$

Same observation can be done for the diagonal lengths expressed in meter

$(w)$

$$
\begin{array}{r}
x=1,2,3 \\
\begin{array}{r}
(y) \\
2 \\
2 \\
7
\end{array}\left[\begin{array}{cccc}
d_{\operatorname{diag}_{11}} & d_{\operatorname{diag}_{12}} & \cdots & d_{\text {diag }_{114}} \\
d_{\operatorname{diag}_{21}} & d_{\operatorname{diag}_{22}} & \cdots & d_{\text {diag }_{214}} \\
\vdots & \vdots & \ddots & \vdots \\
d_{\text {diag }_{71}} & d_{\text {diag }_{72}} & \cdots & d_{\text {diag }_{714}}
\end{array}\right]
\end{array}
$$

The angles are small on each day of measurement and, accordingly, the Trench 
coefficient is equal within the third digit after the comma. It implies that its matrix is the same on each day of measurement and it only differs by each electron distribution taken into consideration.

The closer we get to limb with telescope observations the more the distance between the Sun and the Earth increases. It may seem irrelevant but the most decisive contribution is precisely in the vicinity of the first concentric radii of the solar corona where the electron density is higher. If we create a vector $i$ having as components the quantities shown in Table 6 then we can express the length of the intervals through the matrix $I_{\text {yixw }}$ as follows

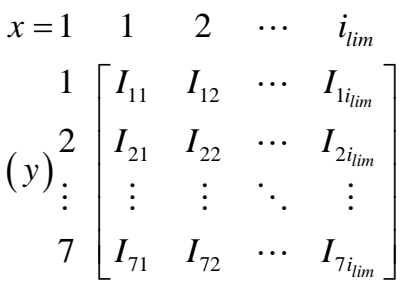

In Figure 17, we can recognize three different matrices for each day of measurement for each wavelength of reference. We have totally $3 \times 14=42$ matrices.

By taking into account the three different electron distributions under examination, the number of matrices reaches the number of $42 \times 3=126$. We will pick up and show only one instance of a matrix for each electron distribution in Appendix B.

\subsubsection{Condition on Each Interval}

The condition that has to be verified on the interval is expressed by Equation (5.6). It can be only applied in the $0^{\circ}$ direction of observation since the diagonal

Table 6. Vector components for the intervals.

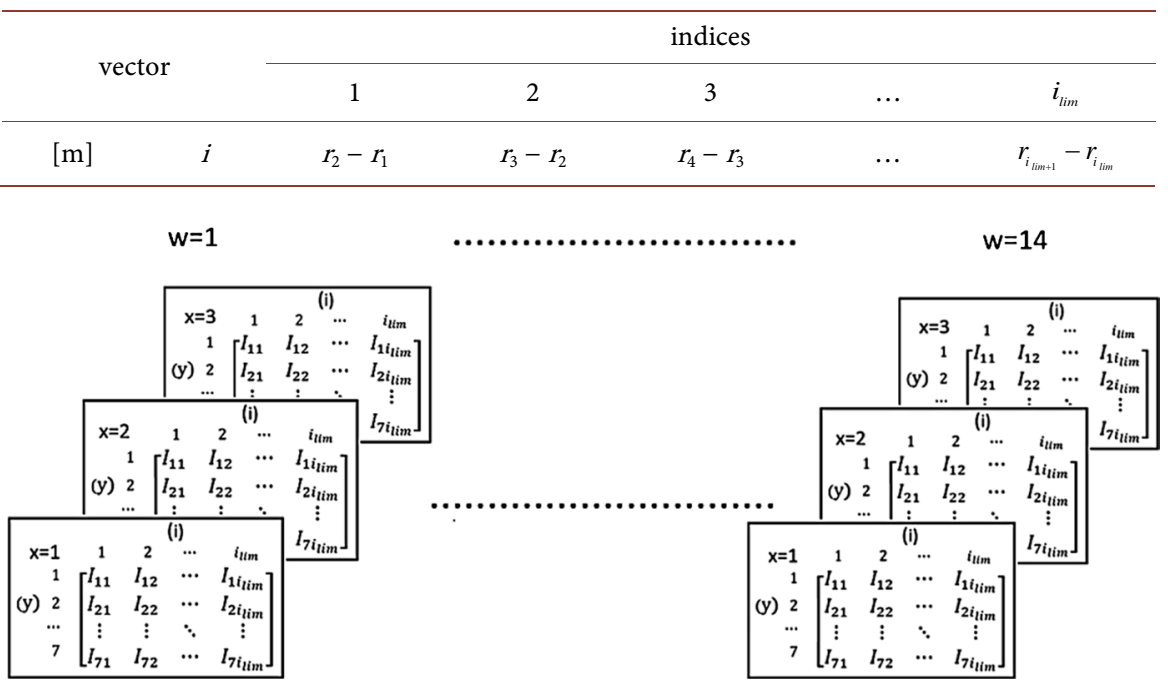

Figure 17. Length of the intervals on each day of measurement for each wavelength acc. to A. Trinchera's calculation. 
Table 7. Hubble constant at each interval.

\begin{tabular}{|c|c|c|c|c|c|c|}
\hline \multirow{2}{*}{\multicolumn{2}{|c|}{ vector }} & \multicolumn{5}{|c|}{ indices } \\
\hline & & 1 & 2 & 3 & $\ldots$ & $i_{\text {lim }}$ \\
\hline$[1 / \mathrm{sec}]$ & $\mathrm{Hi}$ & $\frac{2 \bar{n}_{e_{1}} h r_{e}}{m_{e}}$ & $\frac{2 \bar{n}_{e_{2}} h r_{e}}{m_{e}}$ & $\frac{2 \bar{n}_{e_{3}} h r_{e}}{m_{e}}$ & $\cdots$ & $\frac{2 \bar{n}_{e i_{i m}} h r_{e}}{m_{e}}$ \\
\hline
\end{tabular}

intervals are always greater than the $\Lambda$ for greater angles along the observation line. This mentioned condition is used as verification of the calculations.

\subsubsection{Hubble Constant at Each Interval}

Based on the NTL [2] [3] [4], the value of the Hubble constant expressed in 1/sec is only a function of the properties of the electron

$$
H=\frac{2 n_{e} h r_{e}}{m_{e}}
$$

so that we can apply it to each determined interactional interval as if it were the only distance travelled (each interactional interval works out as the intergalactic distance between source and observer in the NTL. In this study, the source is the generic radius $r_{p}$ the observer is the generic radius $r_{i+1}$ and we want to sum up all interactions). The electron density distribution varies radially but we can use the average electron distribution for each range previously calculated. Thus, we can customize Equation (6.49) by using a vector having the following components (Table 7).

\subsubsection{Products HI}

According to the NTL, the final redshift formula is the exponential of the product of the Hubble constant for the considered distance minus one as shown below

$$
Z=\mathrm{e}^{\frac{H d}{c}}-1
$$

As in our case we have as many Hubble constants as the considered intervals for the calculation, we have to compute as many products as the number of calculated Hubble constants. The following products are quantities expressed in $\mathrm{m} / \mathrm{sec}$ by the matrix $H I_{\text {yix }}$ as follows

$$
\begin{gathered}
x=1 \\
\begin{array}{c}
(y)^{2} \\
\vdots \\
7 \\
H_{1}
\end{array}\left[\begin{array}{cccc}
H_{1} I_{11} & H_{2} I_{12} & \cdots & H_{i_{\text {lim }}} I_{1 i_{\text {lim }}} \\
H_{1} I_{21} & H_{2} I_{22} & \cdots & H_{i_{\text {lim }}} I_{2 i_{\text {lim }}} \\
\vdots & \vdots & \ddots & \vdots \\
H_{1} I_{7} & H_{7} I_{72} & \cdots & H_{i_{\text {lim }}} I_{7 i_{\text {lim }}}
\end{array}\right]
\end{gathered}
$$

We can count three different matrices for each day of measurement for each wavelength of reference. We have totally $3 \times 14=42$ matrices.

In Figure 18, by taking into account the three different electron distributions 


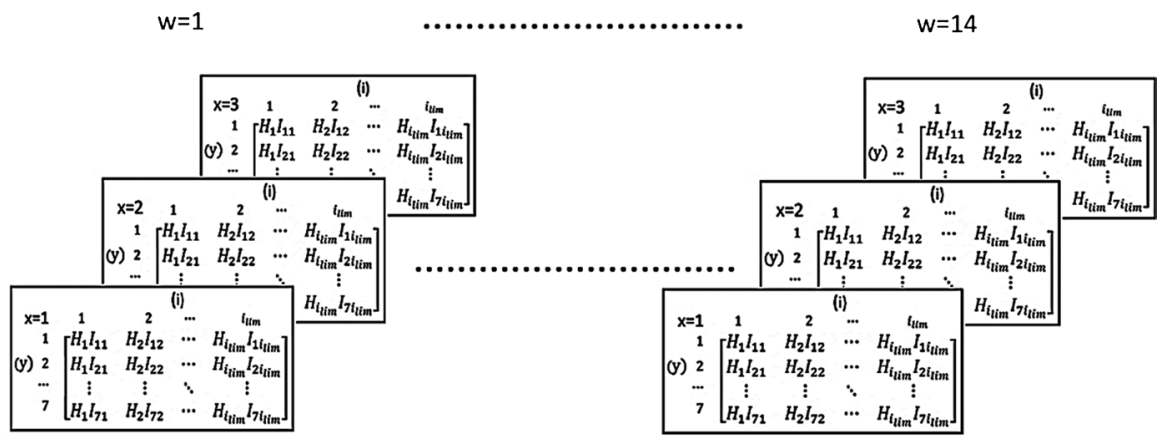

Figure 18. Products HI at each interval for each wavelength.

under examination, the number of matrices reach the number of $42 \times 3=126$. Also in this case, we will pick up and show only one instance of matrix for each electron distribution in Appendix B.

\subsubsection{Interactional Redshift}

The value of the redshift in the NTL is an exponential function with the distance. The more a photon travels in an environment made up of electrons the higher is the redshift and it increases exponentially as the distance increases. On a cosmological level, considering objects distant many light years, this effect gives the impression that there is an alleged expansion of space or even its acceleration. In reality, it is a deception linked to multiple interactions between photons emitted by the source and the electrons permeating the space. The multiple interactions between them provide us with an exponential redshift trend. In our case, the distances are very close in astronomical terms but the electron distribution is very high so that it allows an estimation of the redshift as follows

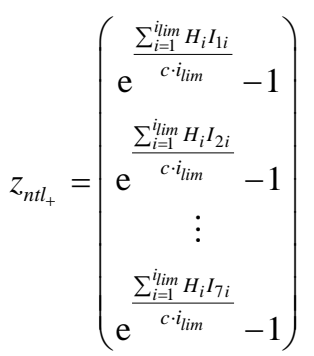

It has the same vector components on each day of measurement as it is not dependent on the distance between the Sun and the Earth but rather only on the electron distribution in the considered interactional interval.

\subsection{Total Redshift}

In terms of indices and the successive calculations, as indicated in Table 4, we can take a step further for determining the values of the redshift at each point of the solar disk. If we focus on the left-hand side of the solar disk and consider the sum of all redshift contributes, then

$$
z_{L}=\sum_{j=1}^{8} z_{j}
$$




$$
z_{L}=z_{g r_{+}}^{S}+z_{g r_{-}}^{E}+z_{p r_{-}}^{S}+z_{p r_{+L}}^{E}+z_{o m_{-}}^{E}+z_{g m h_{-}}^{S}+z_{g m r_{-}}^{S}+z_{n t l_{+}}
$$

We can build the matrix $M_{y s_{L} x}$ with the corresponding redshift contributes having different values on each day of measurement

$$
\begin{aligned}
& \left(s_{L}\right) \\
& \begin{array}{lllll}
x=1 & 1 & 2 & \cdots & 8
\end{array} \\
& \begin{array}{r}
1 \\
(y) \\
2 \\
2 \\
7 \\
7
\end{array}\left[\begin{array}{cccc}
Z_{L 11} & Z_{L 12} & \cdots & Z_{L 18} \\
Z_{L 21} & Z_{L 22} & \cdots & Z_{L 28} \\
\vdots & \vdots & \ddots & \vdots \\
Z_{L 71} & Z_{L 72} & \cdots & Z_{L 78}
\end{array}\right]
\end{aligned}
$$

The matrix, referred to the three days of measurement, becomes three different matrices in Figure 19.

Afterwards it becomes the vector $L_{y \overline{S_{L}}}$ as we need to sum up all components related to every row $y$ and to divide them by the number of days of measurement which give a different average value $\bar{S}_{L}$ in each raw.

$$
L_{y \overline{s_{L}}}=\left(\begin{array}{c}
\frac{\sum_{s_{L}=1}^{8} \sum_{x=1}^{3} M_{1 s_{L} x}}{3} \\
\frac{\sum_{s_{L}=1}^{8} \sum_{x=1}^{3} M_{2 s_{L^{x}}}}{3} \\
\vdots \\
\frac{\sum_{s_{L}=1}^{8} \sum_{x=1}^{3} M_{7 s_{L^{x}}}}{3}
\end{array}\right)
$$

If we now focus on the right-hand side of the solar disk and consider the sum of all redshift contributes, then

$$
Z_{R}=\sum_{j=1}^{8} Z_{j}
$$

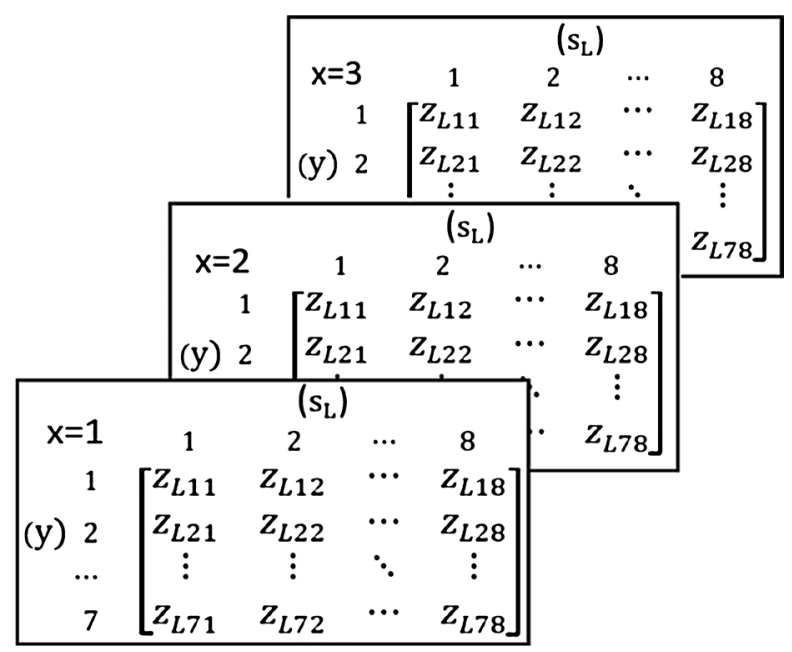

Figure 19. In-between redshift matrix for the left-hand side of the solar disk acc. to A. Trinchera's calculations. 


$$
z_{R}=z_{g r_{+}}^{S}+z_{g r_{-}}^{E}+z_{p r_{+}}^{S}+z_{p r_{+}}^{E}+z_{o m_{-}}^{E}+z_{g m h_{+}}^{S}+z_{g m r_{-}}^{S}+z_{n t l_{+}}
$$

We can build the matrix $M_{y s_{R} x}$ with the corresponding redshift contributes having different values on each day of measurement

$$
\begin{aligned}
& \left(s_{R}\right) \\
& \begin{array}{lllll}
x=1 & 1 & 2 & \cdots & 8
\end{array} \\
& \begin{array}{r}
1 \\
(y) \\
2 \\
\vdots \\
7
\end{array}\left[\begin{array}{cccc}
z_{R 11} & z_{R 12} & \cdots & z_{R 18} \\
z_{R 21} & z_{R 22} & \cdots & z_{R 28} \\
\vdots & \vdots & \ddots & \vdots \\
z_{R 71} & z_{R 72} & \cdots & z_{R 78}
\end{array}\right]
\end{aligned}
$$

The matrix, referred to the three days of measurement, becomes three different matrices in Figure 20.

Subsequently, it becomes the vector $R_{y \bar{s}_{R}}$ which gives a different average value $\bar{S}_{R}$ in each raw.

$$
R_{y \bar{s}_{R}}=\left(\begin{array}{c}
\frac{\sum_{s_{R}=1}^{8} \sum_{x=1}^{3} M_{1 s_{L R} x}}{3} \\
\frac{\sum_{s_{R}=1}^{8} \sum_{x=1}^{3} M_{2 s_{R} X}}{3} \\
\vdots \\
\frac{\sum_{s_{R}=1}^{8} \sum_{x=1}^{3} M_{7 s_{R} x}}{3}
\end{array}\right)
$$

Both $L_{y \bar{s}_{L}}$ and $R_{y \bar{s}_{R}}$ vary over the three days of measurement. The final redshift will be given by the sum of all components in row for left-hand side and right-hand side of the solar corona divided by 2 as it represents an average value along all solar disk, in order to compare these values with the redshift values which results from M.G. Adam's research

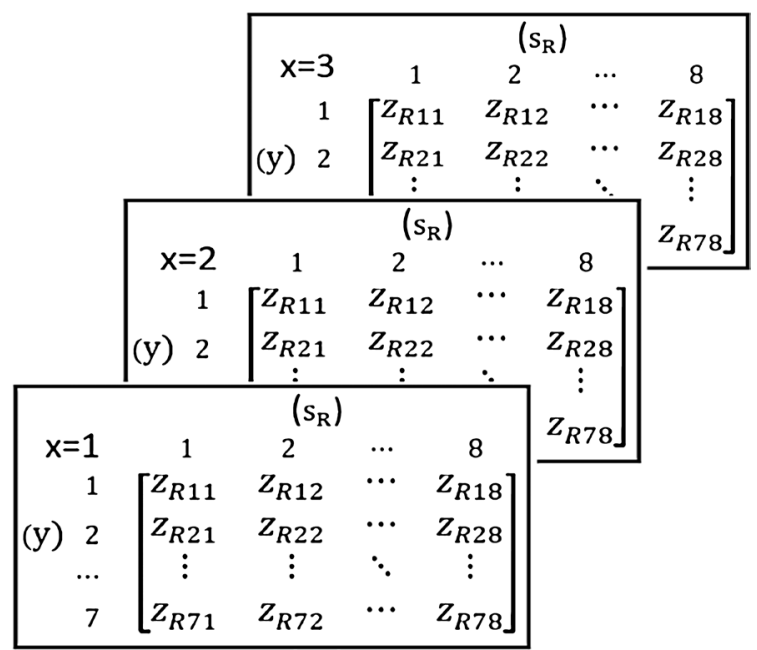

Figure 20. In-between redshift matrix for the right-hand side of the solar disk acc. to A. Trinchera's calculations. 


$$
Z=\left(\begin{array}{c}
\frac{L_{11}+R_{11}}{2} \\
\frac{L_{21}+R_{21}}{2} \\
\vdots \\
\frac{L_{71}+R_{71}}{2}
\end{array}\right)
$$

We will compare three different $z$ vectors corresponding to three different electron distributions in order to have a full analysis.

\section{Results}

The final results of the redshift calculation on the solar disk for the three different electron distributions are shown in the tables and graphs below. Each considered distribution of electrons, respectively, Mex 1, Mex 2 and Mgs has experimental differences affected by the mathematical parameters $t$ and $\varepsilon$ which, in turn, describe their trend of the distribution in space between the Sun and the Earth by which we can draw important conclusions systematically.

All calculations related to the redshift contributes for all three cases Mex 1 (Mex Oct. 2006), Mex 2 (Mex Dec. 2008) and Mgs (Mgs Aug 2002) are reported in Appendix B.

\subsection{Mex 1}

Based on Equation (6.61) we can calculate the total redshiftas

$$
z=\left(\begin{array}{c}
4.909 E-06 \\
4.155 E-06 \\
3.341 E-06 \\
2.769 E-06 \\
1.803 E-06 \\
7.890 E-07 \\
-6.637 E-07
\end{array}\right)
$$

where the reference redshift trend on the solar disk, according to Adam's research (see previous Table 1), is

$$
Z_{\text {ref }}=\left(\begin{array}{l}
4.315 \mathrm{E}-06 \\
3.040 \mathrm{E}-06 \\
2.402 \mathrm{E}-06 \\
1.961 \mathrm{E}-06 \\
1.742 \mathrm{E}-06 \\
1.780 \mathrm{E}-06 \\
1.675 \mathrm{E}-06
\end{array}\right)
$$

We can plot these two sets of values found in the following graph Figure 21.

The total redshift has an exponential trend clear enough to state that the interactions between photons and electrons are responsible for this result but 


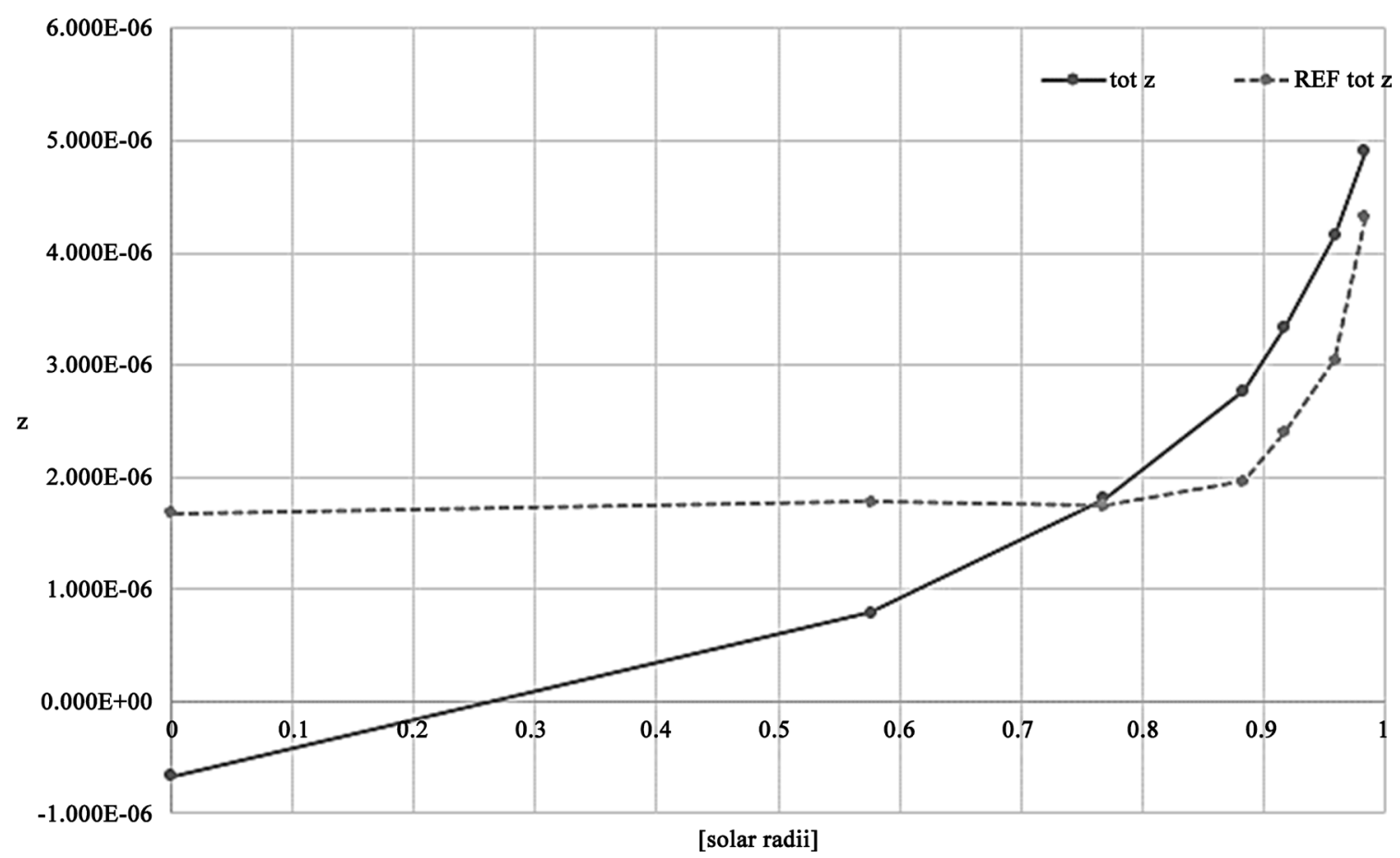

Figure 21. M.G. Adam's reference redshift (dashed line) vs. A. Trinchera's redshift (continuous line) case Mex 1. The latter takes into account the max radial velocity component of granular motion.

apparently it does not match the reference redshift of the observational data. The reason lies in an assumption made related to the granular motion: we have assumed in our calculation that the radial (or upwards) velocity assumes only a maximum value starting from which we have determined the velocity components along the line of sight. This velocity component varies not only in every point of the solar disk but in every point of the photosphere of the Sun. Additionally, it also varies in every measurement taken during the three days considered depending on the size of the grain as well. In literature, we can find variable values of this parameter ranging up, on average, to a minimum peak equal to $-1000 \mathrm{~m} / \mathrm{sec}$ and to a maximum peak up to $1000 \mathrm{~m} / \mathrm{sec}$. In reality, the maximum velocity at each instant of measurement occurs with a low probability. Its behaviour on the solar disk cannot be clearly assumed in advance but can be deduced logically and mathematically with the following reasoning. If we do not consider the upwards velocity component of granular motion by subtracting their value in Equation (7.1) of the total redshift, we can obtain the new total redshift vector as follows

$$
Z_{w / o g m r}=\left(\begin{array}{c}
5.503 \mathrm{E}-06 \\
5.101 \mathrm{E}-06 \\
4.664 \mathrm{E}-06 \\
4.328 \mathrm{E}-06 \\
3.936 \mathrm{E}-06 \\
3.513 \mathrm{E}-06 \\
2.672 \mathrm{E}-06
\end{array}\right)
$$


The graph of the total redshift becomes accordingly as follows Figure 22 .

Based on the graph, the difference of the values in row between the redshift without the radial component of granular motion (vector 7.3) and the reference redshift from Adam's research (vector 7.2), provides us with the redshift excess vector

$$
z_{\text {e gmr }}=\left(\begin{array}{l}
1.188 \mathrm{E}-06 \\
2.060 \mathrm{E}-06 \\
2.262 \mathrm{E}-06 \\
2.367 \mathrm{E}-06 \\
2.193 \mathrm{E}-06 \\
1.733 \mathrm{E}-06 \\
9.969 \mathrm{E}-07
\end{array}\right)
$$

We can calculate mathematically the upwards component of granular motion considering the velocities in Doppler terms case approach as follows

$$
z_{\text {gmr }}^{S}=\sqrt{\frac{1-\beta_{\text {egmr }}^{S}}{1+\beta_{\text {egmr }}^{S}}}-1
$$

from which, knowing the definition of the factor $\beta$ and removing suffixes and indices for simplicity, we can extrapolate the velocity

$$
v_{\text {e gmr }}=\frac{1-(z-1)^{2}}{1+(z-1)^{2}} c
$$

Therefore, the excess velocity vector with the components expressed in $\mathrm{m} / \mathrm{sec}$ is

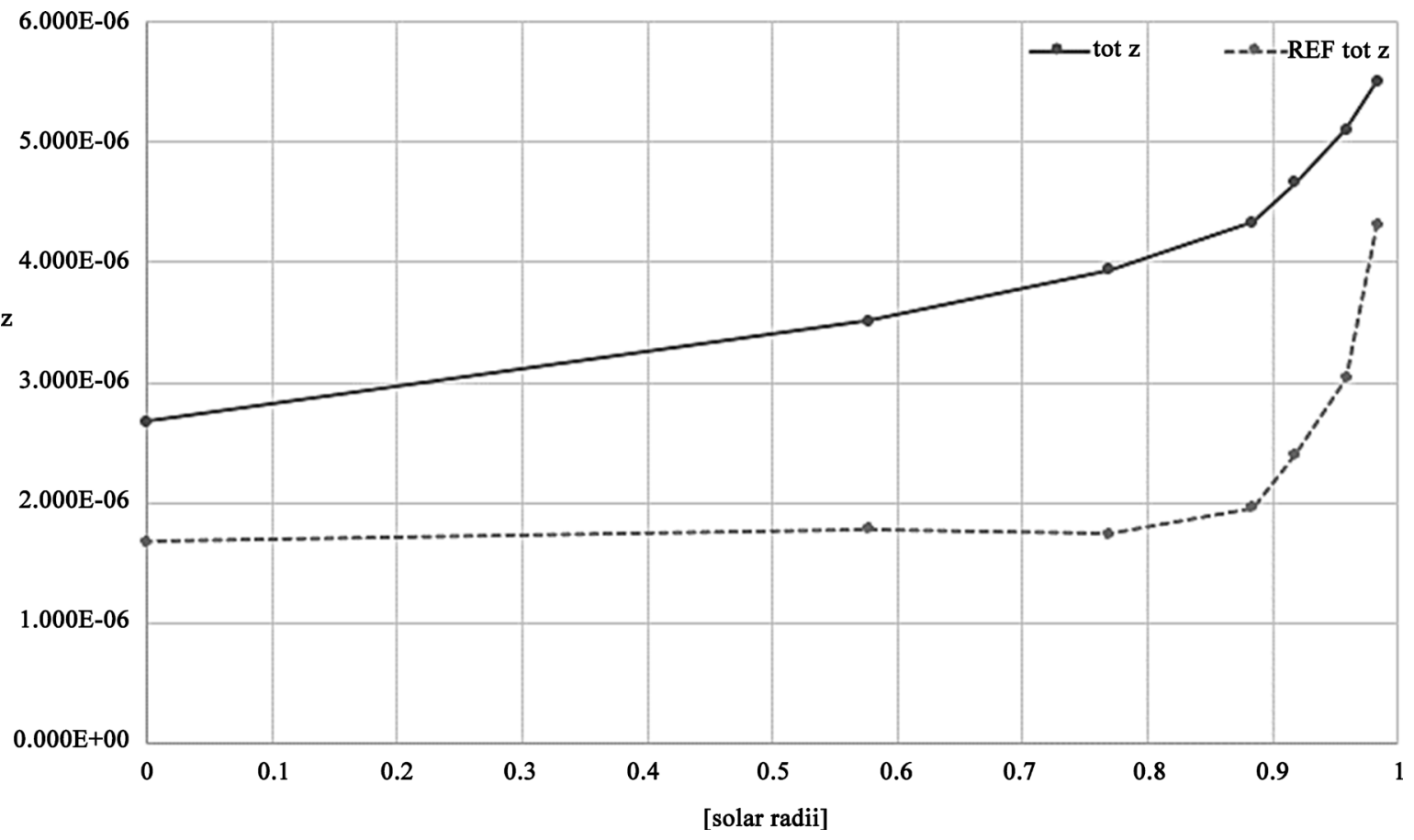

Figure 22. M.G. Adam's reference redshift (dashed line) vs. A. Trinchera's redshift (continuous line) case Mex 1. The latter does not take into account the radial velocity component of granular motion. 


$$
v_{\text {egmr }}=\left(\begin{array}{c}
356.2 \\
617.7 \\
678.3 \\
709.7 \\
657.7 \\
519.7 \\
298.9
\end{array}\right)
$$

As we can see, the average radial velocity component calculated shows an increase in trend from the center (value $298.9 \mathrm{~m} / \mathrm{sec}$ ) to the point $0.884 \mathrm{R}_{\mathrm{s}}$ on the solar disk (value $709.7 \mathrm{~m} / \mathrm{sec}$ ) and a decrease up to the limb (value $356.2 \mathrm{~m} / \mathrm{sec}$ ). Theoretically, if the maximum radial velocity is $1000 \mathrm{~m} / \mathrm{sec}$, the corresponding maximum velocity components on each point of the solar disk under observation are given by the previous Equation (6.40) from which the admissible vector of velocity components expressed in $\mathrm{m} / \mathrm{sec}$ is

$$
v_{g m r_{\text {max }}}=\left(\begin{array}{c}
178.2 \\
283.4 \\
396.6 \\
467.4 \\
639.2 \\
816.7 \\
1000
\end{array}\right)
$$

The maximum velocity component is exactly in front of our line of sight, at the center of the solar disk, with an angle $0^{\circ}$, namely 0 solar radii, whereas the minimal value on the maximum line of sight is $10.2^{\circ}$, at the solar limb, corresponding to 0.984 solar radii. There are some important remarks to make on both range of velocity components, respectively, on those that we calculated through the redshift in excess (vector 7.7) and those with maximum admissible values (vector 7.8 ):

- the last two velocity components, corresponding to the solar radii 0 and 0.577 of the solar disk are within the admissible values (respectively $298.9<$ $1000 \mathrm{~m} / \mathrm{sec}, 519.7<816 \mathrm{~m} / \mathrm{sec}$ );

- we found a turnover point where the velocity component corresponding to 0.769 solar radii on the solar disk is almost equal to the admissible value $(657.7>639.2 \mathrm{~m} / \mathrm{sec})$ over which, for higher solar radii, the velocities decrease;

- the remaining velocity components are greater than the admissible value but with a decreasing trend which can be used to verify the correctness of the method used, without computing errors.

Concerning the first two remarks, it is an expected result since the velocity components are supposed to be statistically smaller than the maximum velocity components. With respect to the last remark, there are two factors to justify the excess of radial velocity: in the first place the solar flares, which occur regularly and randomly in terms of position and time on the photosphere of the Sun, provide an outwards non-relativistic acceleration to the electron in the solar corona 
which should be added up to the calculated values. They cause a further redshift contribute effect due to interactions between photons and electrons. Moreover, the exact position and moment in which the solar flares occur cannot be predicted but can only be deduced by statistical analyses. Secondly, if we assume, for instance, a solar flare phenomenon at 0.769 solar radii taking place during a day of measurement, the effect of the electrons ejected in the first layers of the solar corona will in general influence all redshift contributes in the zones behind (0.884, $0.918,0.959$ and 0.984 solar radii). In the line of sight, the photons of light will encounter more electrons on their journey to Earth, as shown in Figure 23. The effect is strongly reduced on a global calculation scale since it is averaged with other measurements on different days. On the contrary, a solar flare, occurring in the $0^{\circ}$ direction with respect to the line of observation, would only generate a redshift in this line and would not influence the remaining zones of the solar disk. For this reason, the excess of redshift measured is not only a factor related to the variability of the radial velocity of the granular motion but it is also related to unpredictable events (such as solar flares or past residual events characterized by electrons being accelerated or even moved from different zones of the solar corona) which took place during the measurements.

Therefore, based on the values obtained and, on the reasoning concerning the solar granules, we can state that the redshift excess is compatible with the real radial velocity of the granules which are partially affected from electrons in movement due to solar flares or past residual acceleration effects. Likewise, we can affirm that the total redshift calculated matches the observational data and that, in this specific case, the Mex 1 data is a reliable distribution of electron between the Earth and the Sun in Figure 24.

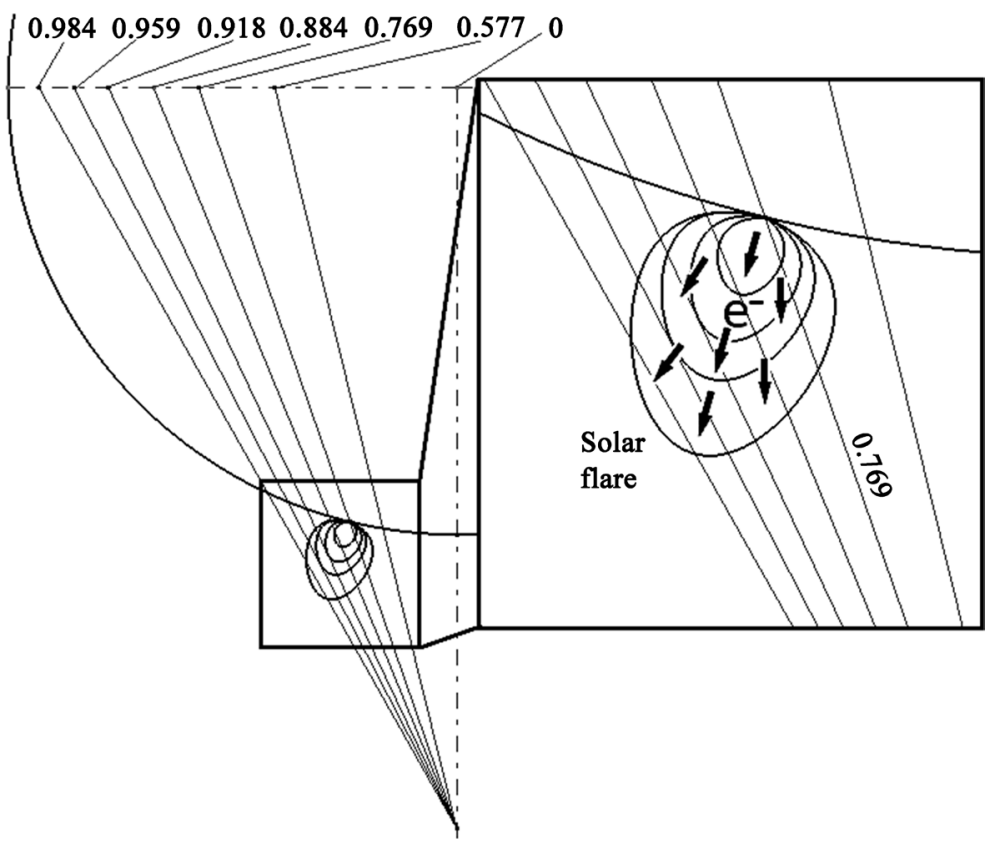

Figure 23. Representation of a solar flare on the photosphere of the Sun at 0.759 solar radii in the line of sight. 


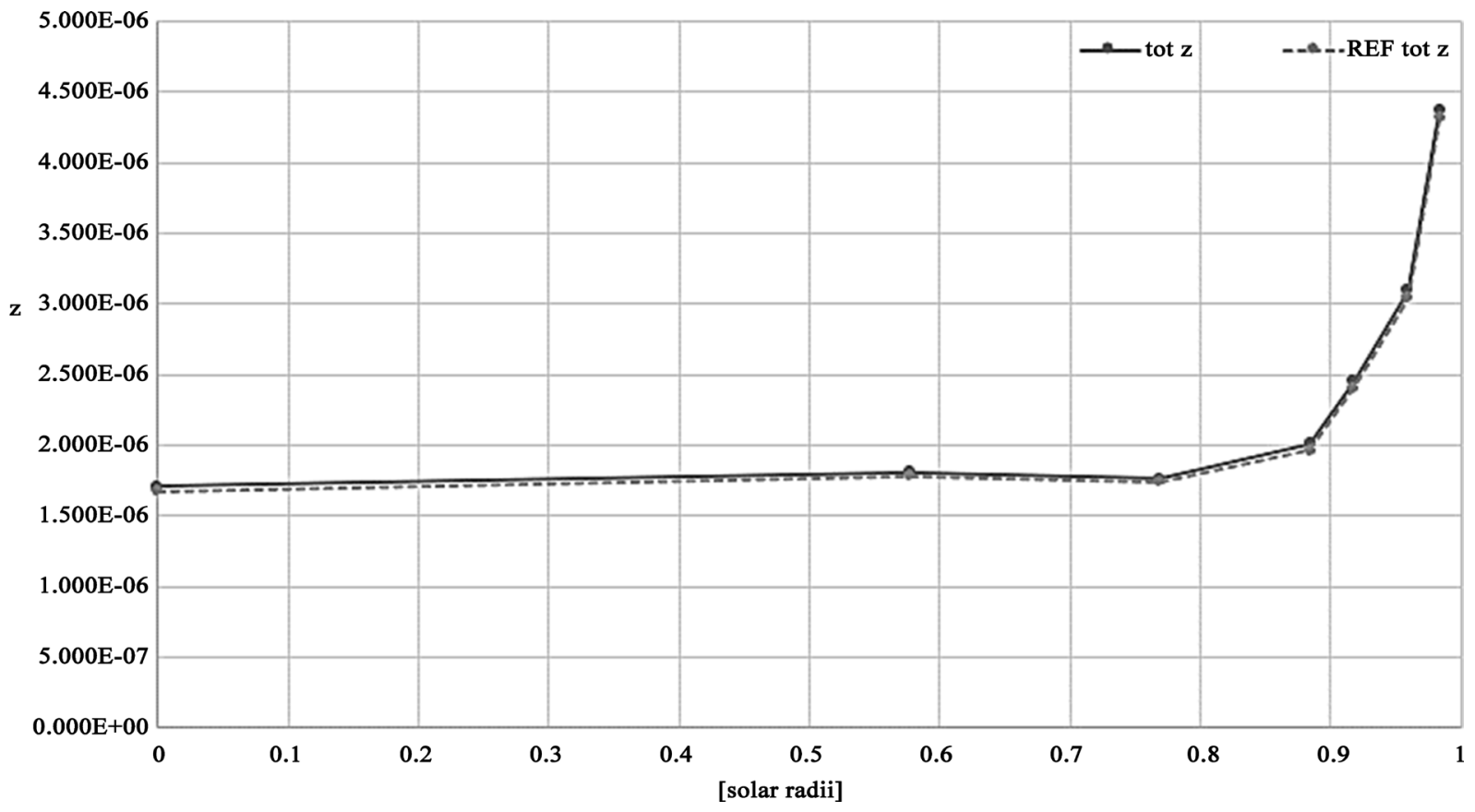

Figure 24. M.G. Adam's reference redshift (dashed line) vs. A. Trinchera's redshift (continuous line) case Mex 1. The latter takes into account the radial velocity component of granular motion as redshift excess of the total redshift calculated.

\subsection{Mex 2}

Based on Equation (6.61), we can calculate the total redshiftas

$$
z=\left(\begin{array}{c}
7.166 \mathrm{E}-06 \\
5.877 \mathrm{E}-06 \\
4.594 \mathrm{E}-06 \\
3.776 \mathrm{E}-06 \\
2.348 \mathrm{E}-06 \\
1.009 \mathrm{E}-06 \\
-6.636 \mathrm{E}-07
\end{array}\right)
$$

where the reference redshift trend on the solar disk, according to Adam's research, has already been shown in the vector 7.2. We can plot these two sets of values found as follows Figure 25 .

Also in this case, the total redshift has an exponential trend. Nonetheless, we observe a difference of redshift as the two extremes seem to reach higher values. We exclude the radial velocity components of granular motion to obtain a total redshift vector equal to

$$
Z_{w / o g m r}=\left(\begin{array}{l}
7.761 \mathrm{E}-06 \\
6.822 \mathrm{E}-06 \\
5.917 \mathrm{E}-06 \\
5.335 \mathrm{E}-06 \\
4.481 \mathrm{E}-06 \\
3.733 \mathrm{E}-06 \\
2.672 \mathrm{E}-06
\end{array}\right)
$$


The graph of the total redshift becomes accordingly as follows Figure 26.

In this case, we can also calculate mathematically the upwards component of granular motion starting from the Doppler shift formula case approach. We

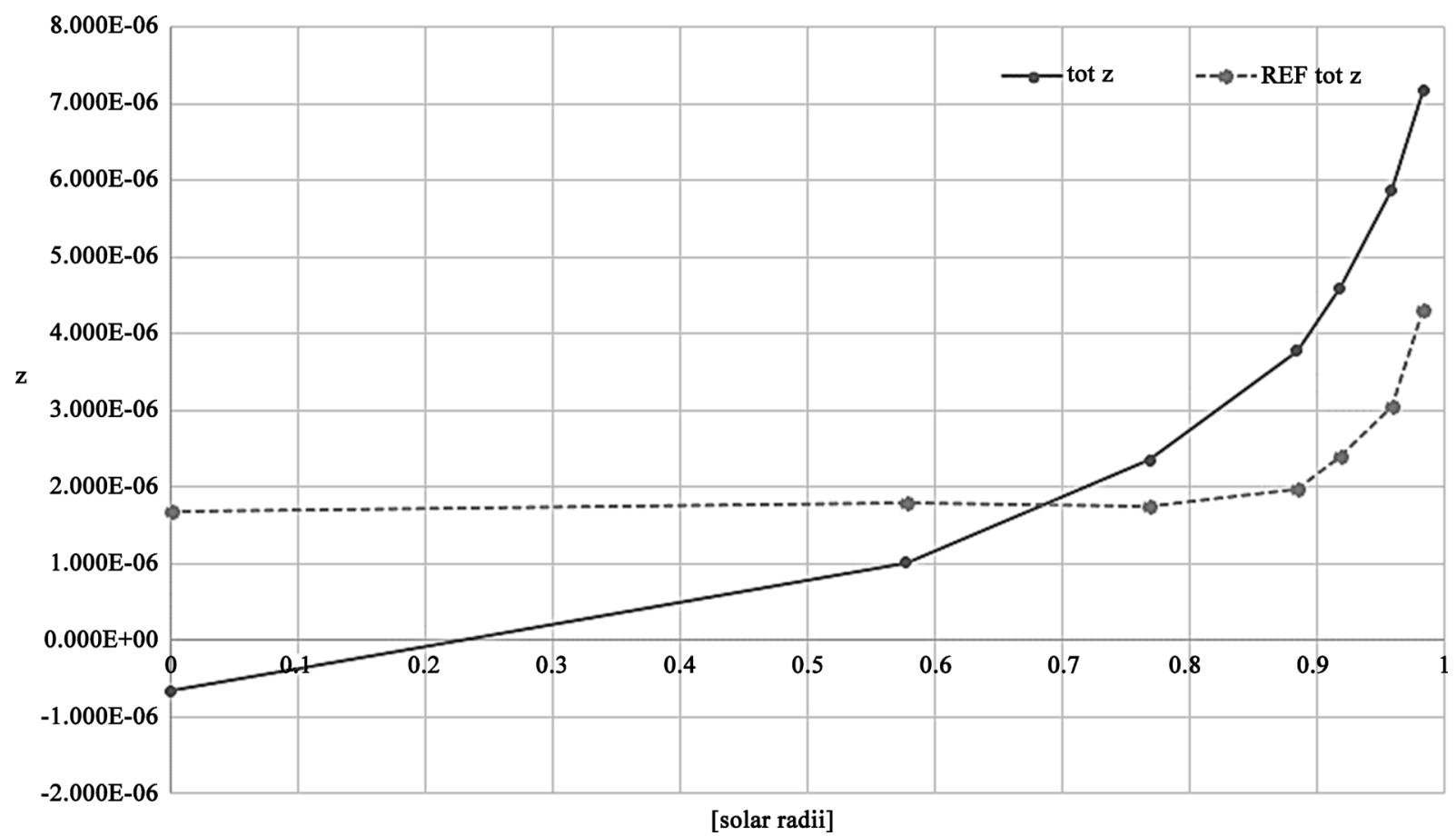

Figure 25. M.G. Adam's reference redshift (dashed line) vs. A. Trinchera's redshift (continuous line) case Mex 2. The latter takes into account the max radial velocity component of granular motion.

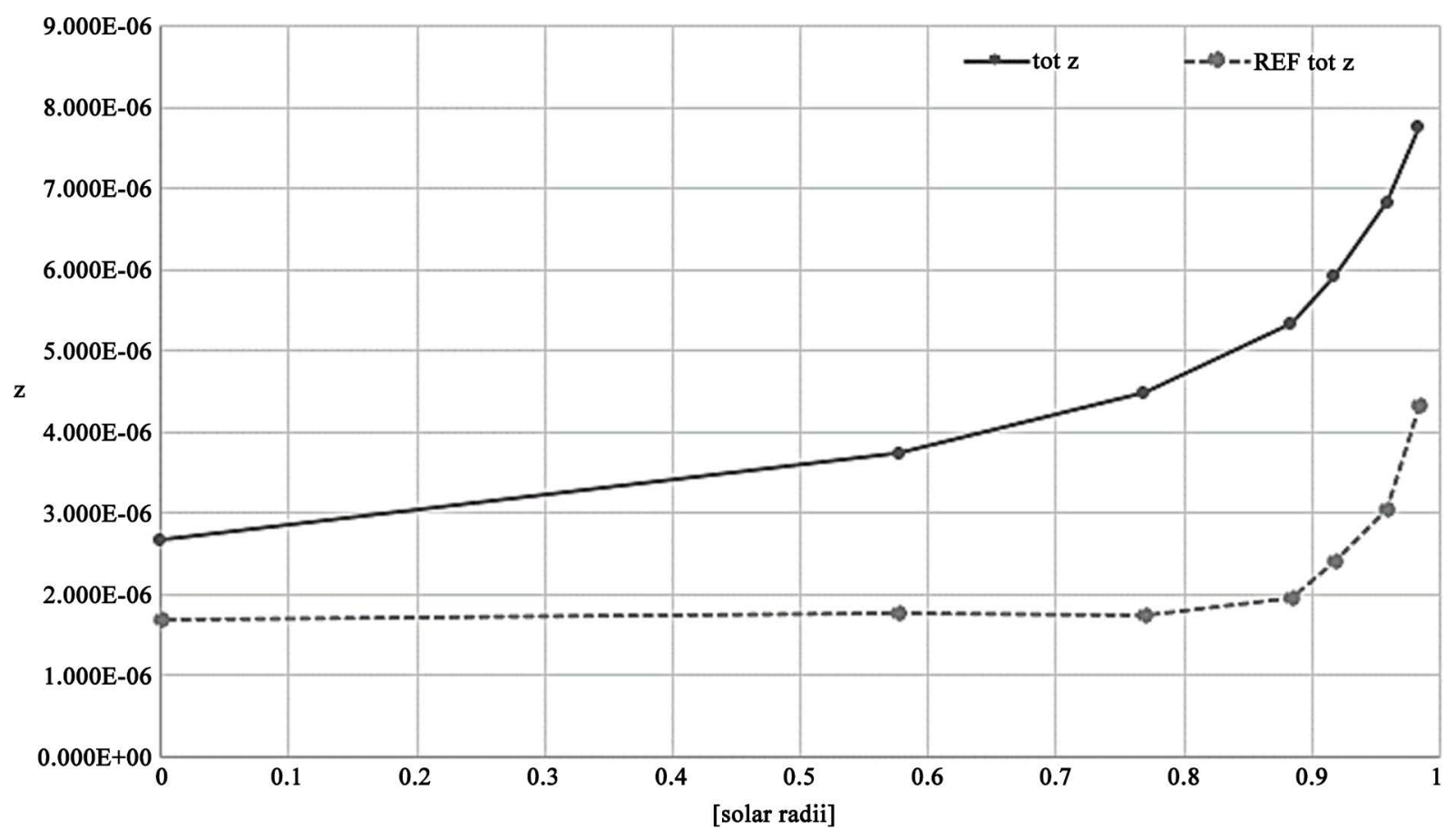

Figure 26. M.G. Adam's reference redshift (dashed line) vs. A. Trinchera's redshift (continuous line) case Mex 2. The latter does not take into account the radial velocity component of granular motion. 
subtract the values in row between the redshift without the radial component of granular motion of the vector 7.10 and the reference redshift in the vector 7.2, giving the redshift excess vector equal to

$$
z_{\text {e gmr }}=\left(\begin{array}{c}
3.446 \mathrm{E}-06 \\
3.782 \mathrm{E}-06 \\
3.515 \mathrm{E}-06 \\
3.375 \mathrm{E}-06 \\
2.739 \mathrm{E}-06 \\
1.953 \mathrm{E}-06 \\
9.971 \mathrm{E}-07
\end{array}\right)
$$

As previously stated, the average radial velocity component of granular motion can be obtained by the Doppler shift Equation (7.6). Substituting the excess redshift values, the components of the vector velocity expressed in $\mathrm{m} / \mathrm{sec}$ become

$$
v_{\text {egmr }}=\left(\begin{array}{c}
1033.0 \\
1133.8 \\
1053.7 \\
1011.7 \\
821.1 \\
585.6 \\
298.9
\end{array}\right)
$$

We can compare the latter to the admissible vector of velocity components, vector 7.8, expressed in $\mathrm{m} / \mathrm{sec}$ as previously determined. The values of the velocity components of the vector 7.12 are too high for representing average values. Most of them clearly exceed the maximum components of the vector 7.8. We can therefore state that the Mex 2 data only approximates the electron distribution between the Sun and the Earth and it is the reason why, accordingly, the values of redshift calculated do not properly match the observational data.

\subsection{Mgs}

Based on Equation (6.61), we can calculate the total redshiftas

$$
Z=\left(\begin{array}{c}
1.607 \mathrm{E}-05 \\
1.419 \mathrm{E}-05 \\
1.231 \mathrm{E}-05 \\
1.097 \mathrm{E}-05 \\
8.508 \mathrm{E}-06 \\
5.545 \mathrm{E}-06 \\
-6.847 \mathrm{E}-07
\end{array}\right)
$$

where, once again, the reference redshift trend on the solar disk is shown in the vector 7.2. We can plot these two sets of values found as follows Figure 27.

We can omit the radial velocity components of granular motion to obtain a total redshift vector equal to 


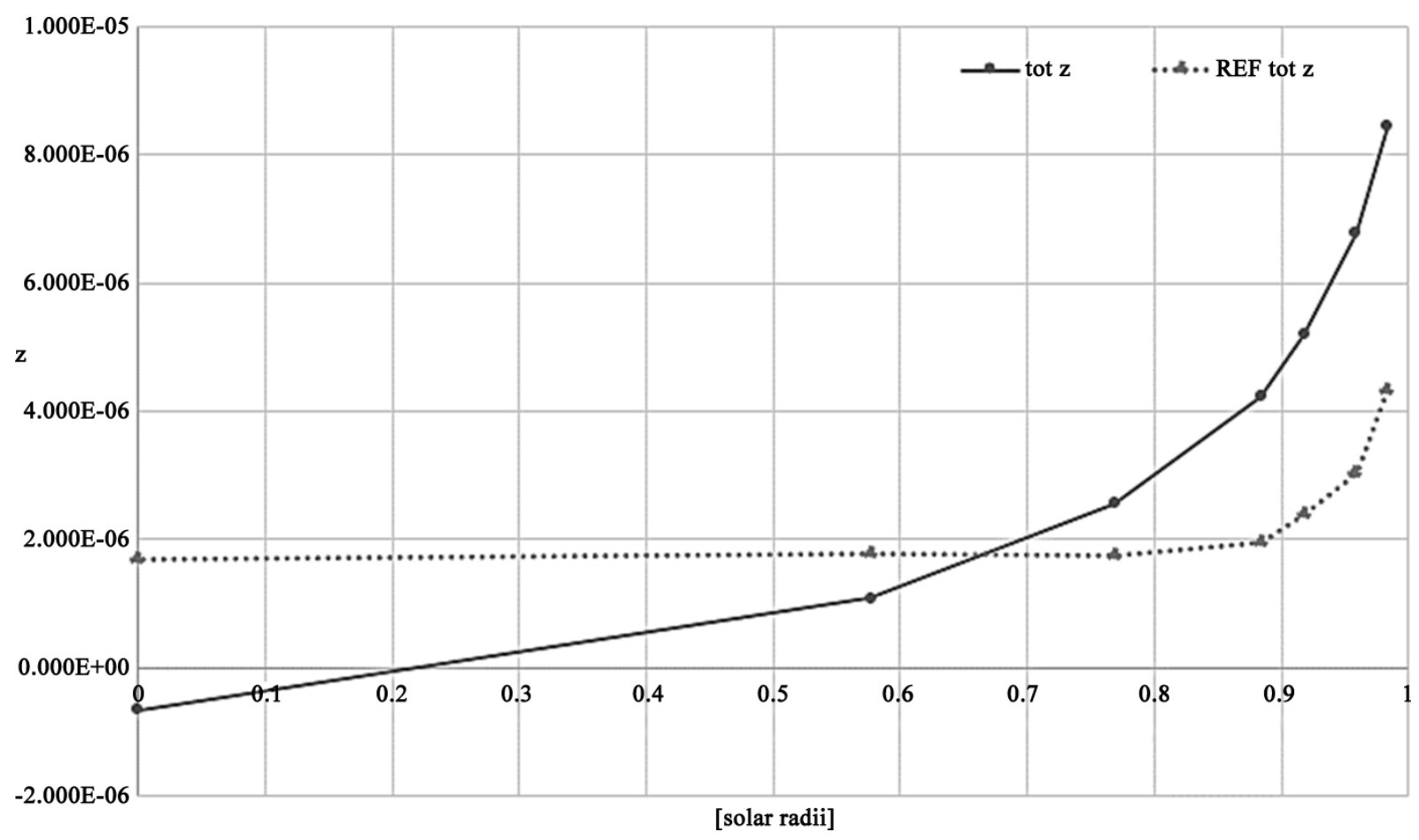

Figure 27. M.G. Adam's reference redshift (dashed line) vs. A. Trinchera's redshift (continuous line) case Mgs. The latter takes into account the max radial velocity component of granular motion.

$$
Z_{w / o g m r}=\left(\begin{array}{c}
9.049 \mathrm{E}-06 \\
7.722 \mathrm{E}-06 \\
6.511 \mathrm{E}-06 \\
5.787 \mathrm{E}-06 \\
4.696 \mathrm{E}-06 \\
3.812 \mathrm{E}-06 \\
2.672 \mathrm{E}-06
\end{array}\right)
$$

The graph of the total redshift becomes accordingly as follows Figure 28.

As done previously, we can calculate mathematically the upwards component of granular motion starting from the Doppler shift formula case approach. We can subtract the values in row between the redshift without the radial component of granular motion of the vector 7.14 and the reference redshift in the vector 7.2, giving the redshift excess vector equal to

$$
z_{\text {e gmr }}=\left(\begin{array}{l}
4.734 \mathrm{E}-06 \\
4.681 \mathrm{E}-06 \\
4.110 \mathrm{E}-06 \\
3.826 \mathrm{E}-06 \\
2.955 \mathrm{E}-06 \\
2.033 \mathrm{E}-06 \\
9.971 \mathrm{E}-07
\end{array}\right)
$$

The average radial velocity component of granular motion can be obtained by the Doppler shift Equation (7.6). Substituting the excess redshift values, the 


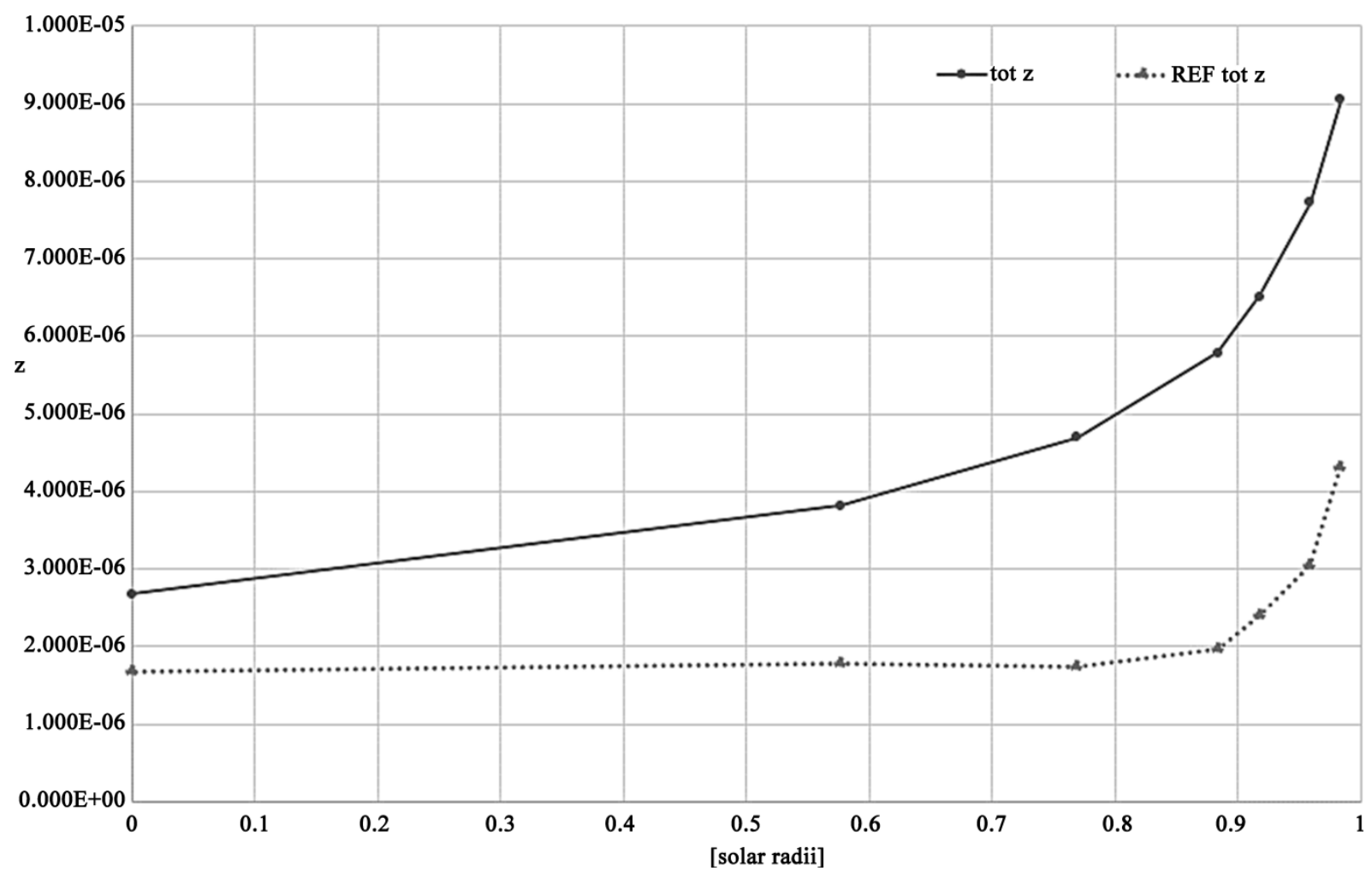

Figure 28. M.G. Adam's reference redshift (dashed line) vs. A. Trinchera's redshift (continuous line) case Mgs. The latter does not take into account the radial velocity component of granular motion.

components of the vector velocity expressed in $\mathrm{m} / \mathrm{sec}$ become

$$
v_{\text {e gmr }}=\left(\begin{array}{c}
1419.3 \\
1403.4 \\
1232.1 \\
1147.1 \\
885.8 \\
609.3 \\
298.9
\end{array}\right)
$$

We can compare this vector to the admissible vector of velocity components, vector 7.8, expressed in $\mathrm{m} / \mathrm{sec}$ as previously determined. The velocity components are even higher to represent average values. Solar flares responsible of these calculated effects, occurring continuously in all days of measurement, are to exclude. The latter would be the only way two explain high-excess redshifts but in this specific case we suggest that the density of electron described by the Mgs data is too high and therefore cannot match the observational data properly.

\section{Discussions}

In the Mex 1 result case, we have seen how the study, based on the NTL applied to the space between the Sun and the Earth, describes exactly the trend of the redshift on the solar disk. The study of the redshift excess is related either to the radial outgoing velocities of the solar granules that vary along the solar disk or to 
local unpredictable events, such as solar flares, that accelerate electrons into the volume intersecting the observation line of a terrestrial observer. This calculation procedure provides a clear confirmation that there would be, to a certain degree, a connection between the excess of redshift and the solar flares observed by a telescope. The variability of the horizontal velocity component of the granular motion, with respect to the radial velocity component, is not decisive due to the Doppler shift which is balanced between the left-hand side and the right-hand side of the solar disk, even inverting the Doppler sign. Concerning the limb effect, intended as the reduction of the intensity of the radiation according to the line of sight of an observer on Earth, it does not play a decisive role in the anomaly problem as only a single photon, in the Tired Light approach, would be sufficient to determine exactly the same graphs that we calculated independently from the intensity of the radiation.

The variation of the redshift between the center and the limb is due to interactions between photons and electrons inside the solar corona. Photons travel with evidence a wider path in correspondence to the limb than to the center from a terrestrial observer's perspective. This study shows that the higher the electron density between a source and an observer is, the higher is the measured redshift. If it was not dependent on the multiple interactions between photons and electrons as well as on the geometrical configuration, we would not obtain an exponential redshift trend with the highest values in correspondence to the limb and the smallest ones to the center. In order to obtain these curves, too many coincidences would be required. However, this is not the case. The energy loss, namely the redshift, is higher where the distribution of electron is higher as well. The reason for this fact is that the number of interactions between photons and electrons is consistent with NTL physics.

In order to describe properly what occurs at great cosmological scales, we should first focus on our nearby environment, as suggested and concretely performed by this study. We can take for granted the fundamental assumption that the universal laws are the same everywhere without exception. On the contrary, the cosmological principle, valid from a distance of $300 \mathrm{Mpc}$ away from us ignoring our local environment and physics, was created intentionally by the scientific community in order to justify and defend the Standard Model. Our nearest star, the Sun, is one decisive sample over billions of similar cases that we can expect in the Cosmos. It provides us with concrete answers to what happens even to farther and different astronomical objects. The redshift anomaly of the Sun definitively ceases to be an anomaly if we approach the problem from a different perspective as it leads us to solve controversial redshifts and to interpret low and high redshifts of astronomical objects all over the Cosmos such as galaxies and especially Quasars.

\section{Conflicts of Interest}

The author declares no conflicts of interest regarding the publication of this paper. 


\section{References}

[1] Zwicky, F. (1929) On the Red Shift of Spectral Lines through Interstellar Space. Proceedings of the National Academy of Sciences of the United States of America, 15, 773-785. https://doi.org/10.1073/pnas.15.10.773

[2] Ashmore, L.E. (2006) Recoil between Photons and Electrons Leading to the Hubble Constant and CMB. Galilean Electrodynamics, 17, 54-55.

[3] Ashmore, L.E. (2016) An Explanation of Redshifts in a Static Universe. In: Amoroso, R.L., Kauffman, L.H. and Rowlands, P., Eds., Unified Field Mechanics, World Scientific Publishers, Singapore, 456-462.

[4] Ashmore, L.E. (2016) A Relationship Between Dispersion Measure and Redshift Derived in Terms of New Tired Light. Journal of High Energy Physics, Gravitation and Cosmology, 2, 512-530. https://doi.org/10.4236/jhepgc.2016.24045

[5] Hubble, E.P. (1929) The Structure of the Universe. In: Carnegie Institution of Washington, Ed., News Service Bulletin, Carnegie Institution of Washington, Washington DC, 49-51.

[6] Hubble, E.P. and Tolman, R.C. (1935) Two Methods of Investigating the Nature of Nebular Red-Shift. Astrophysical Journal, 22, 391-426.

https://doi.org/10.1086/143682

[7] Hubble, E.P. (1947) The 200-inch Telescope and Some Problems It May Solve. Publications of the Astronomical Society of the Pacific, 59, 153-167. https://doi.org/10.1086/125931

[8] Verma, A.K., Fienga, A., Laskar, J., Issautier, K., Manche, H. and Gastineau, M. (2013) Electron Density Distribution and Solar Plasma Correction of Radio Signals Using MGS, MEX and VEX Spacecraft Navigation Data and Its Application to Planetary Ephemerides. Astronomy \& Astrophysics, 550, A124.

https://doi.org/10.1051/0004-6361/201219883

[9] Adam, M.G. (1948) Interferometric Measurements of Solar Wavelengths and an Investigation of the Einstein Gravitational Displacement. Monthly Notices of the Royal Astronomical Society, 108, 446-464. https://doi.org/10.1093/mnras/108.6.446

[10] Arp, H. (1987) Quasars, Redshifts and Controversies. Interstellar Media, Barkeley. https://doi.org/10.1017/CBO9780511564857

[11] Longair, M.S. (1992) High Energy Astrophysics. Cambridge University Press, Cambridge.

[12] Rincon, F. and Rieutord, M. (2018) The Sun's Supergranulation. Living Reviews in Solar Physics, 15, Article No. 6. https://doi.org/10.1007/s41116-018-0013-5

[13] Falco, M., Puglisi, G., Guglielmino, S.L., Romano, P., Ermolli, I. and Zuccarello, F. (2017) Comparison of Different Populations of Granular Features in the Solar Photosphere. Astronomy \& Astrophysics, 605, A87. https://doi.org/10.1051/0004-6361/201629881 


\section{Appendix A}

Planck constant

Electron mass $m_{e}$

Electron radius $r_{e}$

Speed of light $c$

Sun radius $R_{\text {sun }}$

Sun mass $M_{s}$

Gravitational const. $G$

Earth radius $R_{E}$

Earth mass $M_{E}$

Astronomic. unit AU

$\begin{array}{ll}6.626 \mathrm{E}-034 & \mathrm{~m}^{2} \mathrm{Kg} / \mathrm{sec} \\ 9.109 \mathrm{E}-031 & \mathrm{Kg} \\ 2.818 \mathrm{E}-015 & \mathrm{~m} \\ 299,792,458 & \mathrm{~m} / \mathrm{sec} \\ 695,510,000 & \mathrm{~m} \\ 1.989 \mathrm{E}+030 & \mathrm{Kg} \\ 6.674 \mathrm{E}-011 & \mathrm{~m}^{3} / \mathrm{Kgsec}^{2} \\ 6371,000 & \mathrm{~m} \\ 5.972 \mathrm{E}+024 & \mathrm{Kg} \\ 149.597 \mathrm{E}+09 & \mathrm{~m}\end{array}$

\section{Appendix B}

Mex 1

\begin{tabular}{|c|c|c|c|c|c|c|c|c|c|c|c|c|c|c|}
\hline \multirow{7}{*}{$k_{\lambda 1}=k_{\lambda 2}=k_{\lambda 3}=$} & 1.563 & 1.563 & 1.563 & 1.563 & 1.562 & 1.560 & 1.558 & 1.558 & 1.554 & 1.554 & 1.547 & 1.545 & 1.541 & 1.541 \\
\hline & 1.472 & 1.472 & 1.471 & 1.471 & 1.471 & 1.470 & 1.469 & 1.469 & 1.465 & 1.464 & 1.458 & 1.458 & 1.454 & 1.454 \\
\hline & 1.380 & 1.380 & 1.380 & 1.380 & 1.379 & 1.379 & 1.378 & 1.377 & 1.375 & 1.374 & 1.370 & 1.369 & 1.367 & 1.367 \\
\hline & 1.327 & 1.326 & 1.326 & 1.326 & 1.326 & 1.325 & 1.325 & 1.324 & 1.322 & 1.322 & 1.318 & 1.317 & 1.315 & 1.315 \\
\hline & 1.207 & 1.207 & 1.207 & 1.207 & 1.207 & 1.206 & 1.206 & 1.206 & 1.204 & 1.204 & 1.202 & 1.202 & 1.201 & 1.200 \\
\hline & 1.098 & 1.098 & 1.098 & 1.098 & 1.098 & 1.098 & 1.098 & 1.098 & 1.097 & 1.097 & 1.096 & 1.096 & 1.095 & 1.00 \\
\hline & 1 & 1 & 1 & 1 & 1 & 1 & 1 & 1 & 1 & 1 & 1 & 1 & 1 & \\
\hline
\end{tabular}

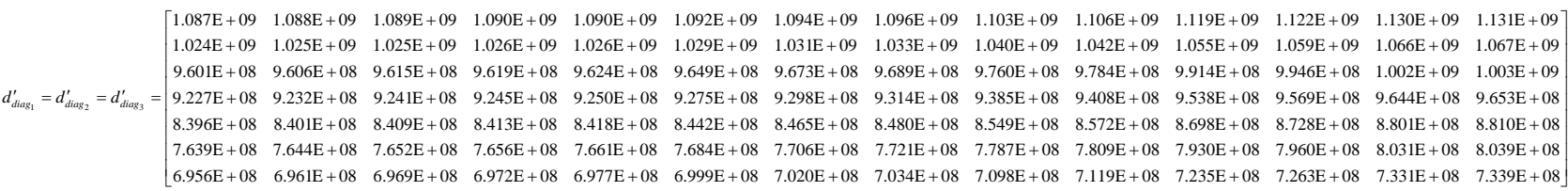

$$
\begin{aligned}
I_{114} & =\left[\begin{array}{lllll}
3.180 \mathrm{E}+08 & 3.180 \mathrm{E}+08 & 3.180 \mathrm{E}+08 & \cdots & 4.838 \mathrm{E}+12 \\
3.000 \mathrm{E}+08 & 3.000 \mathrm{E}+08 & 3.000 \mathrm{E}+08 & \cdots & 4.565 \mathrm{E}+12 \\
2.820 \mathrm{E}+08 & 2.820 \mathrm{E}+08 & 2.821 \mathrm{E}+08 & \cdots & 4.291 \mathrm{E}+12 \\
2.714 \mathrm{E}+08 & 2.714 \mathrm{E}+08 & 2.714 \mathrm{E}+08 & \cdots & 4.129 \mathrm{E}+12 \\
2.477 \mathrm{E}+08 & 2.477 \mathrm{E}+08 & 2.477 \mathrm{E}+08 & \cdots & 3.769 \mathrm{E}+12 \\
2.260 \mathrm{E}+08 & 2.260 \mathrm{E}+08 & 2.261 \mathrm{E}+08 & \cdots & 3.439 \mathrm{E}+12 \\
2.064 \mathrm{E}+08 & 2.064 \mathrm{E}+08 & 2.064 \mathrm{E}+08 & \cdots & 3.140 \mathrm{E}+12
\end{array}\right] \\
H I_{114} & {\left[\begin{array}{llllll}
1.788 \mathrm{E}+03 & 1.788 \mathrm{E}+03 & 1.788 \mathrm{E}+03 & \cdots & 1.788 \mathrm{E}+03 \\
1.687 \mathrm{E}+03 & 1.687 \mathrm{E}+03 & 1.687 \mathrm{E}+03 & \cdots & 1.687 \mathrm{E}+03 \\
1.586 \mathrm{E}+03 & 1.586 \mathrm{E}+03 & 1.586 \mathrm{E}+03 & \cdots & 1.586 \mathrm{E}+03 \\
1.526 \mathrm{E}+03 & 1.526 \mathrm{E}+03 & 1.526 \mathrm{E}+03 & \cdots & 1.526 \mathrm{E}+03 \\
1.393 \mathrm{E}+03 & 1.393 \mathrm{E}+03 & 1.393 \mathrm{E}+03 & \cdots & 1.393 \mathrm{E}+03 \\
1.271 \mathrm{E}+03 & 1.271 \mathrm{E}+03 & 1.271 \mathrm{E}+03 & \cdots & 1.271 \mathrm{E}+03 \\
1.160 \mathrm{E}+03 & 1.160 \mathrm{E}+03 & 1.160 \mathrm{E}+03 & \cdots & 1.160 \mathrm{E}+03
\end{array}\right] }
\end{aligned}
$$




$$
\begin{aligned}
& M_{y s_{L} 1}=\left[\begin{array}{cccccccc}
9.822 \mathrm{E}-09 & -6.961 \mathrm{E}-10 & -6.485 \mathrm{E}-06 & 6.344 \mathrm{E}-07 & -1.118 \mathrm{E}-06 & -1.149 \mathrm{E}-06 & -5.945 \mathrm{E}-07 & 6.134 \mathrm{E}-06 \\
9.822 \mathrm{E}-09 & -6.961 \mathrm{E}-10 & -6.320 \mathrm{E}-06 & 6.005 \mathrm{E}-07 & -1.130 \mathrm{E}-06 & -1.120 \mathrm{E}-06 & -9.455 \mathrm{E}-07 & 5.783 \mathrm{E}-06 \\
9.822 \mathrm{E}-09 & -6.961 \mathrm{E}-10 & -6.050 \mathrm{E}-06 & 7.216 \mathrm{E}-07 & -1.149 \mathrm{E}-06 & -1.072 \mathrm{E}-06 & -1.323 \mathrm{E}-06 & 5.429 \mathrm{E}-06 \\
9.822 \mathrm{E}-09 & -6.961 \mathrm{E}-10 & -5.826 \mathrm{E}-06 & 6.963 \mathrm{E}-07 & -1.164 \mathrm{E}-06 & -1.032 \mathrm{E}-06 & -1.559 \mathrm{E}-06 & 5.221 \mathrm{E}-06 \\
9.822 \mathrm{E}-09 & -6.961 \mathrm{E}-10 & -5.068 \mathrm{E}-06 & 6.318 \mathrm{E}-07 & -1.216 \mathrm{E}-06 & -8.978 \mathrm{E}-07 & -2.132 \mathrm{E}-06 & 4.758 \mathrm{E}-06 \\
9.822 \mathrm{E}-09 & -6.961 \mathrm{E}-10 & -3.803 \mathrm{E}-06 & 6.043 \mathrm{E}-07 & -1.304 \mathrm{E}-06 & -6.736 \mathrm{E}-07 & -2.724 \mathrm{E}-06 & 4.335 \mathrm{E}-06 \\
9.822 \mathrm{E}-09 & -6.961 \mathrm{E}-10 & 0 & 3.262 \mathrm{E}-07 & -1.567 \mathrm{E}-06 & 0 & -3.336 \mathrm{E}-06 & 3.952 \mathrm{E}-06
\end{array}\right] \\
& \begin{aligned}
M_{{y s_{L} 2}} & =\left[\begin{array}{llllllll}
9.857 \mathrm{E}-09 & -6.961 \mathrm{E}-10 & -6.485 \mathrm{E}-06 & 4.119 \mathrm{E}-07 & -1.196 \mathrm{E}-06 & -1.149 \mathrm{E}-06 & -5.945 \mathrm{E}-07 & 6.134 \mathrm{E}-06 \\
9.857 \mathrm{E}-09 & -6.961 \mathrm{E}-10 & -6.320 \mathrm{E}-06 & 3.770 \mathrm{E}-07 & -1.208 \mathrm{E}-06 & -1.120 \mathrm{E}-06 & -9.455 \mathrm{E}-07 & 5.783 \mathrm{E}-06 \\
9.857 \mathrm{E}-09 & -6.961 \mathrm{E}-10 & -6.050 \mathrm{E}-06 & 2.760 \mathrm{E}-07 & -1.227 \mathrm{E}-06 & -1.072 \mathrm{E}-06 & -1.323 \mathrm{E}-06 & 5.429 \mathrm{E}-06 \\
9.857 \mathrm{E}-09 & -6.961 \mathrm{E}-10 & -5.826 \mathrm{E}-06 & 3.388 \mathrm{E}-07 & -1.243 \mathrm{E}-06 & -1.032 \mathrm{E}-06 & -1.559 \mathrm{E}-06 & 5.221 \mathrm{E}-06 \\
9.857 \mathrm{E}-09 & -6.961 \mathrm{E}-10 & -5.068 \mathrm{E}-06 & 3.737 \mathrm{E}-07 & -1.295 \mathrm{E}-06 & -8.978 \mathrm{E}-07 & -2.132 \mathrm{E}-06 & 4.758 \mathrm{E}-06 \\
9.857 \mathrm{E}-09 & -6.961 \mathrm{E}-10 & -3.803 \mathrm{E}-06 & 5.927 \mathrm{E}-07 & -1.384 \mathrm{E}-06 & -6.736 \mathrm{E}-07 & -2.724 \mathrm{E}-06 & 4.335 \mathrm{E}-06 \\
9.857 \mathrm{E}-09 & -6.961 \mathrm{E}-10 & 0 & 2.574 \mathrm{E}-07 & -1.648 \mathrm{E}-06 & 0 & -3.336 \mathrm{E}-06 & 3.952 \mathrm{E}-06
\end{array}\right] \\
M_{y s_{L} 3} & {\left[\begin{array}{lrrrrrrrr}
9.894 \mathrm{E}-09 & -6.961 \mathrm{E}-10 & -6.485 \mathrm{E}-06 & 5.888 \mathrm{E}-07 & -1.190 \mathrm{E}-06 & -1.149 \mathrm{E}-06 & -5.945 \mathrm{E}-07 & 6.134 \mathrm{E}-06 \\
9.894 \mathrm{E}-09 & -6.961 \mathrm{E}-10 & -6.320 \mathrm{E}-06 & 5.514 \mathrm{E}-07 & -1.202 \mathrm{E}-06 & -1.120 \mathrm{E}-06 & -9.455 \mathrm{E}-07 & 5.783 \mathrm{E}-06 \\
9.894 \mathrm{E}-09 & -6.961 \mathrm{E}-10 & -6.050 \mathrm{E}-06 & 2.724 \mathrm{E}-07 & -1.221 \mathrm{E}-06 & -1.072 \mathrm{E}-06 & -1.323 \mathrm{E}-06 & 5.429 \mathrm{E}-06 \\
9.894 \mathrm{E}-09 & -6.961 \mathrm{E}-10 & -5.826 \mathrm{E}-06 & 2.400 \mathrm{E}-07 & -1.237 \mathrm{E}-06 & -1.032 \mathrm{E}-06 & -1.559 \mathrm{E}-06 & 5.221 \mathrm{E}-06 \\
9.894 \mathrm{E}-09 & -6.961 \mathrm{E}-10 & -5.068 \mathrm{E}-06 & 3.679 \mathrm{E}-07 & -1.291 \mathrm{E}-06 & -8.978 \mathrm{E}-07 & -2.132 \mathrm{E}-06 & 4.758 \mathrm{E}-06 \\
9.894 \mathrm{E}-09 & -6.961 \mathrm{E}-10 & -3.803 \mathrm{E}-06 & 4.360 \mathrm{E}-07 & -1.379 \mathrm{E}-06 & -6.736 \mathrm{E}-07 & -2.724 \mathrm{E}-06 & 4.335 \mathrm{E}-06 \\
9.894 \mathrm{E}-09 & -6.961 \mathrm{E}-10 & 0 & 4.724 \mathrm{E}-07 & -1.646 \mathrm{E}-06 & 0 & -3.336 \mathrm{E}-06 & 3.952 \mathrm{E}-06
\end{array}\right] }
\end{aligned} \\
& L_{y \overline{s_{L}}}=\left(\begin{array}{l}
-2.707 \mathrm{E}-06 \\
-3.263 \mathrm{E}-06 \\
-3.782 \mathrm{E}-06 \\
-3.976 \mathrm{E}-06 \\
-4.140 \mathrm{E}-06 \\
-3.667 \mathrm{E}-06 \\
-6.425 \mathrm{E}-07
\end{array}\right)
\end{aligned}
$$$$
\begin{aligned}
M_{y s_{R} 1} & =\left[\begin{array}{lrrrrrrr}
9.822 \mathrm{E}-09 & -6.961 \mathrm{E}-10 & 6.485 \mathrm{E}-06 & 5.184 \mathrm{E}-07 & -1.118 \mathrm{E}-06 & 1.149 \mathrm{E}-06 & -5.945 \mathrm{E}-07 & 6.134 \mathrm{E}-06 \\
9.822 \mathrm{E}-09 & -6.961 \mathrm{E}-10 & 6.320 \mathrm{E}-06 & 4.640 \mathrm{E}-07 & -1.130 \mathrm{E}-06 & 1.120 \mathrm{E}-06 & -9.455 \mathrm{E}-07 & 5.783 \mathrm{E}-06 \\
9.822 \mathrm{E}-09 & -6.961 \mathrm{E}-10 & 6.050 \mathrm{E}-06 & 7.989 \mathrm{E}-07 & -1.149 \mathrm{E}-06 & 1.072 \mathrm{E}-06 & -1.323 \mathrm{E}-06 & 5.429 \mathrm{E}-06 \\
9.822 \mathrm{E}-09 & -6.961 \mathrm{E}-10 & 5.826 \mathrm{E}-06 & 2.165 \mathrm{E}-07 & -1.164 \mathrm{E}-06 & 1.032 \mathrm{E}-06 & -1.559 \mathrm{E}-06 & 5.221 \mathrm{E}-06 \\
9.822 \mathrm{E}-09 & -6.961 \mathrm{E}-10 & 5.068 \mathrm{E}-06 & 4.984 \mathrm{E}-07 & -1.216 \mathrm{E}-06 & 8.978 \mathrm{E}-07 & -2.132 \mathrm{E}-06 & 4.758 \mathrm{E}-06 \\
9.822 \mathrm{E}-09 & -6.961 \mathrm{E}-10 & 3.803 \mathrm{E}-06 & 5.476 \mathrm{E}-07 & -1.304 \mathrm{E}-06 & 6.736 \mathrm{E}-07 & -2.724 \mathrm{E}-06 & 4.335 \mathrm{E}-06 \\
9.822 \mathrm{E}-09 & -6.961 \mathrm{E}-10 & 0 & 0 & -1.567 \mathrm{E}-06 & 0 & -3.336 \mathrm{E}-06 & 3.952 \mathrm{E}-06
\end{array}\right] \\
M_{y s_{R} 2} & =\left[\begin{array}{lrrrrrrrrr}
9.857 \mathrm{E}-09 & -6.961 \mathrm{E}-10 & 6.485 \mathrm{E}-06 & 3.107 \mathrm{E}-07 & -1.196 \mathrm{E}-06 & 1.149 \mathrm{E}-06 & -5.945 \mathrm{E}-07 & 6.134 \mathrm{E}-06 \\
9.857 \mathrm{E}-09 & -6.961 \mathrm{E}-10 & 6.320 \mathrm{E}-06 & 2.724 \mathrm{E}-07 & -1.208 \mathrm{E}-06 & 1.120 \mathrm{E}-06 & -9.455 \mathrm{E}-07 & 5.783 \mathrm{E}-06 \\
9.857 \mathrm{E}-09 & -6.961 \mathrm{E}-10 & 6.050 \mathrm{E}-06 & 2.103 \mathrm{E}-07 & -1.227 \mathrm{E}-06 & 1.072 \mathrm{E}-06 & -1.323 \mathrm{E}-06 & 5.429 \mathrm{E}-06 \\
9.857 \mathrm{E}-09 & -6.961 \mathrm{E}-10 & 5.826 \mathrm{E}-06 & 1.878 \mathrm{E}-07 & -1.243 \mathrm{E}-06 & 1.032 \mathrm{E}-06 & -1.559 \mathrm{E}-06 & 5.221 \mathrm{E}-06 \\
9.857 \mathrm{E}-09 & -6.961 \mathrm{E}-10 & 5.068 \mathrm{E}-06 & 4.402 \mathrm{E}-07 & -1.295 \mathrm{E}-06 & 8.978 \mathrm{E}-07 & -2.132 \mathrm{E}-06 & 4.758 \mathrm{E}-06 \\
9.857 \mathrm{E}-09 & -6.961 \mathrm{E}-10 & 3.803 \mathrm{E}-06 & 4.836 \mathrm{E}-07 & -1.384 \mathrm{E}-06 & 6.736 \mathrm{E}-07 & -2.724 \mathrm{E}-06 & 4.335 \mathrm{E}-06 \\
9.857 \mathrm{E}-09 & -6.961 \mathrm{E}-10 & 0 & 5.062 \mathrm{E}-07 & -1.648 \mathrm{E}-06 & 0 & -3.336 \mathrm{E}-06 & 3.952 \mathrm{E}-06
\end{array}\right]
\end{aligned}
$$ 


$$
\begin{gathered}
M_{{y s_{R} 3}=}=\left[\begin{array}{ccccccccc}
9.894 \mathrm{E}-09 & -6.961 \mathrm{E}-10 & 6.485 \mathrm{E}-06 & 7.011 \mathrm{E}-07 & -1.190 \mathrm{E}-06 & 1.149 \mathrm{E}-06 & -5.945 \mathrm{E}-07 & 6.134 \mathrm{E}-06 \\
9.894 \mathrm{E}-09 & -6.961 \mathrm{E}-10 & 6.320 \mathrm{E}-06 & 6.671 \mathrm{E}-07 & -1.202 \mathrm{E}-06 & 1.120 \mathrm{E}-06 & -9.455 \mathrm{E}-07 & 5.783 \mathrm{E}-06 \\
9.894 \mathrm{E}-09 & -6.961 \mathrm{E}-10 & 6.050 \mathrm{E}-06 & 2.725 \mathrm{E}-07 & -1.221 \mathrm{E}-06 & 1.072 \mathrm{E}-06 & -1.323 \mathrm{E}-06 & 5.429 \mathrm{E}-06 \\
9.894 \mathrm{E}-09 & -6.961 \mathrm{E}-10 & 5.826 \mathrm{E}-06 & 1.968 \mathrm{E}-07 & -1.237 \mathrm{E}-06 & 1.032 \mathrm{E}-06 & -1.559 \mathrm{E}-06 & 5.221 \mathrm{E}-06 \\
9.894 \mathrm{E}-09 & -6.961 \mathrm{E}-10 & 5.068 \mathrm{E}-06 & 3.030 \mathrm{E}-07 & -1.291 \mathrm{E}-06 & 8.978 \mathrm{E}-07 & -2.132 \mathrm{E}-06 & 4.758 \mathrm{E}-06 \\
9.894 \mathrm{E}-09 & -6.961 \mathrm{E}-10 & 3.803 \mathrm{E}-06 & 4.856 \mathrm{E}-07 & -1.379 \mathrm{E}-06 & 6.736 \mathrm{E}-07 & -2.724 \mathrm{E}-06 & 4.335 \mathrm{E}-06 \\
9.894 \mathrm{E}-09 & -6.961 \mathrm{E}-10 & 0 & 4.229 \mathrm{E}-07 & -1.646 \mathrm{E}-06 & 0 & -3.336 \mathrm{E}-06 & 3.952 \mathrm{E}-06
\end{array}\right] \\
R_{y \bar{s}_{R}}=\left(\begin{array}{c}
1.252 \mathrm{E}-05 \\
1.157 \mathrm{E}-05 \\
1.046 \mathrm{E}-05 \\
9.514 \mathrm{E}-06 \\
7.747 \mathrm{E}-06 \\
5.245 \mathrm{E}-06 \\
-6.848 \mathrm{E}-07
\end{array}\right)
\end{gathered}
$$

\begin{tabular}{|c|c|c|c|c|c|c|c|c|c|c|c|c|c|c|}
\hline \multirow{7}{*}{$k_{\lambda 1}=k_{\lambda 2}=k_{\lambda 3}=$} & 2.160 & 2.160 & 2.159 & 2.158 & 2.157 & 2.152 & 2.148 & 2.145 & 2.132 & 2.127 & 2.105 & 2.099 & 2.086 & 2.085 \\
\hline & 1.925 & 1.926 & 1.924 & 1.924 & 1.923 & 1.920 & 1.917 & 1.914 & 1.905 & 1.902 & 1.885 & 1.882 & 1.872 & 1.871 \\
\hline & 1.708 & 1.709 & 1.708 & 1.708 & 1.707 & 1.705 & 1.703 & 1.701 & 1.695 & 1.693 & 1.682 & 1.679 & 1.673 & 1.672 \\
\hline & 1.590 & 1.590 & 1.590 & 1.589 & 1.589 & 1.587 & 1.586 & 1.585 & 1.580 & 1.578 & 1.569 & 1.567 & 1.562 & 1.562 \\
\hline & 1.348 & 1.349 & 1.349 & 1.349 & 1.349 & 1.348 & 1.347 & 1.346 & 1.344 & 1.343 & 1.339 & 1.338 & 1.335 & 1.335 \\
\hline & 1.155 & 1.155 & 1.155 & 1.155 & 1.155 & 1.155 & 1.155 & 1.154 & 1.154 & 1.153 & 1.152 & 1.151 & 1.150 & 1.150 \\
\hline & 1 & 1 & 1 & 1 & 1 & 1 & 1 & 1 & 1 & 1 & 1 & 1 & 1 & 1 \\
\hline
\end{tabular}

Mex 2

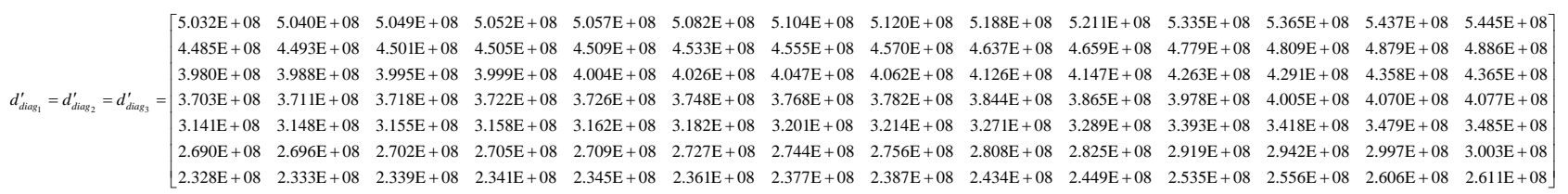

$$
I_{114}=\left[\begin{array}{lllll}
1.558 \mathrm{E}+09 & 1.558 \mathrm{E}+09 & 1.399 \mathrm{E}+09 & \cdots & 8.119 \mathrm{E}+12 \\
1.399 \mathrm{E}+09 & 1.399 \mathrm{E}+09 & 1.399 \mathrm{E}+09 & \cdots & 7.287 \mathrm{E}+12 \\
1.249 \mathrm{E}+09 & 1.250 \mathrm{E}+09 & 1.250 \mathrm{E}+09 & \cdots & 6.510 \mathrm{E}+12 \\
1.167 \mathrm{E}+09 & 1.167 \mathrm{E}+09 & 1.167 \mathrm{E}+09 & \cdots & 6.081 \mathrm{E}+12 \\
9.976 \mathrm{E}+08 & 9.976 \mathrm{E}+08 & 9.977 \mathrm{E}+08 & \cdots & 5.198 \mathrm{E}+12 \\
8.596 \mathrm{E}+08 & 8.596 \mathrm{E}+08 & 8.597 \mathrm{E}+08 & \cdots & 4.479 \mathrm{E}+12 \\
7.474 \mathrm{E}+08 & 7.474 \mathrm{E}+08 & 7.474 \mathrm{E}+08 & \cdots & 3.894 \mathrm{E}+12
\end{array}\right]
$$




$$
\begin{aligned}
& M_{y s_{L} 1}=\left[\begin{array}{cccccccc}
9.822 \mathrm{E}-09 & -6.961 \mathrm{E}-10 & -6.485 \mathrm{E}-06 & 6.344 \mathrm{E}-07 & -1.118 \mathrm{E}-06 & -1.149 \mathrm{E}-06 & -5.945 \mathrm{E}-07 & 8.392 \mathrm{E}-06 \\
9.822 \mathrm{E}-09 & -6.961 \mathrm{E}-10 & -6.320 \mathrm{E}-06 & 6.005 \mathrm{E}-07 & -1.130 \mathrm{E}-06 & -1.120 \mathrm{E}-06 & -9.455 \mathrm{E}-07 & 7.505 \mathrm{E}-06 \\
9.822 \mathrm{E}-09 & -6.961 \mathrm{E}-10 & -6.050 \mathrm{E}-06 & 7.216 \mathrm{E}-07 & -1.149 \mathrm{E}-06 & -1.072 \mathrm{E}-06 & -1.323 \mathrm{E}-06 & 6.681 \mathrm{E}-06 \\
9.822 \mathrm{E}-09 & -6.961 \mathrm{E}-10 & -5.826 \mathrm{E}-06 & 6.963 \mathrm{E}-07 & -1.164 \mathrm{E}-06 & -1.032 \mathrm{E}-06 & -1.559 \mathrm{E}-06 & 6.228 \mathrm{E}-06 \\
9.822 \mathrm{E}-09 & -6.961 \mathrm{E}-10 & -5.068 \mathrm{E}-06 & 6.318 \mathrm{E}-07 & -1.216 \mathrm{E}-06 & -8.978 \mathrm{E}-07 & -2.132 \mathrm{E}-06 & 5.303 \mathrm{E}-06 \\
9.822 \mathrm{E}-09 & -6.961 \mathrm{E}-10 & -3.803 \mathrm{E}-06 & 6.043 \mathrm{E}-07 & -1.304 \mathrm{E}-06 & -6.736 \mathrm{E}-07 & -2.724 \mathrm{E}-06 & 4.555 \mathrm{E}-06 \\
9.822 \mathrm{E}-09 & -6.961 \mathrm{E}-10 & 0 & 3.262 \mathrm{E}-07 & -1.567 \mathrm{E}-06 & 0 & -3.336 \mathrm{E}-06 & 3.952 \mathrm{E}-06
\end{array}\right] \\
& M_{y s_{L} 2}=\left[\begin{array}{cccccccc}
9.857 \mathrm{E}-09 & -6.961 \mathrm{E}-10 & -6.485 \mathrm{E}-06 & 4.119 \mathrm{E}-07 & -1.196 \mathrm{E}-06 & -1.149 \mathrm{E}-06 & -5.945 \mathrm{E}-07 & 8.392 \mathrm{E}-06 \\
9.857 \mathrm{E}-09 & -6.961 \mathrm{E}-10 & -6.320 \mathrm{E}-06 & 3.770 \mathrm{E}-07 & -1.208 \mathrm{E}-06 & -1.120 \mathrm{E}-06 & -9.455 \mathrm{E}-07 & 7.505 \mathrm{E}-06 \\
9.857 \mathrm{E}-09 & -6.961 \mathrm{E}-10 & -6.050 \mathrm{E}-06 & 2.760 \mathrm{E}-07 & -1.227 \mathrm{E}-06 & -1.072 \mathrm{E}-06 & -1.323 \mathrm{E}-06 & 6.681 \mathrm{E}-06 \\
9.857 \mathrm{E}-09 & -6.961 \mathrm{E}-10 & -5.826 \mathrm{E}-06 & 3.388 \mathrm{E}-07 & -1.243 \mathrm{E}-06 & -1.032 \mathrm{E}-06 & -1.559 \mathrm{E}-06 & 6.228 \mathrm{E}-06 \\
9.857 \mathrm{E}-09 & -6.961 \mathrm{E}-10 & -5.068 \mathrm{E}-06 & 3.737 \mathrm{E}-07 & -1.295 \mathrm{E}-06 & -8.978 \mathrm{E}-07 & -2.132 \mathrm{E}-06 & 5.303 \mathrm{E}-06 \\
9.857 \mathrm{E}-09 & -6.961 \mathrm{E}-10 & -3.803 \mathrm{E}-06 & 5.927 \mathrm{E}-07 & -1.384 \mathrm{E}-06 & -6.736 \mathrm{E}-07 & -2.724 \mathrm{E}-06 & 4.555 \mathrm{E}-06 \\
9.857 \mathrm{E}-09 & -6.961 \mathrm{E}-10 & 0 & 2.574 \mathrm{E}-07 & -1.648 \mathrm{E}-06 & 0 & -3.336 \mathrm{E}-06 & 3.952 \mathrm{E}-06
\end{array}\right] \\
& M_{y s_{L} 3}=\left[\begin{array}{ccccccccc}
9.894 \mathrm{E}-09 & -6.961 \mathrm{E}-10 & -6.485 \mathrm{E}-06 & 5.888 \mathrm{E}-07 & -1.190 \mathrm{E}-06 & -1.149 \mathrm{E}-06 & -5.945 \mathrm{E}-07 & 8.392 \mathrm{E}-06 \\
9.894 \mathrm{E}-09 & -6.961 \mathrm{E}-10 & -6.320 \mathrm{E}-06 & 5.514 \mathrm{E}-07 & -1.202 \mathrm{E}-06 & -1.120 \mathrm{E}-06 & -9.455 \mathrm{E}-07 & 7.505 \mathrm{E}-06 \\
9.894 \mathrm{E}-09 & -6.961 \mathrm{E}-10 & -6.050 \mathrm{E}-06 & 2.724 \mathrm{E}-07 & -1.221 \mathrm{E}-06 & -1.072 \mathrm{E}-06 & -1.323 \mathrm{E}-06 & 6.681 \mathrm{E}-06 \\
9.894 \mathrm{E}-09 & -6.961 \mathrm{E}-10 & -5.826 \mathrm{E}-06 & 2.400 \mathrm{E}-07 & -1.237 \mathrm{E}-06 & -1.032 \mathrm{E}-06 & -1.559 \mathrm{E}-06 & 6.228 \mathrm{E}-06 \\
9.894 \mathrm{E}-09 & -6.961 \mathrm{E}-10 & -5.068 \mathrm{E}-06 & 3.679 \mathrm{E}-07 & -1.291 \mathrm{E}-06 & -8.978 \mathrm{E}-07 & -2.132 \mathrm{E}-06 & 5.303 \mathrm{E}-06 \\
9.894 \mathrm{E}-09 & -6.961 \mathrm{E}-10 & -3.803 \mathrm{E}-06 & 4.360 \mathrm{E}-07 & -1.379 \mathrm{E}-06 & -6.736 \mathrm{E}-07 & -2.724 \mathrm{E}-06 & 4.555 \mathrm{E}-06 \\
9.894 \mathrm{E}-09 & -6.961 \mathrm{E}-10 & 0 & 4.724 \mathrm{E}-07 & -1.646 \mathrm{E}-06 & 0 & -3.336 \mathrm{E}-06 & 3.952 \mathrm{E}-06
\end{array}\right] \\
& L_{y \bar{s}_{L}}=\left(\begin{array}{l}
-4.500 \mathrm{E}-07 \\
-1.542 \mathrm{E}-06 \\
-2.530 \mathrm{E}-06 \\
-2.970 \mathrm{E}-06 \\
-3.595 \mathrm{E}-06 \\
-3.448 \mathrm{E}-06 \\
-6.425 \mathrm{E}-07
\end{array}\right)
\end{aligned}
$$$$
\begin{aligned}
M_{y_{R_{R}}}= & {\left[\begin{array}{lrrrrrrr}
9.822 \mathrm{E}-09 & -6.961 \mathrm{E}-10 & 6.485 \mathrm{E}-06 & 5.184 \mathrm{E}-07 & -1.118 \mathrm{E}-06 & 1.149 \mathrm{E}-06 & -5.945 \mathrm{E}-07 & 8.392 \mathrm{E}-06 \\
9.822 \mathrm{E}-09 & -6.961 \mathrm{E}-10 & 6.320 \mathrm{E}-06 & 4.640 \mathrm{E}-07 & -1.130 \mathrm{E}-06 & 1.120 \mathrm{E}-06 & -9.455 \mathrm{E}-07 & 7.505 \mathrm{E}-06 \\
9.822 \mathrm{E}-09 & -6.961 \mathrm{E}-10 & 6.050 \mathrm{E}-06 & 7.989 \mathrm{E}-07 & -1.149 \mathrm{E}-06 & 1.072 \mathrm{E}-06 & -1.323 \mathrm{E}-06 & 6.681 \mathrm{E}-06 \\
9.822 \mathrm{E}-09 & -6.961 \mathrm{E}-10 & 5.826 \mathrm{E}-06 & 2.165 \mathrm{E}-07 & -1.164 \mathrm{E}-06 & 1.032 \mathrm{E}-06 & -1.559 \mathrm{E}-06 & 6.228 \mathrm{E}-06 \\
9.822 \mathrm{E}-09 & -6.961 \mathrm{E}-10 & 5.068 \mathrm{E}-06 & 4.984 \mathrm{E}-07 & -1.216 \mathrm{E}-06 & 8.978 \mathrm{E}-07 & -2.132 \mathrm{E}-06 & 5.303 \mathrm{E}-06 \\
9.822 \mathrm{E}-09 & -6.961 \mathrm{E}-10 & 3.803 \mathrm{E}-06 & 5.476 \mathrm{E}-07 & -1.304 \mathrm{E}-06 & 6.736 \mathrm{E}-07 & -2.724 \mathrm{E}-06 & 4.555 \mathrm{E}-06 \\
9.822 \mathrm{E}-09 & -6.961 \mathrm{E}-10 & 0 & 0 & -1.567 \mathrm{E}-06 & 0 & -3.336 \mathrm{E}-06 & 3.952 \mathrm{E}-06
\end{array}\right] } \\
M_{y s_{R} 2}= & {\left[\begin{array}{lrrrrrrrrr}
9.857 \mathrm{E}-09 & -6.961 \mathrm{E}-10 & 6.485 \mathrm{E}-06 & 3.107 \mathrm{E}-07 & -1.196 \mathrm{E}-06 & 1.149 \mathrm{E}-06 & -5.945 \mathrm{E}-07 & 8.392 \mathrm{E}-06 \\
9.857 \mathrm{E}-09 & -6.961 \mathrm{E}-10 & 6.320 \mathrm{E}-06 & 2.724 \mathrm{E}-07 & -1.208 \mathrm{E}-06 & 1.120 \mathrm{E}-06 & -9.455 \mathrm{E}-07 & 7.505 \mathrm{E}-06 \\
9.857 \mathrm{E}-09 & -6.961 \mathrm{E}-10 & 6.050 \mathrm{E}-06 & 2.103 \mathrm{E}-07 & -1.227 \mathrm{E}-06 & 1.072 \mathrm{E}-06 & -1.323 \mathrm{E}-06 & 6.681 \mathrm{E}-06 \\
9.857 \mathrm{E}-09 & -6.961 \mathrm{E}-10 & 5.826 \mathrm{E}-06 & 1.878 \mathrm{E}-07 & -1.243 \mathrm{E}-06 & 1.032 \mathrm{E}-06 & -1.559 \mathrm{E}-06 & 6.228 \mathrm{E}-06 \\
9.857 \mathrm{E}-09 & -6.961 \mathrm{E}-10 & 5.068 \mathrm{E}-06 & 4.402 \mathrm{E}-07 & -1.295 \mathrm{E}-06 & 8.978 \mathrm{E}-07 & -2.132 \mathrm{E}-06 & 5.303 \mathrm{E}-06 \\
9.857 \mathrm{E}-09 & -6.961 \mathrm{E}-10 & 3.803 \mathrm{E}-06 & 4.836 \mathrm{E}-07 & -1.384 \mathrm{E}-06 & 6.736 \mathrm{E}-07 & -2.724 \mathrm{E}-06 & 4.555 \mathrm{E}-06 \\
9.857 \mathrm{E}-09 & -6.961 \mathrm{E}-10 & 0 & 5.062 \mathrm{E}-07 & -1.648 \mathrm{E}-06 & 0 & -3.336 \mathrm{E}-06 & 3.952 \mathrm{E}-06
\end{array}\right] }
\end{aligned}
$$ 


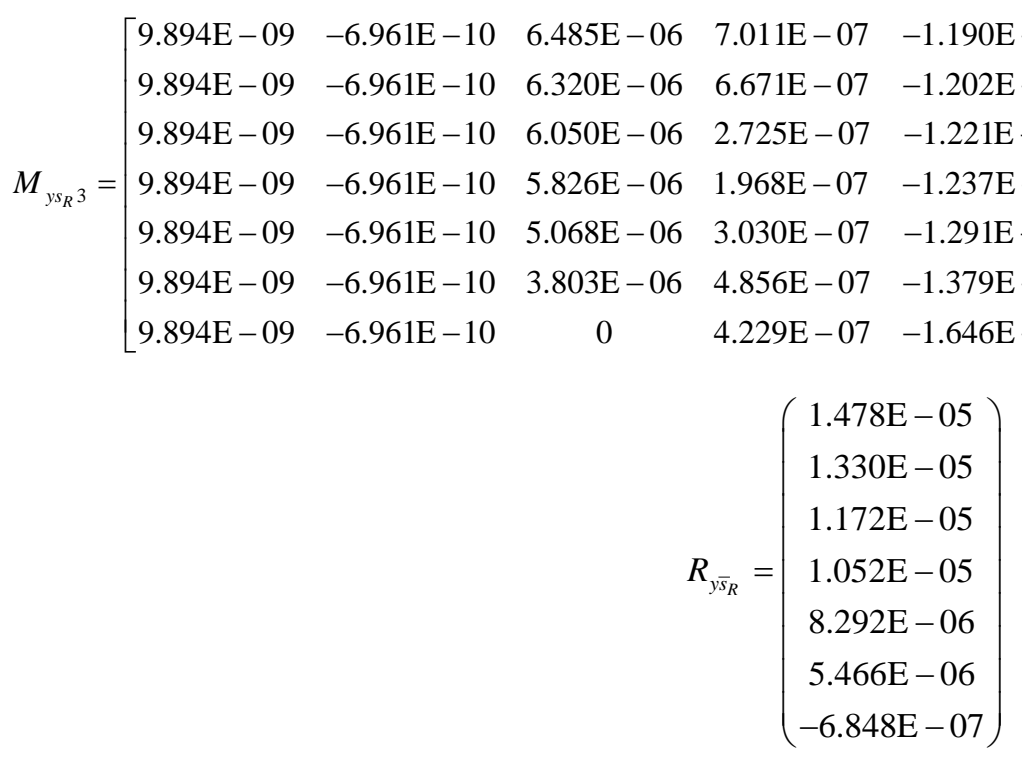

Mgs

\begin{tabular}{|c|c|c|c|c|c|c|c|c|c|c|c|c|c|c|}
\hline \multirow{7}{*}{$k_{\lambda 1}=k_{\lambda 2}=k_{\lambda 3}=$} & 2.534 & 2.532 & 2.528 & 2.526 & 2.524 & 2.512 & 2.502 & 2.495 & 2.464 & 2.455 & 2.403 & 2.391 & 2.363 & 2.360 \\
\hline & 2.184 & 2.182 & 2.180 & 2.178 & 2.177 & 2.169 & 2.162 & 2.158 & 2.137 & 2.130 & 2.095 & 2.087 & 2.068 & 2.066 \\
\hline & 1.878 & 1.877 & 1.875 & 1.874 & 1.873 & 1.868 & 1.864 & 1.861 & 1.848 & 1.844 & 1.821 & 1.816 & 1.804 & 1.803 \\
\hline & 1.717 & 1.717 & 1.715 & 1.715 & 1.714 & 1.711 & 1.707 & 1.705 & 1.696 & 1.693 & 1.676 & 1.672 & 1.663 & 1.662 \\
\hline & 1.348 & 1.349 & 1.349 & 1.349 & 1.349 & 1.348 & 1.347 & 1.346 & 1.344 & 1.343 & 1.339 & 1.338 & 1.335 & 1.335 \\
\hline & 1.177 & 1.177 & 1.176 & 1.176 & 1.176 & 1.176 & 1.175 & 1.175 & 1.173 & 1.173 & 1.170 & 1.170 & 1.168 & 1.168 \\
\hline & 1 & 1 & 1 & 1 & 1 & 1 & 1 & 1 & 1 & 1 & 1 & 1 & 1 & \\
\hline
\end{tabular}

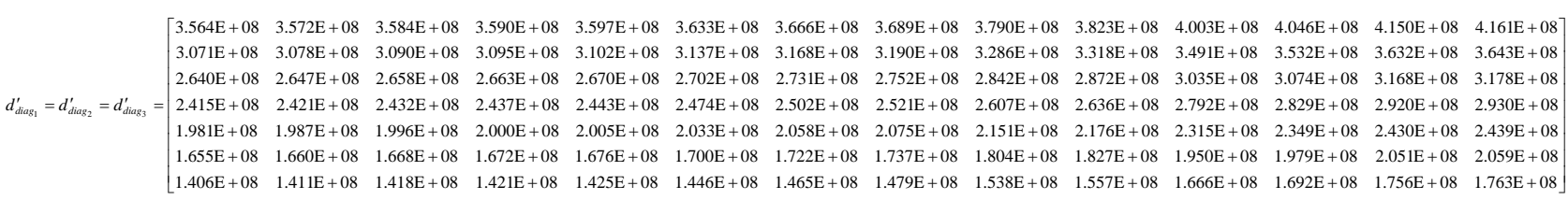

$$
\begin{aligned}
I_{114} & =\left[\begin{array}{lllll}
6.475 \mathrm{E}+09 & 6.475 \mathrm{E}+09 & 6.475 \mathrm{E}+09 & \cdots & 3.534 \mathrm{E}+11 \\
5.669 \mathrm{E}+09 & 5.669 \mathrm{E}+09 & 5.669 \mathrm{E}+09 & \cdots & 3.094 \mathrm{E}+11 \\
4.946 \mathrm{E}+09 & 4.946 \mathrm{E}+09 & 4.946 \mathrm{E}+09 & \cdots & 2.699 \mathrm{E}+11 \\
4.559 \mathrm{E}+09 & 4.559 \mathrm{E}+09 & 4.559 \mathrm{E}+09 & \cdots & 2.488 \mathrm{E}+11 \\
3.795 \mathrm{E}+09 & 3.795 \mathrm{E}+09 & 3.795 \mathrm{E}+09 & \cdots & 2.071 \mathrm{E}+11 \\
3.204 \mathrm{E}+09 & 3.204 \mathrm{E}+09 & 3.205 \mathrm{E}+09 & \cdots & 1.749 \mathrm{E}+11 \\
2.744 \mathrm{E}+09 & 2.744 \mathrm{E}+09 & 2.744 \mathrm{E}+09 & \cdots & 1.497 \mathrm{E}+11
\end{array}\right] \\
H I_{114} & {\left[\begin{array}{llllll}
2.738 \mathrm{E}+03 & 2.738 \mathrm{E}+03 & 2.738 \mathrm{E}+03 & \cdots & 2.738 \mathrm{E}+03 \\
2.397 \mathrm{E}+03 & 2.397 \mathrm{E}+03 & 2.397 \mathrm{E}+03 & \cdots & 2.397 \mathrm{E}+03 \\
2.091 \mathrm{E}+03 & 2.091 \mathrm{E}+03 & 2.091 \mathrm{E}+03 & \cdots & 2.091 \mathrm{E}+03 \\
1.928 \mathrm{E}+03 & 1.928 \mathrm{E}+03 & 1.928 \mathrm{E}+03 & \cdots & 1.928 \mathrm{E}+03 \\
1.605 \mathrm{E}+03 & 1.605 \mathrm{E}+03 & 1.605 \mathrm{E}+03 & \cdots & 1.605 \mathrm{E}+03 \\
1.355 \mathrm{E}+03 & 1.355 \mathrm{E}+03 & 1.355 \mathrm{E}+03 & \cdots & 1.355 \mathrm{E}+03 \\
1.160 \mathrm{E}+03 & 1.160 \mathrm{E}+03 & 1.160 \mathrm{E}+03 & \cdots & 1.160 \mathrm{E}+03
\end{array}\right] }
\end{aligned}
$$




$$
\begin{aligned}
& M_{y s_{L} 1}=\left[\begin{array}{ccccccccc}
9.822 \mathrm{E}-09 & -6.961 \mathrm{E}-10 & -6.485 \mathrm{E}-06 & 6.344 \mathrm{E}-07 & -1.118 \mathrm{E}-06 & -1.149 \mathrm{E}-06 & -5.945 \mathrm{E}-07 & 9.680 \mathrm{E}-06 \\
9.822 \mathrm{E}-09 & -6.961 \mathrm{E}-10 & -6.320 \mathrm{E}-06 & 6.005 \mathrm{E}-07 & -1.130 \mathrm{E}-06 & -1.120 \mathrm{E}-06 & -9.455 \mathrm{E}-07 & 8.404 \mathrm{E}-06 \\
9.822 \mathrm{E}-09 & -6.961 \mathrm{E}-10 & -6.050 \mathrm{E}-06 & 7.216 \mathrm{E}-07 & -1.149 \mathrm{E}-06 & -1.072 \mathrm{E}-06 & -1.323 \mathrm{E}-06 & 7.276 \mathrm{E}-06 \\
9.822 \mathrm{E}-09 & -6.961 \mathrm{E}-10 & -5.826 \mathrm{E}-06 & 6.963 \mathrm{E}-07 & -1.164 \mathrm{E}-06 & -1.032 \mathrm{E}-06 & -1.559 \mathrm{E}-06 & 6.680 \mathrm{E}-06 \\
9.822 \mathrm{E}-09 & -6.961 \mathrm{E}-10 & -5.068 \mathrm{E}-06 & 6.318 \mathrm{E}-07 & -1.216 \mathrm{E}-06 & -8.978 \mathrm{E}-07 & -2.132 \mathrm{E}-06 & 5.519 \mathrm{E}-06 \\
9.822 \mathrm{E}-09 & -6.961 \mathrm{E}-10 & -3.803 \mathrm{E}-06 & 6.043 \mathrm{E}-07 & -1.304 \mathrm{E}-06 & -6.736 \mathrm{E}-07 & -2.724 \mathrm{E}-06 & 4.634 \mathrm{E}-06 \\
9.822 \mathrm{E}-09 & -6.961 \mathrm{E}-10 & 0 & 3.262 \mathrm{E}-07 & -1.567 \mathrm{E}-06 & 0 & -3.336 \mathrm{E}-06 & 3.952 \mathrm{E}-06
\end{array}\right] \\
& M_{y s_{L} 2}=\left[\begin{array}{cccccccc}
9.857 \mathrm{E}-09 & -6.961 \mathrm{E}-10 & -6.485 \mathrm{E}-06 & 4.119 \mathrm{E}-07 & -1.196 \mathrm{E}-06 & -1.149 \mathrm{E}-06 & -5.945 \mathrm{E}-07 & 9.680 \mathrm{E}-06 \\
9.857 \mathrm{E}-09 & -6.961 \mathrm{E}-10 & -6.320 \mathrm{E}-06 & 3.770 \mathrm{E}-07 & -1.208 \mathrm{E}-06 & -1.120 \mathrm{E}-06 & -9.455 \mathrm{E}-07 & 8.404 \mathrm{E}-06 \\
9.857 \mathrm{E}-09 & -6.961 \mathrm{E}-10 & -6.050 \mathrm{E}-06 & 2.760 \mathrm{E}-07 & -1.227 \mathrm{E}-06 & -1.072 \mathrm{E}-06 & -1.323 \mathrm{E}-06 & 7.276 \mathrm{E}-06 \\
9.857 \mathrm{E}-09 & -6.961 \mathrm{E}-10 & -5.826 \mathrm{E}-06 & 3.388 \mathrm{E}-07 & -1.243 \mathrm{E}-06 & -1.032 \mathrm{E}-06 & -1.559 \mathrm{E}-06 & 6.680 \mathrm{E}-06 \\
9.857 \mathrm{E}-09 & -6.961 \mathrm{E}-10 & -5.068 \mathrm{E}-06 & 3.737 \mathrm{E}-07 & -1.295 \mathrm{E}-06 & -8.978 \mathrm{E}-07 & -2.132 \mathrm{E}-06 & 5.519 \mathrm{E}-06 \\
9.857 \mathrm{E}-09 & -6.961 \mathrm{E}-10 & -3.803 \mathrm{E}-06 & 5.927 \mathrm{E}-07 & -1.384 \mathrm{E}-06 & -6.736 \mathrm{E}-07 & -2.724 \mathrm{E}-06 & 4.634 \mathrm{E}-06 \\
9.857 \mathrm{E}-09 & -6.961 \mathrm{E}-10 & 0 & 2.574 \mathrm{E}-07 & -1.648 \mathrm{E}-06 & 0 & -3.336 \mathrm{E}-06 & 3.952 \mathrm{E}-06
\end{array}\right] \\
& M_{y s_{L} 3}=\left[\begin{array}{cccccccc}
9.894 \mathrm{E}-09 & -6.961 \mathrm{E}-10 & -6.485 \mathrm{E}-06 & 5.888 \mathrm{E}-07 & -1.190 \mathrm{E}-06 & -1.149 \mathrm{E}-06 & -5.945 \mathrm{E}-07 & 9.680 \mathrm{E}-06 \\
9.894 \mathrm{E}-09 & -6.961 \mathrm{E}-10 & -6.320 \mathrm{E}-06 & 5.514 \mathrm{E}-07 & -1.202 \mathrm{E}-06 & -1.120 \mathrm{E}-06 & -9.455 \mathrm{E}-07 & 8.404 \mathrm{E}-06 \\
9.894 \mathrm{E}-09 & -6.961 \mathrm{E}-10 & -6.050 \mathrm{E}-06 & 2.724 \mathrm{E}-07 & -1.221 \mathrm{E}-06 & -1.072 \mathrm{E}-06 & -1.323 \mathrm{E}-06 & 7.276 \mathrm{E}-06 \\
9.894 \mathrm{E}-09 & -6.961 \mathrm{E}-10 & -5.826 \mathrm{E}-06 & 2.400 \mathrm{E}-07 & -1.237 \mathrm{E}-06 & -1.032 \mathrm{E}-06 & -1.559 \mathrm{E}-06 & 6.680 \mathrm{E}-06 \\
9.894 \mathrm{E}-09 & -6.961 \mathrm{E}-10 & -5.068 \mathrm{E}-06 & 3.679 \mathrm{E}-07 & -1.291 \mathrm{E}-06 & -8.978 \mathrm{E}-07 & -2.132 \mathrm{E}-06 & 5.519 \mathrm{E}-06 \\
9.894 \mathrm{E}-09 & -6.961 \mathrm{E}-10 & -3.803 \mathrm{E}-06 & 4.360 \mathrm{E}-07 & -1.379 \mathrm{E}-06 & -6.736 \mathrm{E}-07 & -2.724 \mathrm{E}-06 & 4.634 \mathrm{E}-06 \\
9.894 \mathrm{E}-09 & -6.961 \mathrm{E}-10 & 0 & 4.724 \mathrm{E}-07 & -1.646 \mathrm{E}-06 & 0 & -3.336 \mathrm{E}-06 & 3.952 \mathrm{E}-06
\end{array}\right]
\end{aligned}
$$$$
L_{y \bar{s}_{L}}=\left(\begin{array}{c}
8.384 \mathrm{E}-07 \\
-6.427 \mathrm{E}-07 \\
-1.935 \mathrm{E}-06 \\
-2.518 \mathrm{E}-06 \\
-3.380 \mathrm{E}-06 \\
-3.369 \mathrm{E}-06 \\
-6.424 \mathrm{E}-07
\end{array}\right)
$$

$\begin{aligned} M_{y s_{R} 1} & =\left[\begin{array}{lrrrrrrr}9.822 \mathrm{E}-09 & -6.961 \mathrm{E}-10 & 6.485 \mathrm{E}-06 & 5.184 \mathrm{E}-07 & -1.118 \mathrm{E}-06 & 1.149 \mathrm{E}-06 & -5.945 \mathrm{E}-07 & 9.680 \mathrm{E}-06 \\ 9.822 \mathrm{E}-09 & -6.961 \mathrm{E}-10 & 6.320 \mathrm{E}-06 & 4.640 \mathrm{E}-07 & -1.130 \mathrm{E}-06 & 1.120 \mathrm{E}-06 & -9.455 \mathrm{E}-07 & 8.404 \mathrm{E}-06 \\ 9.822 \mathrm{E}-09 & -6.961 \mathrm{E}-10 & 6.050 \mathrm{E}-06 & 7.989 \mathrm{E}-07 & -1.149 \mathrm{E}-06 & 1.072 \mathrm{E}-06 & -1.323 \mathrm{E}-06 & 7.276 \mathrm{E}-06 \\ 9.822 \mathrm{E}-09 & -6.961 \mathrm{E}-10 & 5.826 \mathrm{E}-06 & 2.165 \mathrm{E}-07 & -1.164 \mathrm{E}-06 & 1.032 \mathrm{E}-06 & -1.559 \mathrm{E}-06 & 6.680 \mathrm{E}-06 \\ 9.822 \mathrm{E}-09 & -6.961 \mathrm{E}-10 & 5.068 \mathrm{E}-06 & 4.984 \mathrm{E}-07 & -1.216 \mathrm{E}-06 & 8.978 \mathrm{E}-07 & -2.132 \mathrm{E}-06 & 5.519 \mathrm{E}-06 \\ 9.822 \mathrm{E}-09 & -6.961 \mathrm{E}-10 & 3.803 \mathrm{E}-06 & 5.476 \mathrm{E}-07 & -1.304 \mathrm{E}-06 & 6.736 \mathrm{E}-07 & -2.724 \mathrm{E}-06 & 4.634 \mathrm{E}-06 \\ 9.822 \mathrm{E}-09 & -6.961 \mathrm{E}-10 & 0 & 0 & -1.567 \mathrm{E}-06 & 0 & -3.336 \mathrm{E}-06 & 3.952 \mathrm{E}-06\end{array}\right] \\ M_{y s_{R} 2} & =\left[\begin{array}{lrrrrrrrrr}9.857 \mathrm{E}-09 & -6.961 \mathrm{E}-10 & 6.485 \mathrm{E}-06 & 3.107 \mathrm{E}-07 & -1.196 \mathrm{E}-06 & 1.149 \mathrm{E}-06 & -5.945 \mathrm{E}-07 & 9.680 \mathrm{E}-06 \\ 9.857 \mathrm{E}-09 & -6.961 \mathrm{E}-10 & 6.320 \mathrm{E}-06 & 2.724 \mathrm{E}-07 & -1.208 \mathrm{E}-06 & 1.120 \mathrm{E}-06 & -9.455 \mathrm{E}-07 & 8.404 \mathrm{E}-06 \\ 9.857 \mathrm{E}-09 & -6.961 \mathrm{E}-10 & 6.050 \mathrm{E}-06 & 2.103 \mathrm{E}-07 & -1.227 \mathrm{E}-06 & 1.072 \mathrm{E}-06 & -1.323 \mathrm{E}-06 & 7.276 \mathrm{E}-06 \\ 9.857 \mathrm{E}-09 & -6.961 \mathrm{E}-10 & 5.826 \mathrm{E}-06 & 1.878 \mathrm{E}-07 & -1.243 \mathrm{E}-06 & 1.032 \mathrm{E}-06 & -1.559 \mathrm{E}-06 & 6.680 \mathrm{E}-06 \\ 9.857 \mathrm{E}-09 & -6.961 \mathrm{E}-10 & 5.068 \mathrm{E}-06 & 4.402 \mathrm{E}-07 & -1.295 \mathrm{E}-06 & 8.978 \mathrm{E}-07 & -2.132 \mathrm{E}-06 & 5.519 \mathrm{E}-06 \\ 9.857 \mathrm{E}-09 & -6.961 \mathrm{E}-10 & 3.803 \mathrm{E}-06 & 4.836 \mathrm{E}-07 & -1.384 \mathrm{E}-06 & 6.736 \mathrm{E}-07 & -2.724 \mathrm{E}-06 & 4.634 \mathrm{E}-06 \\ 9.857 \mathrm{E}-09 & -6.961 \mathrm{E}-10 & 0 & 5.062 \mathrm{E}-07 & -1.648 \mathrm{E}-06 & 0 & -3.336 \mathrm{E}-06 & 3.952 \mathrm{E}-06\end{array}\right]\end{aligned}$




$$
\begin{aligned}
& M_{y_{S_{R} 3}}=\left[\begin{array}{cccccccc}
9.894 \mathrm{E}-09 & -6.961 \mathrm{E}-10 & 6.485 \mathrm{E}-06 & 7.011 \mathrm{E}-07 & -1.190 \mathrm{E}-06 & 1.149 \mathrm{E}-06 & -5.945 \mathrm{E}-07 & 9.680 \mathrm{E}-06 \\
9.894 \mathrm{E}-09 & -6.961 \mathrm{E}-10 & 6.320 \mathrm{E}-06 & 6.671 \mathrm{E}-07 & -1.202 \mathrm{E}-06 & 1.120 \mathrm{E}-06 & -9.455 \mathrm{E}-07 & 8.404 \mathrm{E}-06 \\
9.894 \mathrm{E}-09 & -6.961 \mathrm{E}-10 & 6.050 \mathrm{E}-06 & 2.725 \mathrm{E}-07 & -1.221 \mathrm{E}-06 & 1.072 \mathrm{E}-06 & -1.323 \mathrm{E}-06 & 7.276 \mathrm{E}-06 \\
9.894 \mathrm{E}-09 & -6.961 \mathrm{E}-10 & 5.826 \mathrm{E}-06 & 1.968 \mathrm{E}-07 & -1.237 \mathrm{E}-06 & 1.032 \mathrm{E}-06 & -1.559 \mathrm{E}-06 & 6.680 \mathrm{E}-06 \\
9.894 \mathrm{E}-09 & -6.961 \mathrm{E}-10 & 5.068 \mathrm{E}-06 & 3.030 \mathrm{E}-07 & -1.291 \mathrm{E}-06 & 8.978 \mathrm{E}-07 & -2.132 \mathrm{E}-06 & 5.519 \mathrm{E}-06 \\
9.894 \mathrm{E}-09 & -6.961 \mathrm{E}-10 & 3.803 \mathrm{E}-06 & 4.856 \mathrm{E}-07 & -1.379 \mathrm{E}-06 & 6.736 \mathrm{E}-07 & -2.724 \mathrm{E}-06 & 4.634 \mathrm{E}-06 \\
9.894 \mathrm{E}-09 & -6.961 \mathrm{E}-10 & 0 & 4.229 \mathrm{E}-07 & -1.646 \mathrm{E}-06 & 0 & -3.336 \mathrm{E}-06 & 3.952 \mathrm{E}-06
\end{array}\right] \\
& R_{\overline{y s}_{R}}=\left(\begin{array}{c}
1.478 \mathrm{E}-05 \\
1.330 \mathrm{E}-05 \\
1.172 \mathrm{E}-05 \\
1.052 \mathrm{E}-05 \\
8.292 \mathrm{E}-06 \\
5.466 \mathrm{E}-06 \\
-6.848 \mathrm{E}-07
\end{array}\right)
\end{aligned}
$$

